К ВОПРОСУ О РАСПРОСТРАНЁННОСТИ ДЕФИЦИТА И НЕДОСТАТОЧНОСТИ ВИТАМИНА D

\author{
( В.А. Авдеева' ${ }^{1}$ Л.А. Суплотова' ${ }^{1}$ Л.Я. Рожинская²
}

'ФГБОУ ВО Тюменский ГМУ Минздрава России, Тюмень

ФГБУ «НМИЦ эндокринологии» Минздрава России, Москва

В настоящее время установлено, что дефицит витамина D является мировой проблемой, которая отражается не только на состоянии костного метаболизма, но и на целом ряде острых и хронических заболеваний. Интерес исследователей к поиску тесных взаимоотношений между дефицитом витамина D и ассоциированных с ним патологических состояний подкреплен высокой частотой встречаемости низкого статуса витамина D в популяции. Считается, что от $20 \%$ до $90 \%$ взрослых мужчин и женщин во всем мире страдает от дефицита или недостаточности витамина D. Широкая распространенность дефицита и недостаточности витамина D, в первую очередь, зависит от сезонных колебаний и географической широты. Известно, что эти факторы напрямую сопряжены с уровнем солнечной инсоляции и возможностью образования витамина D в кожных покровах. Территория Тюмени располагается на $57^{\circ} 09^{1}$ с.ш., которая соотносятся с месторасположением других российских городов, таких как Псков, Ярославль, Иваново, Кострома. Принимая во внимание факт единой географической широты и отсутствие данных о распространённости дефицита и недостаточности витамина D, исследование уровня обеспеченности витамина D в Тюменском регионе определяет актуальность и цель настоящего исследования.

Цель - оценить уровень обеспеченности витамином D в Тюменском регионе для определения D-статуса на географической широте $57^{\circ} 09^{1}$ с.ш.

Материалы и методы. Объектом проведенных исследований было взрослое население Тюмени и Тюменского района. Обеспеченность витамином D оценена у 440 взрослых жителей (227 (51\%) женщин и 213 (49\%) мужчин) в возрасте старше 18 лет, медиана возраста - 53 [22,2; 74,3] года. Включение в исследование проводилось по принципу случайной выборки с помощью программы случайных чисел, с учетом гендерных и возрастных особенностей. Набор участников исследования осуществлялся в период с ноября 2017 по март 2018 гг. - в период наименьшей инсоляции и короткого светового дня. Отобранным участникам исследования определялся уровень 25(OH)D в сыворотке крови. Определение уровня 25(OH)D в сыворотке крови проводились методом ИФА-анализа при помощи тест-систем Euroimmin 25-ОН Vitamin D ELISA фирмы Sunrise, USA. Лаборатория участвует в международной программе внешнего контроля и стандартизация 25(OH)D в сыворотке крови (DEQAS, UK). Статистическая обработка полученных данных в процессе исследования проводилась с использованием программы SPSS (версия 17.0). Количественные показатели представлены в виде медианы (Ме) и интерквартильного размаха [25-75 процентиль - Q25-Q75].

Результаты и обсуждение. Уровень витамина D оценивался по классификации, принятой Российской ассоциацией эндокринологов (2015 г). Согласно рекомендациям за адекватную обеспеченность витамином D приняты значения 25(OH)D в сыворотке крови, равные или превышающие 30 нг/мл; за недостаточную - значения от 20 до 30 нг/мл; 3 начения ниже 20 нг/мл расцениваются как дефицит витамина D. Уровень 25(OH)D варьировал от 4,3 нг/мл до 53,1 нг/мл, медиана составила $16,9[11,0 ; 22,4]$ нг/мл, что соответствует статусу дефицита витамина D. Показатели 25(OH)D в группах с дефицитом, недостаточностью и оптимальным уровнем обеспеченности витамина D составили 12,9 [9,4; 16,9]; 23,3 [22,0; 25,5] и 36,0 [32,8; 39,6] нг/мл соответственно. По результатам исследования, оптимальный уровень 25(OH)D в сыворотке крови среди жителей Тюменского региона выявлен у 32 обследованных (7,3\%), его недостаточность выявлена у 97 человек (22,0\%), а дефицит - у 311 (70,7\%). Таким образом, согласно национальным клиническим рекомендациям уровень распространенности дефицита и недостаточности витамина D среди всех обследованных жителей Тюменского региона РФ составляет 92,7\%. При анализе уровня 25(OH)D между мужчинами и женщинами не было получено статистически значимых различий. Оптимальный уровень витамина D диагностирован у $11 \%$ женщин и 3,2\% мужчин ( $p=0,6)$, уровень его недостаточности зарегистрирован у 25,1\% женщин и 26,3\% мужчин ( $p=0,17)$, а состояние дефицита также представлены с одинаковой частотой в обеих группах: у 63,9\% женщин и 70,5\% мужчин ( $p=0,32)$. Кроме этого проанализирован уровень обеспеченности 25(OH)D между различными возрастными группами. Во всех возрастных группах преобладают значения 25(OH)D в сыворотке крови, соответствующие уровню дефицита витамина D (менее 20 нг/мл). При этом статистически достоверных различий между возрастом и уровнем обеспеченности витамином D установлено не было.

Выводы. Исследование об обеспеченности витамином D в Тюмени и Тюменском районе проведено впервые. Выявлена высокая частота низкого статуса дефицита витамина D (до 70,7\%) и его недостаточности (22,0\%) среди взрослых жителей, проживающих на территории Тюменского региона, не связанная с гендерными и возрастными особенностями. Широкая распространенность дефицита и недостаточности витамина D во всех возрастных группах, как среди мужчин, так и среди женщин указывает на необходимость проведения профилактических, диагностических, образовательных и лечебных мероприятий, направленных на ликвидацию тотального дефицита витамина D. 
ON THE QUESTION OF THE PREVALENCE OF VITAMIN D DEFICIENCY AND INSUFFICIENCY

(c) Avdeeva V.A. ${ }^{1}$, Suplotova L.A. ${ }^{1}$, Rozhinskaya L.Ya. ${ }^{2}$

${ }^{1}$ Tyumen State Medical University of the Ministry of Health of the Russian Federation, Tyumen ${ }^{2}$ Endocrinology Research Centre of the Ministry of Health of the Russian Federation, Moscow 
ПОКАЗАТЕЛИ МИНЕРАЛЬНОЙ ПЛОТНОСТИ КОСТНОЙ ТКАНИ

У ЖЕНЩИН СТАРШЕЙ ВОЗРАСТНОЙ ГРУППЫ ПРИ ОСТЕОАРТРИТЕ

КОЛЕННЫХ И ТАЗОБЕДРЕННЫХ СУСТАВОВ

() Ю.А. Аверкиева, Т.А. Раскина, И.И. Григорьева, М.В. Летаева, О.С. Малышенко

ФГБОУ ВО «Кемеровский государственный медицинский университет» Минздрава России, Кемерово

Цель. Изучить состояние минеральной плотности кости (МПК) в шейке бедренной кости и поясничном отделе позвоночника у женщин пожилого и старческого возраста с верифицированным остеоартритом (ОА) коленных и тазобедренных суставов.

Материал и методы. Исследуемая когорта включила 124 женщины (средний возраст 73,3土8,46 лет) с установленным диагнозом ОА, верифицированным согласно диагностическим критериям Американской коллегии ревматологов (ACR), подписавшим информированное согласие. Всем пациенткам проведена рентгенография коленных и тазобедренных суставов в прямой проекции с оценкой рентгенологической стадии ОА на основании классификации Kellgren и Lawrence. Оценка MПК поясничного отдела позвоночника (L,- $\mathrm{L}_{\mathrm{VV}}$ и шейки бедренной кости выполнена методом двухэнергетической рентгеновской абсорбциометрии на костном денситометре Lunar Prodigy Primo.

Результаты и обсуждение. Остеопороз (ОП) в исследуемой когорте выявлен у 28\% женщин, остеопения (ОПе) у $41 \%$. ОП установлен у $20 \%$ женщин в возрасте $60-74$ лет и у $38 \%$ - в возрасте $75-90$ лет (р<0,05). ОПе выявлена у $41 \%$ пациенток пожилого возраста и у 42\% - старческого ( $>>0,05)$. Анализ показателей МПК в шейке бедра у женщин с ОА тазобедренных суставов I-II и III-IV стадии в возрастной группе 65-74 лет показал, что абсолютные величины МПК были значимо выше у женщин с более поздними стадиями заболевания ( $<<0,05)$. В группе пациентов 75 лет и старше отмечались значимо более высокие показатели МПК в шейке бедренной кости у женщин с ОА тазобедренных суставов III и IV стадии по сравнению с женщинами с I и II стадией $(p<0,05)$. В то же время в поясничном отделе позвоночника более поздние рентгенологические стадии ОА тазобедренных суставов были ассоциированы с более низкими показателями МПК (р<0,05). Отмечено, что пациентки, страдающие ОА коленных суставов III и IV стадии, имели значимо более высокие значения МПК в поясничном отделе позвоночника как в группе женщин пожилого, так и старческого возраста (p<0,05). Показатели MПК в шейке бедра у больных ОА коленных суставов I-II и III-IV стадий были сопоставимы в обеих возрастных группах ( $>>0,05)$.

Выводы. Установлено, что показатели МПК шейки бедра у женщин пожилого возраста с ОА тазобедренных суставов III и IV стадии были значимо выше по сравнению с показателями пациенток с I и II стадиями заболевания. Показатели МПК поясничного отдела позвоночника были сопоставимы в группе женщин пожилого возраста вне зависимости от ОА, в то время как у пациенток старческого возраста с III и IV стадией ОА тазобедренных суставов выявлено значимое снижение величины МПК в данной локализации.

КЛЮЧЕВЫЕ СЛОВА: Остеоартрит; денситометрия; минеральная плотность кости.

\section{BONE MINERAL DENSITY IN WOMEN IN THE OLDER AGE GROUP WITH OSTEOARTHRITIS} OF THE KNEE AND HIP JOINTS

(c) Averkieva Y.A., Raskina T.A., Grigorieva I.I., Letaeva M.V., Malyshenko O.S.

Kemerovo State Medical University, Kemerovo 


\section{(ㄱ А.В. Адаменко', Э.В. Руденко², Ю.В. Мещеряков 3}

'Республиканский клинический медицинский центр управления делами Президента Республики Беларусь, Минск

21-я Городская клиническая больница, Минск

${ }^{3}$ Белорусская академия последипломного образования, Минск

Цель исследования - определить «возраст ограничения» использования денситометрических сканов поясничного отдела позвоночника для женщин старше 50 лет.

Материалы и методы. Методом случайной выборки из базы денситометра, пациентов, обратившихся для диагностики остеопороза в Минский городской центр остеопороза и болезней костно-мышечной системы, были отобраны

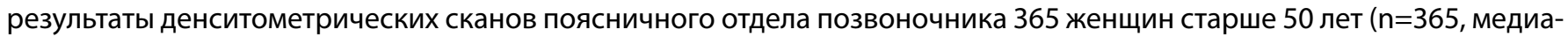
на возраста 77 [73:81] лет). Минеральная плотность кости (МПК, BMD-Bone Mineral Density, г/см²) определялась методом рентгеновской денситометрии (DXA, денситометр рентгеновский LUNAR Prodigy Advance, GE, USA, 2008) в поясничном отделе (L1-L4) позвоночника в переднезадней проекции и в проксимальных отделах шеек бедренных костей. Стандартная рентгенография поясничного отдела позвоночника в боковой проекции выполнялась при выявлении артефактов на сканах DXA. У всех обследованных проводился сбор анамнеза с целью выявления низкоэнергетических переломов и факторов риска остеопороза.

Для статистической обработки данных использовался пакет программного обеспечения MedCalc Software reg. Number BE 0809344640. Win pro №X18-45392. Work order №162000450. Чувствительность, специфичность рассчитывались с использованием таблиц 2*2 с подсчетом истинно положительных, истинно отрицательных, ложноположительных и ложноотрицательных результатов, отношений правдоподобия положительного и отрицательного результата, а также прогностической ценности положительного результата, прогностической ценности отрицательного результата. Для оценки диагностической точности метода выполняли ROC-анализ с подсчетом площади под кривой (AUC ROC). При помощи индекса Йодена определяли пороговые значения метода рентгеновской денситометрии с максимальными показателями чувствительности и специфичности.

Результаты и обсуждение. Деформации позвонков в поясничном отделе позвоночника, установленные по результатам анализа сканов рентгеновской денситометрии и подтвержденные рентгеновской морфометрией или стандартной рентгенографией, были диагностированы у 103 (28,2\%) женщин; дегенеративно-дистрофические изменения, приводящие к дополнительной патологической оссификации - диффузный идиопатический скелетный гиперостоз (Болезнь Форестье), остеохондроз, спондилоартропатия, определялись у 120 (32.8\%) женщин. Количество артефактов (остеоартрит, врожденный и приобретённый вывих бедра, асептический некроз головки бедренной кости) в денситометрических сканах проксимальных отделов бедренной кости было диагностировано у 10 (2,7\%) женщин.

Общеизвестно, что количество артефактов увеличивается с возрастом. Дегенеративно-реактивные изменения в телах позвонков проявляются в виде краевых костных разрастаний (остеофиты) и субхондрального склероза. Наличие остеофитов приводит к значительному увеличению BMD позвонков. Tак, Rand et al. исследовали 144 женщины в возрасте от 40 до 84 лет (средний возраст 63,3 года) на наличие остеофитов в поясничном отделе позвоночника. Было установлено, что у женщин до 50 лет изменения наблюдались в 10\% случаев, в возрасте от 50 до 55 лет - в $40 \%$ случаев, а от 56 до 70 лет - в 85\% случаев. В исследовании Cann at al. увеличение BMD в поясничном отделе позвоночника, обусловленное остеофитами, составляло от 9,5\% до 13,9\%. Эффект завышения BMD, который может проявляться в диспропорциональном изменении BMD от L1 к L4, часто становится причиной неверной интерпретации результатов рентгеновской денситометрии.

Диагностическую эффективность рентгеновской денситометрии поясничного отдела позвоночника в зависимости от возраста обследуемых оценивали при помощи операционных характеристических кривых наблюдателя (Receiver Operating Characteristic curve), построенных при помощи ROC-анализа. Для ROC-анализа использовались чувствительность, специфичность и индекс Йодена, рассчитываемые по формулам: SENS (Se) = TP/(TP+FN); $\operatorname{SPEC}(\mathrm{Sp})=\mathrm{TN} /(\mathrm{FP}+\mathrm{TN})$; YDN (J) = max (SENS+SPEC-1), где SENS - чувствительность, SPEC - специфичность, YDN индекс Йодена, ТP - число истинно положительных (число положительных примеров, спрогнозированных как положительные), TN - число истинно отрицательных, FP - число ложно отрицательных предсказаний. Для оценки чувствительности и специфичности денситометрии поясничного отдела позвоночника в зависимости от возраста использовался ROC-анализ.

Оптимальной точкой на ROC-кривой считают имеющую наибольшее значение чувствительности при наименьшем значении доли ложноположительных результатов. Эта точка была найдена при помощи индекса Йодена, как максимальное отличие ординат ROC-кривой и диагонали: J = max (Se+Sp-1). Максимальным индексом Йодена стало значение 0,38, которое соответствует чувствительности - 78,95\% и специфичности - 59,32\% для ассоциативного 
критерия 72,14 года. Прогностическая ценность (эффективность) - 0,69 (AUC - площадь под кривой). Принято считать, что коэффициент площади кривой, находящийся в интервале 0,9-1,0, следует рассматривать как показатель наивысшей информативности диагностического метода; 0,8-0,9 - хорошей; 0,7-0,8 - приемлемой; 0,6-0,7 - слабой.

Таким образом, метод рентгеновской денситометрии поясничного отдела позвоночника для женщин старше 72,14 лет характеризуется слабой информативностью. На основе полученных данных предложено выполнение денситометрии проксимальных отделов бедренных костей для пациенток старше 72 лет в качестве метода первичной диагностики и оценки изменения МПК в динамике. В настоящее время исследуются поясничный отдел позвоночника и проксимальные отделы бедренных костей.

Выводы. Рентгеновская денситометрия проксимальных отделов бедренных костей для женщин старше 72 лет более достоверна, чем денситометрия поясничного отдела позвоночника. При выполнении денситометрии поясничного отдела позвоночника женщинам старше 72 лет целесообразно дополнять исследование морфометрией позвоночника или стандартной рентгенографией поясничного отдела позвоночника для визуализации артефактов и увеличения достоверности ДХА. Было установлено, что денситометрия проксимальных отделов бедренных костей позволяет более точно интерпретировать результаты измерения BMD у женщин старше 72 лет для последующей верификации диагноза остеопороз и динамического наблюдения. Наличие артефактов не позволяет точно оценить изменения BMD в динамике и снижает чувствительность метода ДХА поясничного отдела позвоночника.

КЛЮЧЕВЫЕ СЛОВА: Денситометрия; остеопороз; лучевая диагностика.

AGE RESTRICTIONS ON THE USE OF DUAL-ENERGY X-RAY ABSORPTIOMETRY OF THE LUMBAR SPINE FOR WOMEN OVER 70 YEARS

(c) Adamenko A.V. ${ }^{1}$, Rudenko E.V. ${ }^{2}$, Meshcheryakov, Yu.V. ${ }^{3}$

${ }^{1}$ Republic Clinical Medical Centre of the President's Administration, Minsk

${ }^{2} 1^{\text {st }}$ City Clinical Hospital, Minsk

${ }^{3}$ Belarus Academy of Postgraduate Education, Minsk 


\section{() А.В. Акимова, А.А. Попов, П.А. Палабугина}

ФГБУ ВО «Уральский государственный медицинский университет» Минздрава России, Екатеринбург

Цель: оценка ассоциации числа переломов, риска дефицита магния с числом фенов недифференцированной дисплазии соединительной ткани (ДСТ) у молодых мужчин, годных к военной службе.

Материал и методы. В одномоментное исследование на условиях добровольного информированного согласия включены 143 молодых мужчин в возрасте от 18 до 25 лет (медиана возраста 22 года), признанных годными по состоянию здоровья к военной службе. Определяли внешние и внутренние фены ДСТ на основании Рекомендаций РНМОТ, 2016 г. Оценивали количество внешних фенов ДСТ, наследственные нарушения соединительной ткани, индекс гипермобильности Бейтона, число и локализацию перенесенных переломов. При выявлении 6 фенов и более регистрировали наличие ДСТ. Для выявления симптомов дефицита магния использовали опросник Института микроэлементов ЮНЕСКО. Значение суммы ответов 18 баллов считали критерием высокого риска дефицита магния. Статистическую обработку проводили с помощью программного продукта «Statistica 5.0». Оценку корреляции признаков проводили с помощью коэффициента Спирмана, различия частот оценивали с помощью критерия $x^{2}$.

Результаты. Группу лиц, не имевших переломов составили 92 чел., у 62 (67\%) из них диагностирована ДСТ. Один перелом в течение жизни перенесли 24 чел., из них 17 (71\%) имели критерии ДСТ. В группу лиц с множественными переломами вошли 27 молодых людей, у 20 (74\%) из них диагностирована ДСТ. Среди перенесенных малотравматических переломов в обследованной группе преобладали переломы фаланг пальцев, других костей кистей и стоп, дистальных отделов костей голени и предплечья. Критериям высокого риска дефицита магния соответствовали 59 чел. (41\%). Выявлена слабая положительная корреляция числа переломов у лиц с бо́льшим числом внешних фенов ДСТ $(R=0,27 ; p=0,044)$, наличием семейного анамнеза ДСТ ( $R=0,36 ; p=0,002)$, гипермобильности суставов $(R=0,26 ; p=0,018)$, признаками дефицита магния ( $R=0,28 ; p=0,047)$.

Обсуждение: критериям ДСТ соответствовали 99 чел. (69\%) из 143 обследованных, что, в целом, соответствует частоте ДСТ в соответствующей возрастной группе общей популяции. Выявление ДСТ повышало вероятность переломов при минимальной травме, но перенесенные в молодом возрасте переломы имели локализацию, не типичную для остеопороза, и не сопровождались развитием выраженных функциональных ограничений. Ограничением исследования является отсутствие лабораторного подтверждения дефицита магния. Тем не менее, полученные данные подтверждают актуальность более тщательной оценки эффективности применения при ДСТ препаратов магния, включенных в национальные рекомендации.

Выводы. У молодых мужчин с большим числом фенов ДСТ значимо чаще, чем у их ровесников, не имевших критериев ДСТ, выявлялись малотравматичные переломы, семейный анамнез ДСТ, гипермобильность суставов, признаки дефицита магния. Наиболее частые локализации малотравматичных переломов при ДСТ отличаются от типичных для остеопороза. Наличие в анамнезе переломов при минимальной травме не сопровождалось развитием функциональных ограничений и не служило препятствием для отбора на военную службу.

КЛЮЧЕВЫЕ СЛОВА: Соединительная ткань; дисплазия; магний.

ASSESSMENT OF THE ASSOCIATION OF UNDIFFERENTIATED CONNECTIVE TISSUE DYSPLASIA, NUMBER OF FRACTURES AND THE RISK OF MAGNESIUM DEFICIENCY IN YOUNG MEN

(c) Akimova A.V., Popov A.A., Palabugina P.A.

Ural State Medical University, Ekaterinburg 


\author{
(с) В.А. Александров ${ }^{1,2}$, Л.Н. Шилова' , А.В. Александров ${ }^{1,2}$
}

'ФГБОУ ВО ВолгГМУ Минздрава России, Волгоград

ФГБНУ «НИИ КиЭР им. А.Б. Зборовского», Волгоград

Наиболее разумной стратегией при диагностике остеопороза (ОП) следует признать селективный скрининг с использованием аппаратных и лабораторных методов в хорошо очерченных группах риска. Пациенты с ревматоидным артритом (РА), бесспорно, относятся к такой группе риска.

Цель: изучить роль ангиопоэтин-подобного белка 3 типа (АППБ-З) в метаболических нарушениях, связанных с риском развития переломов шейки бедра у женщин с РА.

Материалы и методы. Под наблюдением находились 88 женщин с достоверным диагнозом РА. Средний воз-

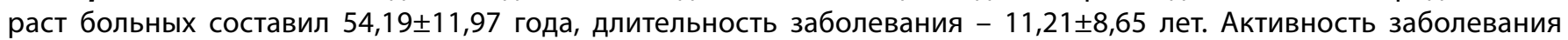
по DAS28: ремиссия отмечена у 19 (21,6\%), минимальная степень - у 10 (11,4\%), средняя - у 52 (59,1\%), высокая 7 (7,9\%) человек. Серопозитивны по наличию ревматоидного фактора в сыворотке крови были 64 человека (72,7\%), по уровню антител к циклическому цитруллинированному пептиду (АЦЦП) - 59 (67\%) человек.

Содержание АППБ-3 в сыворотке крови определяли иммуноферментным методом с использованием коммерческой тест-системы «Human Angiopoietin-like Protein 3 ELISA» (производства «Bio Vendor», Czech Republic).

Остеоденситометрия проводилась на рентгеновском денситометре LUNAR DPX, GE (США). В соответствии с рекомендациями ВОЗ оценка состояния костной ткани проксимального отдела бедра осуществлялась по Т-критерию, снижение которого от $-1,0$ до -2,4 расценивалось как остеопения, значение ниже $-2,5$ рассматривалось как диагностический признак остеопороза.

Результаты и обсуждение. Развитие и прогрессирование РА характеризуются существенными иммунологическими и метаболическими сдвигами с выраженными взаимосвязями между иммунной системой и костной тканью на анатомическом, сосудистом, клеточном и молекулярном уровнях.

При РА кость также является мишенью воспаления - усиление продукции широкого спектра цитокинов, способных увеличивать костную резорбцию, приводит к костным эрозиям, перивоспалительной и системной потере костной ткани. Однако существующие методы определения маркеров синтеза и резорбции кости, как правило, мало информативны для установления взаимосвязи иммунного воспаления и остеопоротических процессов в кости при РА.

В ходе проведенного исследования повышенные значения АППБ-3 (более 445 нг/мл) были выявлены у 71 (80,7\%) пациентки с РА. Установлена достоверная положительная корреляционная связь между АППБ-3 и наличием остеопороза $\left(r_{s}=0,36, p=0,039\right)$ (подтвержденный клинический диагноз на момент исследования), а также отрицательная связь с возрастом пациенток ( $r=-0,83, p=0,006)$. Не было отмечено достоверной связи АППБ-3 с активностью РА по индексу DAS-28 $(p=0,135)$ и уровнем АЦЦП $(p=0,063)$.

При денситометрическом исследовании отклонений в минеральной плотности костной ткани (Bone mineral density, $\mathrm{BMD}$ ) получены данные о тесной связи АППБ-3 и остеопоротическими изменениями в шейке бедра (особенно в зоне Wards): c BMD Total $r=-0,33$ ( $p=0,042)$, BMD Troch $r=-0,36(p=0,038)$ и BMD Wards $r=-0,44$ ( $p=0,009)$. Не было отмечено достоверных связей между уровнем АППБ-3 и снижением BMD в позвоночнике (L1-L4) (p>0,05).

Уровень АППБ-3 у больных РА с подтвержденным клиническим диагнозом ОП на момент исследования (остопоро-

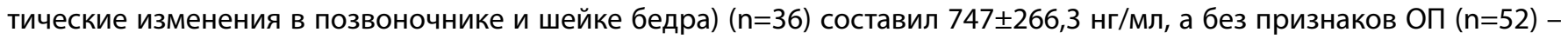
$670,5 \pm 258,8$ нг/мл ( $p=0,181)$. Тем не менее было выявлено, что у пациенток с повышенным уровнем АППБ-3 (более 445 нг/мл) остеопоротические переломы в области шейки бедра происходили в 33,8\% случаев, а при пониженном уровне (менее 248 нг/мл) в 5,9\% (различие статистически достоверно, $X^{2}=5,257, p=0,022$ ).

Таким образом, ангиопоэтин-подобные белки, относящиеся к семейству ангиогенных регулирующих секретируемых белков (в частности АППБ-3), могут выступать в качестве индикаторов патологических процессов, связанных с ревматоидным воспалением. Известно, что семейство ангиопоэтин-подобных белков помимо ангиогенеза участвует во многих физиологических и патофизиологических процессах, таких как липидный обмен, метаболизм глюкозы, развитии воспалительных и злокачественных процессов. Также ранее было отмечено, что ангиопоэтин-подобный белок 3 типа способен активировать процессы ангиогенеза и резорбции кости.

На основании интерпретации результатов клинических наблюдений нами были подобраны критерии выявления риска развития низкоэнергетических переломов шейки бедра у женщин с подтвержденным диагнозом РА по сывороточной концентрации АППБ-3 по следующей градации: при значении показателя уровня АППБ-3 равном 445 нг/мл и выше можно предполагать наличие высокого риска развития переломов шейки бедра, а при значении показателя уровня АППБ-3 равном 248 нг/мл и ниже диагностируется низкий риск развития переломов шейки бедра. При значениях АППБ-3 в диапазоне 248-445 нг/мл пациентку включают в группу биохимического мониторинга для дальнейшего наблюдения (не реже 1 раза в 3 месяца) по поводу риска развития переломов шейки бедра. 
Выводы. Включение в программу стандартного обследования предлагаемого способа прогнозирования дает возможность с высокой достоверностью оценить вероятность возникновения остеопоротических переломов шейки бедра у женщин с РА, оценить активность резорбтивных процессов в костной ткани, не прибегая к широкомасштабным дорогостоящим денситометрическим исследованиям.

КЛЮЧЕВЫЕ СЛОВА: Ревматоидный артрит; остеопороз; ангиопоэтин-подобный белок 3 типа.

ANGIOPOETIN-LIKE PROTEIN 3 AS A MARKER OF OSTEOPOROTIC CHANGES IN THE FEMORAL NECK IN WOMEN WITH RHEUMATOID ARTHRITIS

(c) Alexandrov V.A. ${ }^{1,2}$, Shilova L.N. ${ }^{1}$, Alexandrov A.V. ${ }^{1,2}$

${ }^{1}$ Volgograd State Medical University, Volgograd

${ }^{2}$ Research Institute of Clinical and Experimental Rheumatology named after A.B. Zborovsky, Volgograd 
РАННИЙ ОСТЕОАРТРИТ КОЛЕННЫХ СУСТАВОВ

( Л.И. Алексеева, Е.А. Таскина, К.А. Телышев, Н.Г. Кашеварова, Е.П. Шарапова, С.Г. Аникин, Е.А. Стребкова

ФГБНУ «Научно-исследовательский институт ревматологии им. В.А. Насоновой», Москва

Диагностика раннего остеоартрита (ОА) представляет определенные трудности, поскольку не существует общепринятых критериев, делаются попытки использовать для этой цели биомаркеры, инструментальные методы (магнитно-резонансная томография (МРТ), рентген), артроскопию, некоторые клинические признаки. В 2017 г. международной группой ученых по инициативе итальянских ревматологов были предложены клинические критерии раннего ОА (ESKOA), основанные на сочетании клинических признаков и факторов риска развития ОА.

Цель: апробация критериев ESKOA у пациентов с небольшой длительностью впервые возникшего болевого синдрома в коленных суставах.

Материалы и методы: предварительные данные получены на 27 пациентов (25 жен/2 муж) в возрасте от 36 до 63 лет

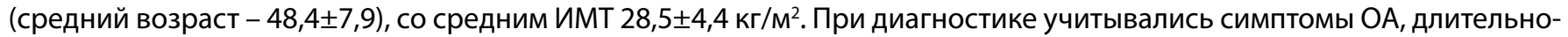
стью не более 6 месяцев (любая боль в коленном суставе за предыдущие 6 месяцев при отсутствии недавней травмы или повреждения; боль при подъеме и спуске по лестнице; боль, усиливающаяся при нагрузке; непродолжительная скованность в коленном суставе в начале движения) и факторы риска (ФР) его развития (ИМТ больше 25 кг/м²; отягощенная наследственность по ОА; травма коленного сустава в анамнезе; ОА другой локализации; метаболический синдром (МС); наличие гипермобильности; асимметрия нижних конечностей; нарушение оси сустава). Диагноз раннего ОА (согласно критериев ESKOA) устанавливался при наличии у пациента 3 и более симптомов; или 2 и более симптомов + 1 и более ФР; или 1 и более симптомов + 2 и более ФР. Кроме того, исключались больные старше 50 лет; при наличии воспалительного артрита или генерализованного болевого синдрома; и больные в возрасте от 35 до 50 лет, если у них имелся хотя бы один ФР развития ОА. Все пациенты подписали информированное согласие, на каждого больного заполнялась специально разработанная анкета и проводилась рентгенография коленных суставов в положении стоя при фиксированном сгибании (в задне-передней проекции) с использованием позиционной рамки. Статистический анализ осуществлялся с помощью программного пакета Statistica 10.0

Результаты. Медиана боли составила 48 [42; 54] мм, длительность болей в коленном суставе - 16 [12; 20$]$ недель. В 100\% случаев пациенты испытывали боль в коленных суставах при нагрузке. У большинства пациентов отмечалась боль при приседании на корточки (81,5\%), при спуске/подъеме по лестнице $(77,8 \%)$ и непродолжительная «стартовая» скованность (74,1\%). В 55,6\% случаев наблюдалась боль при вставании после нахождения в положении сидя и в 40,7\% выявлялись функциональные ограничения в коленных суставах при ходьбе. При анализе ФР продемонстрировано, что отягощенная наследственность по ОА наблюдалась в 74,1\%, гипермобильность - 48, $1 \%$, травма коленного сустава в анамнезе - 14,8\%, нарушение оси сустава и асимметрия нижних конечностей - 11,1\%. Значительное количество пациентов имели избыточную массу тела (ИМТ более 25 кг/м²) - 70,4\%. Гипертоническая болезнь встречалась у 37\% пациентов, МС - 18,5\%, сахарный диабет 2 типа - 7,4\%, гиперхолестеринемия - 40,7\%, гипертриглицеридемия - 11,1\%, гиперурикемия - 3,7\%. При рентгенологическом обследовании, преимущественно выявлялись 0 или I рентгенологическая стадия (справа в 66,7\% и слева в 63\%) ОА коленных суставов, во всех остальных случаях - ІІ стадия. У всех включенных пациентов значения СОЭ и СРБ были в пределах нормы (медиана СОЭ - 6 [4; 9] мм/час и СРБ - 1,2 [0,6; 2,0] мг/л). Вывод: критерии ESKOA (боль при нагрузке, приседании на корточки, спуске/подъеме по лестнице, непродолжительная «стартовая» скованность в коленных суставах при небольшой длительности болевого синдрома) позволяют поставить диагноз раннего ОА более, чем у трети больных с жалобами на боли в коленных суставах, и выделить группу больных с 0 или I рентгенологическими стадиями для дальнейшего динамического наблюдения.

КЛЮЧЕВЫЕ СЛОВА: Коленный сустав; остеоартрит; болевой синдром.

\section{EARLY OSTEOARTHRITIS OF THE KNEE JOINTS}

(c) Alekseeva L.I., Taskina E.A., Telyshev K.A., Kashevarova N.G., Sharapova E.P., Anikin S.G., Strebkova E.A.

V.A. Nasonova Research Institute of Rheumatology, Moscow 
ФАКТОРЫ РИСКА САРКОПЕНИИ У ПАЦИЕНТОВ С РЕВМАТОИДНЫМ АРТРИТОМ С ПОЗДНИМ ДЕБЮТОМ

\author{
(с) Д.Б. Алиев ${ }^{1}$, Ю.А. Сафонова ${ }^{1,2}$
}

'ГБУЗ «Клиническая ревматологическая больница № 25», Санкт-Петербург

2ГБОУ ВПО «Северо-Западный государственный медицинский университет имени И.И. Мечникова» Минздрава России, Санкт-Петербург

Цель: изучить факторы, влияющие на риск развития саркопении у пациентов с поздним дебютом ревматоидного артрита

Материалы и методы: Обследовано 35 пациента (24 женщин и 11 мужчин) с дебютом ревматоидного артрита (PA)

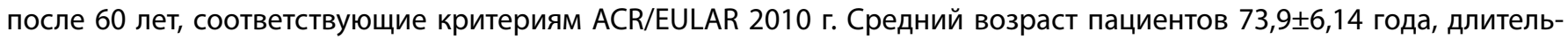
ность заболевания 3,94ะ3,26 лет. Серопозитивными по РФ были 26 человек (74\%), и по АЦЦП 16 (45\%). По данным рентгенологического обследования 2 стадия выявлена у 22 пациентов (62,8\%), с 3 стадией 8 пациентов (22,8\%) и 4 стадией 5 (14,6\%). Мышечную силу оценивали с помощью кистевого динамометра ДК-50. Снижение мышечной силы наблюдается при показателях менее 16 кг для женщин и 27 кг для мужчин. Мышечную функцию изучали по результатам краткого комплекса тестов физической активности SPPB- тестов (short physical performance battery). Hapyшение мышечной функции определяли при снижении общего балла менее 9. Усталость как главный детерминант саркопении изучали с помощью шкалы FACIT. Тяжелая усталость выявлялась при снижении общего балла менее 30.

Результаты и обсуждение: Из 35 пациентов 13 (37,1\%) имели низкую активность заболевания, 22 (68,2\%) высокую активность. Показатели мышечной силы в представленной выборке варьировали от 4 до 35 кг (среднее значение $15,1 \pm 8,71$ кг). У лиц с низкой активностью РА средние значения мышечной силы достоверно выше, чем у пациентов с высокой активностью РА $(22,4 \pm 2,4$ кг и 11,5 $\pm 2,6$ кг соответственно, p $<0,01)$. Показатели мышечной функции по результатам общего балла SPPB-тестов у пациентов с PA варьировалась от 3 до 12 баллов (среднее значение $8,2 \pm 2,67$ балла). Было установлено, что у пациентов с низкой активностью РА мышечная функция статистически значимо лучше, чем у пациентов с высокой активностью $(8,3 \pm 1,2$ балла и 7,3 $\pm 1,2$ балла соответственно, р<0,01). В представленной группе пациентов общий балл шкалы FACIT варьировался от 22 до 49 баллов (среднее значение $33,17 \pm 8,45$ балла). Была выявлена прямая корреляция между качеством жизни и мышечной функцией, т.е чем тяжелее усталость, тем чаще встречается низкая мышечная функция ( $r=0,457 ; p<0,05)$. Обнаружена обратная корреляционная связь между активностью заболевания и результатами динамометрии ( $r=-0,515, p<0,05)$, а также между активностью заболевания и результатами шкалы FACIT ( $r=-0,572, p<0,05)$. Выявлена прямая связь между результатами SPPB-тестов и результатами шкалы FACIT $(r=0,457, p<0,05)$.

Выводы: У пациентов с РА показатели мышечной силы и функции скелетных мышц снижены и находятся в прямой зависимости от активности заболевания. Результаты по шкале FACIT статистически значимо ниже у пациентов с наихудшими показателями мышечной силы и результатами функциональных тестов. Тяжелая усталость по шкале FACIT как главного детерминанта саркопении находится в прямой корреляции с активностью заболевания.

КЛЮЧЕВЫЕ СЛОВА: Саркопения; ревматоидный артрит; факторы риска.

\title{
RISK FACTORS FOR SARCOPENIA IN PATIENTS WITH LATE-DEBUT RHEUMATOID ARTHRITIS
}

(c) Aliev D.B. ${ }^{1}$, Safonova Yu.A. ${ }^{1,2}$

${ }^{1}$ Clinical Rheumatology Hospital No. 25, Saint Petersburg

${ }^{2}$ I.I. Mechnikov North-Western State Medical University, Saint Petersburg 
(ㄱ Н.А. Алиханова, Л.М. Мурашко, В.Е. Новиков, И.А. Скрипникова

ФГБУ «Национальный медицинский научно-исследовательский центр профилактической медицины» Минздрава России, Москва

Цель исследования: изучить ассоциацию минеральной плотности кости (МПК) с показателями сосудистой жесткости и субклинического атеросклероза в зависимости от биомаркеров клеточного старения.

Материалы и методы: В одномоментное исследование включено 107 пациенток от 45 до 82 лет (средний возраст -

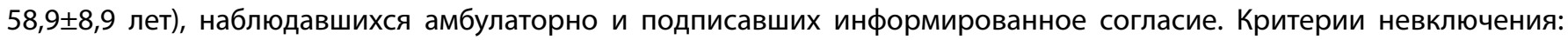
клинические проявления атеросклероза; заболевания, вызывающие вторичный остеопороз; прием препаратов, влияющих на костный обмен и эластичность сосудистой стенки. Исследование МПК проводили методом двухэнергетической рентгеновской абсорбциометрии (ДРА) на аппарате Hologic (Delphi W) в поясничном отделе позвоночника (L1-L4) и проксимальном отделе бедренной кости (ПОБ). Показатели МПК оценивались как в абсолютных значениях г/см², так и в величинах стандартного отклонения (SD) от пика костной массы (Т-критерий). Согласно критериям ВОЗ остеопенией считался уровень Т-критерия от <-1 до -2,5 SD, остеопорозом s-2,5 SD. Толщина комплекса интима-медиа (ТКИМ), наличие и количество атеросклеротических бляшек (АСБ) исследовались с помощью дуплексного сканирования сонных артерий. Значения >0,9 принимались за повышение ТКИМ, локальные увеличения ТКИМ >1,5 мм свидетельствовали о наличии АСБ. Оценка скорости распространения пульсовой волны (СРПВ), индекса аугментации (ИА) проводилось методом аппланационной тонометрии (SphygmoCor). СРПВ $\geq 10$ м/с считалась патологической и свидетельствовала о существенном поражении сосудистой стенки. ИА считался нормальным при отрицательном его значении, положительный ИА свидетельствовал о повышенной жесткости. Был выбран медианный порог >20\%. Длина теломер в лейкоцитах (ДТ) измерялась методом ПЦР в реальном времени. Медиана ДТ составила 9,75 усл. ед. ДТ $\geq 10,00$ усл. ед. принималась за «длинную» ДТ. «Самой короткой» ДТ считалась ДТ <9,50 усл. ед. Определение активности теломеразы (АТ) проводилось на чисто выделенной моноцитарной фракции клеток крови на основании теломеразной полимеразной реакции. Медиана АТ составила - 0,5\%. Значения АТ <0,5\% считались сниженными, a AT >0,5\% - повышенными. Статистический анализ осуществлялся с помощью пакета прикладных программ Statistical Analysis System (USA).

Результаты: Риск снижения костной массы и развития остеопороза возрастал в 3 раза при высоких значениях СРПВ ( $\geq 10$ м/с), более чем в 4 раза при ИА $\geq 20 \%$ и ТКИМ >0,9мм, в 2,45 раза при наличии АСБ в сонных артериях и при наличии «самых коротких» теломер. Продемонстрирована ассоциация ДТ с параметрами субклинического АС (толщина КИМ, СРПВ, ИА). Вероятность выявления повышенных показателей сосудистой жесткости возрастала при обнаружении «самых коротких» теломер. В многомерном регрессионном анализе отрицательная связь между ИА, толщиой КИМ и МПК осталась достоверной, в то время как в отношении СРПВ, наличия АСБ и ДТ эта корреляция не подтвердилась.

С увеличением продолжительности менопаузы отмечалось постепенное повышение показателей жесткости (СРПВ, ИА, толщина КИМ, наличие АСБ), потеря костной массы и уменьшение ДТ. Максимальные показатели сосудистой жесткости, наиболее низкая МПК и «самые короткие» теломеры были выявлены после 10 лет менопаузы.

Заключение: Снижение МПК у женщин в постменопаузе ассоциируется с высокими показателями ИА и толщины КИМ. Независимая связь МПК с ИА, а не с СРПВ, по-видимому, объясняется вовлечением мелких артериол, питающих костную ткань. Не показана связь костной массы с ДТ. Вероятно, это связано с тем, что в развитии постменопаузального остеопороза большую роль играет повышение функции остеокластов, нежели снижении активности остеобластов, причем эти патологические процессы активно развиваются под действием различных факторов риска, а не в результате физиологического старения клеток.

КЛЮЧЕВЫЕ СЛОВА: Минеральная плотность кости; теломеры; постменопауза.

\section{BONE MINERAL DENSITY AND VASCULAR WALL CONDITION DEPENDING ON THE BIOLOGY OF TELOMERES IN POSTMENOPAUSAL WOMEN}

(c) Alikhanova N.A., Murashko L.M., Novikov V.E., Skripnikova I.A.

National Medical Research Center for Preventive Medicine, Moscow 


\title{
РАСПРОСТРАНЕННОСТЬ ДЕФИЦИТА 25(ОН)D У ЖЕНЩИН
} ПЕРИМЕНОПАУЗАЛЬНОГО ВОЗРАСТА

\author{
() Н.М. Алиханова, Л.С. Аббосхужаева, Г.И. Аллаярова
}

Республиканский Специализированный Научно-Практический Медицинский Центр Эндокринологии Минздрава Республики Узбекистан, Ташкент

Цель - оценить уровень 25(OH)D у женщин перименопаузального возраста.

Материалы и методы. Проведено обследование 79 женщин в возрасте от 40 до 50 лет, средний возраст составил $46,1 \pm 3,28$ лет. Уровни витамина D и ПТГ определяли с помощью электрохемилюминесцентного анализа на автоматическом анализаторе Elecsys и cobas e(Roche).

Результаты. Согласно полученным результатам, дефицит витамина D диагностировался у 41,8\% женщин из 79 обследованных (в среднем 7,31 нг/мл), недостаточное содержание витамина D у 39,2\% (в среднем 13,2 нг/мл), достаточное содержание - при концентрации витамина у 19,0\% (в среднем 30,2 нг/мл).

У $81,0 \%$ женщин уровень 25(OH)D находился в диапазоне 2,5 и 90\% перцентилей в пределах 3,0-19,25 нг/мл. Уровень 25(OH)D ниже 5-ой перцентили встречался у 5,1\%, а выше 93,5 перцентили у 7,6\% обследованных.

Анализ уровня ПТГ у женщин перименопаузального возраста показал, что в среднем содержание ПтГ составило

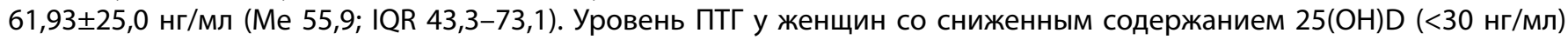
был выше, чем у лиц с уровнем 25(OH)D >30 нг/мл. Уровень 25(OH)D отрицательно коррелировал с уровнем ПтГ $(r=-0,32 ; p<0,05)$.

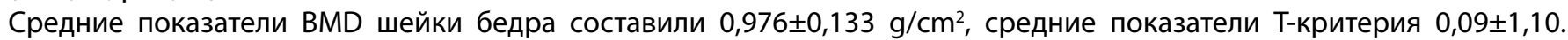

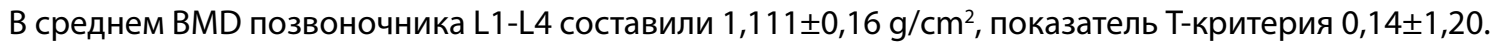

По результатам двухэнергетической абсорбциометрии из 34 женщин у 1(2,9\%) отмечался остеопороз (Т-критерий -2,70; BMD шейки бедра 0,730 g/ $\mathrm{cm}^{2}$ ). Уровень витамина D 8,29 нг/мл, что по классификации соответствует выраженному дефициту. У 5(14,7\%) диагностирована остеопения (в среднем Т-критерий - -1,46士0,31; BMD шейки бедра

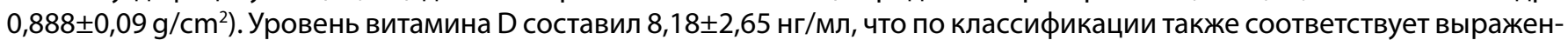
ному дефициту. Следует отметить, что у 16 (47,1\%) из 34 женщин выявлен выраженный дефицит витамина D (в диапазоне 3,0-9,73 нг/мл), у 15 (44,1\%) концентрация 25(OH)D находилась в пределах 10,2-17,3 нг/мл, что также свидетельствует о недостаточности элемента.

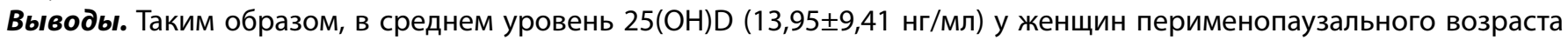
свидетельствует о выраженном дефиците. Уровни 25(OH)D ниже 20 нг/мл выявлены у 81,0\% лиц исследуемой популяции, что свидетельствует о наличии у большей части обследованных недостаточности витамина D разной степени тяжести. Одним из вероятных объяснений этого факта является то, что Узбекистан - это южная страна, в которой у большого числа людей относительно смуглая кожа.

КЛЮЧЕВЫЕ СЛОВА: Витамин D; перименопауза; ренгеновская денситометрия.

\section{PREVALENCE OF 25(OH)D DEFICIENCY IN PERIMENOPAUSAL WOMEN}

(c) Alikhanova N.M., Abboskhuzhayeva L.S., Allayarova G.I.

Republican Specialized Scientific and Practical Medical Center of Endocrinology, Tashkent 
СИНДРОМ ХРУПКОСТИ ПРИ РЕВМАТОИДНОМ АРТРИТЕ: ЧАСТОТА, ПРЕДИКТОРЫ, РИСК ПЕРЕЛОМОВ И ПАДЕНИЙ

() Е.И. Амири', С.Е. Мясоедова', Н.В. Корягина', Х. Амири', В.Ю. Манохин², И.П. Афанасьева², И.А. Петровская², A.В. Рыбин ${ }^{2}$

'ФГБОУ ВО «Ивановская государственная медицинская академия» Минздрава России, Иваново

${ }^{2}$ ОБУ3 «Ивановская областная клиническая больница», Иваново

Цель. Установить частоту и возможные предикторы синдрома хрупкости при ревматоидном артрите (РА), а также его связь с риском переломов и падений.

Материалы и методы. В исследование были включены 70 пациентов (59 женщин и 11 мужчин) с достоверным диагнозом PA по критериям ACR/EULAR (2010), в возрасте 33-81 год (средний возраст 58,2士10,3 лет), проходящих стационарное лечение на базе ОБУ3 «Городская клиническая больница №4» и ОБУ3 «Ивановская областная клиническая

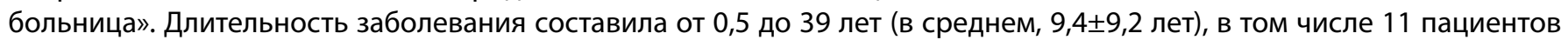
имели ранний РА (длительность <1 года). У 82,9\% больных был серопозитивный РA умеренной активности (DAS28 по СОЭ 4,6士1,4), II-III рентгенологической стадии (65,7\%), II-III функционального класса (98,6\%). Среди коморбидных заболеваний наиболее часто встречались гипертоническая болезнь (у 67,1\%) и хронический гастродуоденит (у 87,6\%). К началу исследования 47 (67,1\%) больных получали базисную противовоспалительную терапию метотре-


чали лечение генно-инженерными биологическими препаратами. 64 пациента ранее принимали глюкокортикостероиды (ГКС) в дозе $\geq 5$ мг/сут. в течение 3 месяцев и более. Синдром хрупкости диагностировали по фенотипической модели L.P. Fried (2001) с использованием опросников по выявлению гиподинамии (International Questionnaire on Physical Activity), синдрома усталости (Fatigue Assessment Scale), немотивированной потери веса (за год $\geq 4,5$ кг) или ИМТ <18,5кг/м², низкой силы сжатия кисти методом динамометрии, снижения скорости ходьбы на 4 метра. Хрупкость диагностировали при наличии $\geq 3$ указанных характеристик, прехрупкость - при наличии 1-2 характеристик. У 37 пациентов была выполнена оценка композиционного состава тела и минеральной плотности кости (МПК) в позвоночнике и бедре на аппарате Lunar Prodidgy (General Electric). Остеопороз (ОП) устанавливался согласно клиническим рекомендациям Российской ассоциации по остеопорозу (2014). Содержание скелетной мышечной ткани оценивали по индексу тощей массы (ИТМ) верхних и нижних конечностей. Саркопению диагностировали при ИТМ <6,0 кг/м², ожирение - по содержании жира в организме $>32 \%$. Факторы риска переломов оценивали по модели FRAX, риск падений - по шкале Морсе. Полученные данные обрабатывались в приложении Microsoft Office Excel и в пакете прикладных программ Statistica 6.0. При нормальном распределении признака результаты были представлены в виде $M \pm \sigma$, где $M$ - средняя, $\sigma$ - среднеквадратичное отклонение. Достоверность различий между группами оценивалась с помощью t-критерия Стьюдента, сопряженность признаков - по критерию хи-квадрат Пирсона. Разница считалась статистически значимой при $\mathrm{p}<0,05$.

Результаты и обсуждение. Синдром хрупкости установлен у 31 (44,3\%), прехрупкости - у 36 (51,4\%) пациентов. «Крепких» пациентов выявлено трое. Хрупкие пациенты были старше по возрасту, чем прехрупкие $(62,7 \pm 9,4$ и 54,1 99,5 лет, $\mathrm{p}=0,0004)$, число лиц молодого и среднего возраста (<60 лет) среди них было ниже (11 и 25 человек, $\mathrm{p}<0,05)$. Достоверных различий по длительности РА, гендерному признаку в группах выявлено не было. У хрупких по сравнению с прехрупкими была выше рентгенологическая стадия РА (II-III стадия - у 71\% пациентов и I-ІІ ста-

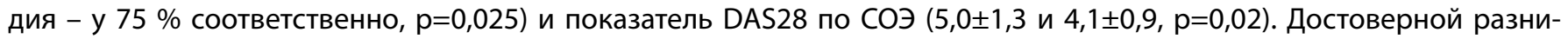
цы между пациентами по дозам метотрексата и частоте его применения не выявлено. Суммарная доза полученных

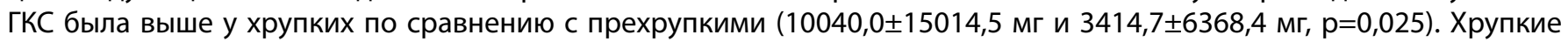
реже работали $(19,4 \%$ и 69,4\%, p<0,05), чаще имели минимальный доход $(80,6 \%$ и 47,2\%, p<0,05) и среди них было больше одиноких людей (59,1\% и 36,1\%). Среди хрупких и прехрупких пациентов число курящих значимо не отличалось (5 - 16,1\% и 6 - 16,7\% пациентов). 2 хрупких пациента злоупотребляли алкоголем, среди прехрупких таковых не оказалось. У хрупких пациентов по сравнению с прехрупкими были снижены показатели динамометрии (5,1+4,9kp и 10,5 $\pm 5,8 \mathrm{kp}, \mathrm{p}=0,0001)$. У 51,6\% хрупких пациентов была выявлена гиподинамия и увеличение времени ходьбы на 4 м

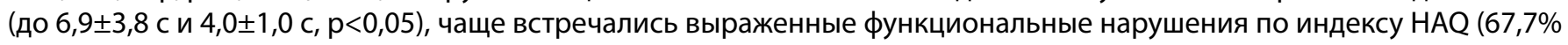
и 5,6\%, p<0,05). Также у них по сравнению с прехрупкими чаще наблюдались немотивированная потеря веса (74,4\% и $11,1 \%, p<0,05)$ и повышенная утомляемость $(96,8 \%$ и 50,0\%, p<0,05). У 18 хрупких и у 19 прехрупких пациентов были проведены остеоденситометрия и исследование КСТ. Установлено, что остеопорозом чаще страдали хрупкие пациенты (p<0,05). У них в 1,5 раза чаще встречались низкоэнергетические переломы и в 1,5 раза чаще отмечалось снижение МПК, соответствовавшее остеопении или ОП. Также у хрупких пациентов был значительно выше риск переломов по FRAX как в шейке бедра $(7,6 \pm 11,6 \%$ и $1,8 \pm 1,7 \%, p=0,04)$, так и общий риск переломов $(23,0 \pm 14,3 \%$ и $14,7 \pm 5,6 \%$, $\mathrm{p}=0,02)$. Вероятность падений была достоверно выше $(\mathrm{p}<0,05)$ у хрупких пациентов по сравнению с прехрупкими: у 10 из 18 пациентов отмечен высокий риск падений, в то время как у прехрупких риск падений отсутствовал или был 
низким у отдельных больных. Пациенты обеих групп достоверно не отличались по индексу массы тела, содержанию жировой и мышечной массы, фенотипам композиционного состава тела. Однако следует отметить, что в обеих группах преобладали пациенты с избыточной массой тела и ожирением. Самым частым фенотипом композиционного состава тела было сочетание остеопении/ОП с ожирением (остеопеничесое ожирение), которое встречалось примерно у 30\% пациентов обеих групп. У хрупких пациентов по сравнению с прехрупкими остеосаркопеническое ожирение наблюдалось в 2 раза чаще.

Синдром хрупкости или старческая астения - гериатрический синдром, который характерен для лиц пожилого возраста (>60 лет), характеризуется снижением физиологического резерва и функций многих систем организма и приводит к повышенной уязвимости организма к воздействию внутренних и внешних факторов и высокому риску развития неблагоприятных исходов для здоровья, потери способности к самообслуживанию и смерти (Клинические рекомендации: Старческая астения, 2018). Есть основания полагать, что хрупкость при РА развивается в более молодом возрасте, что приводит к инвалидности, увеличивает коморбидность и обусловливает преждевременную смертность пациентов. Вместе с тем, проблема хрупкости при РА мало изучена. По результатам нашего исследования выявлена Высокая распространенность хрупкости и прехрупкости при РА. Развитие данного синдрома при РА и его прогрессирование от прехрупкости к хрупкости связано с рядом факторов, среди которых особую роль, вероятно, играет активность, рентгенологическая стадия РА и функциональный статус пациента. Имеет значение социальный статус и возраст пациента, однако почти половина хрупких и три четверти прехрупких пациентов были моложе 60 лет. Синдром хрупкости при РА тесно ассоциирован с ОП, высоким риском переломов и падений. Не выявлено достоверных связей хрупкости с показателями композиционного состава тела, однако это может быть связано с небольшой группой исследуемых пациентов. Кроме того, сравнения проводились между прехрупкими и хрупкими пациентами, группа крепких пациентов была представлена единичными лицами.

Выводы. Синдромы хрупкости и прехрупкости характерны для больных РА и могут проявляться в молодом и среднем возрасте. Наличие хрупкости ассоциировано с более старшим возрастом, низким уровнем социального статуса, более высокой активностью и рентгенологической стадией РА, физическим дефицитом. Хрупкие пациенты по сравнению с прехрупкими чаще страдают ОП и являются группой высокого риска переломов и падений, что необходимо учитывать при ведении этих пациентов.

КЛЮЧЕВЫЕ СЛОВА: Ревматоидный артрит; риск переломов; предикторы.

\section{FRAGILITY SYNDROME IN RHEUMATOID ARTHRITIS: FREQUENCY, PREDICTORS, RISK OF FRACTURES AND FALLS}

(c) Amiri E.I. ${ }^{1}$, Myasoedova S.E. ${ }^{1}$, Koryagina N.V. ${ }^{1}$, Amiri H. ${ }^{1}$, Manokhin V.Yu. ${ }^{2}$, Afanasieva I.P. ${ }^{2}$, Petrovskaya I.A. ${ }^{2}$, Rybin A.V. ${ }^{2}$

${ }^{1}$ Ivanovo State Medical Academy, Ivanovo

${ }^{2}$ Ivanovo Regional Clinical Hospital, Ivanovo 
ПОКАЗАТЕЛИ МИНЕРАЛЬНОЙ ПЛОТНОСТИ КОСТНОЙ ТКАНИ С УЧЕТОМ ТРАБЕКУЛЯРНОГО КОСТНОГО ИНДЕКСА У ПАЦИЕНТОВ С САХАРНЫМ ДИАБЕТОМ 2 ТИПА

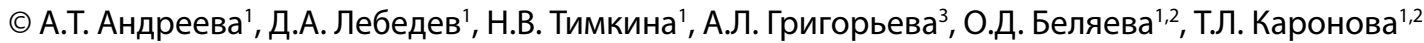

'ФГБУ «Национальный медицинский исследовательский центр им. В. А. Алмазова» Минздрава России, Санкт-

Петербург

${ }^{2}$ ФГБУ «Первый Санкт-Петербургский Государственный Медицинский Университет им. И.П. Павлова» Минздрава

России, Санкт-Петербург

${ }^{3}$ СПб ГБУЗ «Клиническая ревматологическая больница №25», Санкт-Петербург

Введение. У больных сахарным диабетом 2 типа показатели МПК, также 10-летний риск переломов с использованием шкалы $F R A X^{\circledast}$ часто в пределах нормы, в связи с этим в последние годы предлагается использование у этих больных оценки ТКИ

Цель исследования. Оценить показатели МПК с учетом трабекулярного костного индекса, риск переломов у больных сахарным диабетом 2 типа и сопоставить с уровнем обеспеченности витамином D.

Материалы и методы. Обследовано 252 (172 женщины) больных сахарным диабетом 2 типа (СД2) на различной сахароснижающей терапии в возрасте от 36 до 86 лет (в среднем 61,0土8,8). Рентгеновская абсорбциометрия (Lunar Prodigy) была выполнена 124 больным (110 женщин). Уровень 25(OH)D в сыворотке крови (AbbottArchitect 8000) и уровень паратиреоидного гормона (ПТГ) (Biomerica, USA) были оценены у 70 пациентов, уровень гликированного гемоглобина был определен методом ионообменной хроматографии.

Результаты проведенного исследования показали, что 20 (7,9\%) больных СД2 имеют нормальный ИмТ, в то время как 232 (92,1\%) имеют избыточную массу тела или ожирение. Длительность СД2 варьировала от 1 года до 30 лет (в среднем 13,1 66,4$)$. Практически половина больных получала инсулинотерапию или её комбинацию с другими сахароснижающими препаратами. Среднее значение уровня гликированного гемоглобина составило 8,8土1,7\%, Уровень 25(OH)D в сыворотке крови составил от 7,5 до 44,5 нг/мл (в среднем 22,7士9,4), и из них 23\% имели нормальный уровень обеспеченности витамином D, у 77,1\% уровень 25(OH)D соответствовал недостаточности или дефициту. Нами установлена отрицательная корреляционная связь между 25(OH)D и ПTГ (r=-0,37, p=0,002). Уровень 25(OH)D не был ассоциирован с степенью компенсации углеводного обмена.

У 24 пациентов (9.5\%) в анамнезе имелись указания на наличие переломов в зрелом возрасте. Низкая МПК диагностирована у 39 (31.5\%) женщин с СД2. Однако показатели МПК у лиц с переломами и без не различались. Оценка 10-риска переломов показала, что риск основных остеопоротических переломов варьировал от 0,4 до 24,0\% (6,9士3,8)

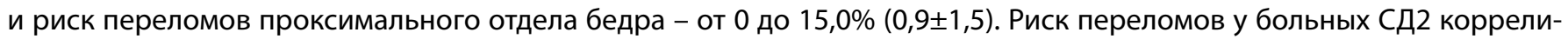
ровал с возрастом ( $r=0,40, p=0,0001)$ и значением ИМТ ( $r=-0,20, p=0,001)$, и не был ассоциирован с длительностью диабета, уровнем $\mathrm{HbA}_{1 c^{\prime}} 25(\mathrm{OH}) \mathrm{D}$ и ПТГ.

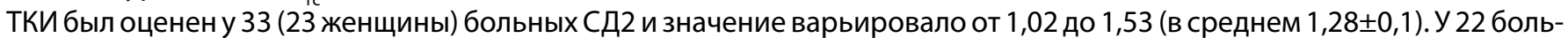
ных (66,7\%), в том числе 5 мужчин, МПК с учетом ТКИ была ниже значения 1,35 г/см². Использование показателя ТКИ не повлияло на увеличение 10-риска переломов бедра или основных остеопоротических у больных СД2 (0,8\% \& 0,6\%; 8,5\% \& 7,4\% с учетом ТКИ и без соответственно для перелом бедра и основных остеопоротических переломов).

Выводы. Результаты настоящего исследования показали, что больные СД2 типа в большинстве случаев имеют недостаток и дефицит витамина D и нормальную МПК, согласно данным денситометрии. Оценка ТКИ позволяет выявить нарушение качества костной ткани у двух третьих больных СД2, что делает целесообразным его использование у данной популяции больных.

КЛЮЧЕВЫЕ СЛОВА: Минеральная плотность кости; трабекулярный костный индекс; сахарный диабет 2 типа.

\section{INDICATORS OF BONE MINERAL DENSITY CONSIDERING WITH TRABECULAR BONE SCORE IN PATIENTS WITH TYPE 2 DIABETES MELLITUS}

(c) Andreeva A.T. ${ }^{1}$, Lebedev D.A. ${ }^{1}$, Timkina N.V. ${ }^{1}$, Grigorieva A.L. ${ }^{3}$, Belyaeva O.D. ${ }^{1,2}$, Karonova T.L. ${ }^{1,2}$

${ }^{1}$ Almazov National Medical Research Center, Saint Petersburg

${ }^{2}$ First Saint Petersburg State Medical University named after I.P. Pavlov, Saint Petersburg

${ }^{3}$ Saint Petersburg Clinical Rheumatology Hospital No. 25, Saint Petersburg 


\section{( ) А.Ф. Ахатов ${ }^{1}$, А.В. Петряйкин ${ }^{2}$, С.А. Рыжкин ${ }^{3}$, Р.Р. Насырова ${ }^{1}$}

'Диагностический центр «БАРСМЕД», Казань

${ }^{2}$ ГБУЗ «Научно Практический Клинический Центр Диагностики и Телемедицинских технологий Департамента

Здравоохранения города Москвы», Москва

${ }^{3}$ ГБОУ ДПО «Казанская государственная медицинская академия» Минздрава России, Казань

В настоящее время, в экономически развитых странах многоуровневая система медицинской помощи является способом обслуживания населения в общественном секторе здравоохранения. Эффективное ее функционирование происходит с использованием технологически ранжированной на уровни и методологически распределенной на последовательные периоды стандартизованной схемы лечения пациентов. Сложившаяся современная система функционирования отрасли здравоохранения Российской Федерации требует модернизации способа обслуживания пациентов. Создание многоуровневой системы медицинской помощи на региональном уровне, специализированной по нозологиям с высоким уровнем смертности, позволит развить сферу профилактической медицины, которая уже организована в ряде развитых стран. В рекомендациях Международного фонда остеопороза (IOF) отмечено, что внедрение служб профилактики повторных переломов (Fracture Liaison Service) является единственным рациональным шагом, который можно сделать для улучшения ухода за пациентами и снижения затрат на медицинское обслуживание, связанных с переломами. С этой целью IOF организовала «Сapture the Fracture» - глобальную кампанию по содействию внедрению служб профилактики повторных переломов (СППП). Кампания устанавливает стандарты для внедрения СППП, предоставляет платформу для их успешного функционирования.

Целью нашего исследования явилось внедрение алгоритмов и критериев ранней диагностики остеопороза на основе рентгеновской денситометрии, магнитно-резонансной томографии, лабораторной диагностики и FRAX, с последующей централизацией радиологической службы остеопороза на территории РТ в рамках государственно-частного партнерства. Модернизация радиологической службы республики будет сформирована с использованием модели трехуровневой системы здравоохранения и интеграцией в эту систему служб профилактики остеопороза на примере кампании «Capture the Fracture», с присвоением соответствующих медалей (согласно критериям лучших служб), в зависимости от уровня медицинской организации (золотая, серебряная и бронзовая медали соответственно).

Методы исследования: двухэнергетическая рентгеновская абсорбциометрия (DXA), магнитно-резонансная томография, лабораторная диагностика, Frax - инструмент оценки риска переломов. С 2016 года в ДЦ «БАРСМЕД» было проведено 4515 исследований денситометрии, в результате у 33\% пациентов выявлен остеопороз, у 44\% - остеопения, у 23\% - норма. Эти данные были использованы и в научных целях - для корреляции с данными МРТ позвоночника. Создание МРТ-критериев диагностики остеопороза стало ключевым моментом в реализации алгоритма по МРТ-скринингу на остеопороз, который состоит из пяти этапов. Первый этап - это идентификация пациента (женщины старше 40 лет, которые проходят МРТ позвоночника (любой отдел)/головного мозга). Второй этап - анкетирование по системе FRAX, в ходе которого выявляется группа риска (граница FRAX равная 20\% и более). Пациенты, имеющие 1 весомый фактор риска, даже при наличии FRAX менее $20 \%$ - включаются в исследование). Третий этап - исследование (пациенты из группы риска/с одним фактором риска направляются на MPT позвоночника в sag-проекции + Dixon. Четвертый этап - анализ (МРТ-диагностика признаков остеопороза: Коэффициент жировой дегенерации КМ >0,7, Морфометрия - 1-3 степень по шкале Genant). При наличии одного из признаков пациент направляется на денситометрию. Пятый этап - Консультация врача. Принимая во внимание весь накопленный опыт по диагностике остеопороза, мы выступили с инициативой по созданию 12 диагностических центров (в гг. Альметьевск, Б. Сабы, Бугульма, Буинск, Елабуга, Зеленодольск, Н. Челны (2 шт.), Нижнекамск, Чистополь, Казань (2 шт.)), которые будут оснащены качественным и надежным оборудованием, укомплектованы штатом профильных специалистов. 12 центров будут разделены на три уровня: 1 уровень - ЦРБ, 2 уровень - городские больницы, 3 уровень - РКБ МЗ РТ. Каждому уровню планируется присвоение медали согласно стандартам Международного фонда остеопороза (IOF): 1 уровень бронзовая, 2 уровень - серебряная, 3 уровень - золотая медали, соответственно. Эти центры смогут обеспечить первичную диагностику нарушений минеральной плотности кости (МПК) непосредственно на местах.

В результате работы по совершенствованию диагностического процесса и внедрения в практику инструментов для улучшения ведения пациентов, БАРСМЕД получил бронзовую звезду на карте лучших СППП. Мы научились конвертировать и отправлять снимки денситометрии в формате Dicom в ЦАМИ (Центральный архив медицинских изображений). В настоящее время количество отправленных снимков достигло более 1,5 тысяч. Реализована система дистанционного описания врачами-рентгенологами снимков, полученных из филиалов организации. Пациенты, у которых диагностирован остеопороз берутся под контроль организации - каждый из них консультируется врачом-эндокринологом. Для филиалов реализован выезд бригады врачей-эндокринологов. 
Выводы: развитие службы профилактики переломов по всей территории республики, с главным координирующим центром в лице РКБ МЗ РТ позволит снизить количество первичных и повторных переломов вследствие остеопороза в РТ, уменьшить затраты здравоохранения на лечение переломов проксимального отдела бедренной кости в 3 раза в долгосрочной перспективе.

Заключение: данный проект, при условии ее реализации, будет пилотным, единственным в своем роде на территории не только России, но и во всем мире. Трехуровневая система медицинской помощи, во главе с координирующим центром ВМП, с центрами профилактики остеопороза на местах, позволит качественно развить диагностическое звено системы здравоохранения. Иерархичная система с присвоением медалей соответствующих уровней значительно повысит качество медицинской помощи. Высокий уровень диагностики в ЦРБ, координация с вышестоящими центрами - позволит избежать сложности в маршрутизации пациента, требующего оказания высокотехнологичной медицинской помощи третьего уровня. Профилактическая миссия проекта приведет не только к успешному достижению целевых показателей национального проекта «Здравоохранения», но и позволит в значительной степени сократить расходы бюджета, в частности за счет снижения общего уровня инвалидности и потребности в реабилитации. Рассмотренный в данной работе алгоритм МРТ-скрининга на остеопороз, в свою очередь, позволит расширить рамки диагностических возможностей, в условиях отсутствия денситометров и выявить «случайных» пациентов для дальнейшего дообследования и лечения.

КЛЮЧЕВЫЕ СЛОВА: Остеопороз; минеральная плотность кости; лучевая диагностика.

CENTRALIZATION OF THE RADIOLOGICAL SERVICE OF OSTEOPOROSIS IN THE FRAMEWORK OF PUBLIC-PRIVATE PARTNERSHIP IN THE TATARSTAN REPUBLIC

(c) Akhatov A.F. ${ }^{1}$, Petryaykin A.V. ${ }^{2}$, Ryzhkin S.A. ${ }^{3}$, Nasyrova R.R. ${ }^{1}$

'Diagnostic Center «BARSMED», Kazan

${ }^{2}$ Scientific and Practical Clinical Center for Diagnostics and Telemedicine Technologies, Moscow

${ }^{3}$ Kazan State Medical Academy, Kazan 


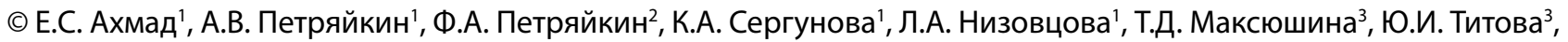
Е.Е. Царева ${ }^{3}$, С.Ю. Кузнецов ${ }^{4}$, С.П. Морозов ${ }^{1}$, О.А. Никитинская ${ }^{5}$, Н.В. Торопцова ${ }^{5}$

'ГБУЗ «Научно-практический клинический центр диагностики и телемедицинских технологий ДЗМ», Москва

${ }^{2}$ Московский государственный университет им. М. В. Ломоносова, Москва

${ }^{3}$ НИИТОН ФГБОУ ВО СГМУ им. В.И. Разумовского Минздрава России, Саратов

${ }^{4}$ ФГБУ «Национальный медицинский исследовательский Центр акушерства, гинекологии и перинатологии имени академика В.И. Кулакова», Москва

${ }^{5}$ ФГБНУ «Научно-исследовательский институт ревматологии имени В.А. Насоновой», Москва

Цель: На основе фантомного моделирования сопоставить результаты измерения минеральной плотности кости по Т-критерию проксимального отдела бедра методом асинхронной КТ денситометрии и двуэнергетической рентгеновской абсорбциометрии.

Материалы и методы: Сравнение двух методов проводилось в двух группах пациентов: группа А - 25 пациентов (возраст 63 [57; 68] года), группа Б - 20 пациентов (возраста 68 [64; 74] лет. В обеих группах сравнивались результаты анализа минеральной плотности кости (МПК) шейки бедра и общего показателя бедра, представленные по Т-критерию. КТ денситометрия выполнялась на программно-аппаратном комплексе QCT PRO ${ }^{\text {TM }}$ Mindways, CШA с приложе-

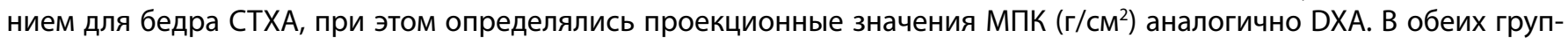
пах пациентов КТ-исследования выполнялись на сканерах Aquilion, Canon с идентичными условиями сканирования, отличие состояло в использованном фильтре реконструкции: FC17 (группа A), FC 08 (группа Б). DXA исследования выполнялись на сканерах Discovery Hologic с широким веерным пучком (группа A) и Prodigy Lunar GE с узкоугольным веерным пучком (группа Б): В обоих случаях при проведении DXA применялась калибровка, поддерживающая точность измерений согласно рекомендациям фирм-производителей.

Сравнение методов СTXА и DXA проводилось путем попарного сопоставления значений Т-критерия для проксимального отдела правого и левого бедра. Для двух групп пациентов рассчитывались коэффициенты корреляции, также проведено сравнение результатов измерений по методу Бленда-Альтмана (оценка разности измерений величины сравниваемым методом СТXА и опорным DXA).

Для оценки точности определения МПК применялся разработанный ранее полуантропоморфный калиевый фантом РСК-ФК2. Фантом содержал секции позвонков со значениями МПК (К2НРО4, мг/мл): 50 (50,13), 100 (100,19), 150 (150,38), 200 (200,49), 250 (250,66), 350 (350,79), 450 (450,99), 550 (551,21). Точность задания объемной концентрации 0,5\%.

Результаты и обсуждение: Для обоснования сопоставимости Т-критериев в диагностике остеопороза были выполнены исследования по прямому сравнению Т-критериев, полученных с помощью двух методов: КТ-денситометрии бедра (CTXA) и DXA. Показана достоверная линейная корреляция между двумя методами определения T-критерия $(p=0,000)$ : для шейки бедра коэффициент корреляции составил $r=0,87$ в группе A и 0,94 в группе Б. Для общего показателя бедра: $r=0,92$ в группе А и 0,93 в группе Б, соответственно. При сравнении результатов измерения по методу Бленда-Альтмана оказалось, что в группе А смещение для шейки бедра составило $\Delta \mathrm{T}=-1,28 \pm 0,55 \mathrm{SD}$, для всего бедра $\Delta T=-1,46 \pm 0,44 S D$, а в группе Б для шейки бедра $\Delta T=-0,22 \pm 0,30 S D$, для всего бедра $-\Delta T=-0,69 \pm 0,35 S D$.

Учитывая высокую корреляцию значений Т-критерия, полученных двумя методами, был проведен анализ систематического занижения Т-критерия по данным КТ денситометрии (СТХА), более выраженное для группы А. Для этого были проанализированы результаты сканирования фантома РСК-ФК2 с расширенным диапазоном заданных значений МПК. На СТХА, где выполнялось исследование группы А и использовался фильтр реконструкции FС17, было показано нелинейное, более выраженное при высоких МПК занижение измеренных показателей относительно заданных значений. Для диапазона концентраций К2HPO4 50-200 мг/мл усредненное занижение (относительная погрешность) составило $\varepsilon=-4,99 \%$, для диапазона 250-550 мг/мл $\varepsilon=-11,2 \%$, а для концентрации 700 мг/мл снижение регистрируемой МПК относительно заданной достигало 17\%. Для условий КТ сканирования пациентов группы Б с фильтром FС08 данного эффекта отмечено не было: снижение измеренных значений МПК было незначительным и составило для диапазона 50-200 мг/мл $\varepsilon=-1,31$ \%, для диапазона 250-550 мг/мл $\varepsilon=-1,22 \%$.

Занижение измеренных значений МПК в области высоких значений существенно для определения проекционной МПК, которая диагностируется при СТХА, когда суммируются значения как губчатого вещества, так и кортикального слоя.

Указанные условия позволили скорректировать данные введя поправочные коэффициенты путем увеличения МПК на 15\% (оценочно) при расчете Т-критерия в группе А и добавляя к полученному при проведении СТХА значению Т-критерия 0,2 во всех случаях. После корректировки анализ данных по методу Бленда-Альтмана для группы А смещение результатов для шейки бедра составило $\Delta \mathrm{T}=-0,73 \pm 0,88 \mathrm{SD}$, для всего бедра $-0,003 \pm 1,09 \mathrm{SD}$; для группы Б - 


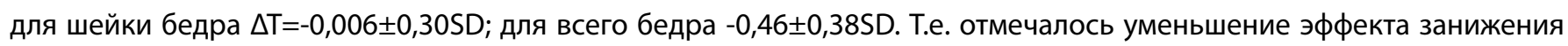
Т-критерия при СТХА, наиболее эффективна коррекция для общего показателя бедра в группе А и для шейки бедра в группе Б.

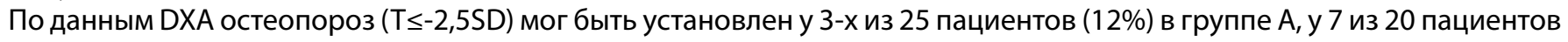
(35\%) в группе Б (по показателям шейки бедра и общего показателя бедра с двух сторон).

Без проведения корректировки по данным СТХА данный диагноз мог быть установлен у 18 из 25 пациентов (72\%) в группе А и у 8 из 20 пациентов (40\%) в группе Б. После предложенной корректировки по данным СТХА остеопороз мог быть выставлен 7 пациентам (28\%) в группе А и 6 пациентам (30\%) в группе Б. Предлагаемая корректировка позволяет устранить выраженную гипердиагностику остеопороза по Т-критерию, особенно в группе А, где использовался фильтр реконструкции FС17.

Выводы: Такими образом, фантомное моделирование показало, что при КТ денситометрии использование фильтра реконструкции FC17 приводит к занижению показателей МПК в области высоких значений, в то время как фильтр реконструкции FC 08 не оказывал влияния на показатели МПК как для низких, так и для высоких значений. Выявленная закономерность приводила к занижению Т-критерия при СТХА обследовании пациентов и может быть частично компенсирована введением разработанного поправочного коэффициента.

КЛЮЧЕВЫЕ СЛОВА: Лучевая диагностика; остеопороз; Т-критерий.

\section{PHANTOM MODELING IN THE ASSESSMENT OF T-SCORE RESULTS USING ASYNCHRONOUS QUANTITATIVE COMPUTED TOMOGRAPHY AND DUAL-ENERGY X-RAY ABSORPTIOMETRY}

(c) Akhmad E.S. ${ }^{1}$, Petryaykin A.V. ${ }^{1}$, Petryaykin F.A. ${ }^{2}$, Sergunova K.A. ${ }^{1}$, Nizovtseva L.A. ${ }^{1}$, Maksyushina T.D. ${ }^{3}$, Titova Yu.I. ${ }^{3}$, Tsareva E.E. ${ }^{3}$, Kuznetsov S.Yu. ${ }^{4}$, Morozov S.P. ${ }^{1}$, Nikitinskaya O.A. ${ }^{5}$, Toroptsova N.V. ${ }^{5}$

'Scientific and Practical Clinical Center for Diagnostics and Telemedicine Technologies, Moscow

${ }^{2}$ Lomonosov Moscow State University, Moscow

${ }^{3}$ V.I. Razumovsky Saratov State Medical University, Saratov

${ }^{4}$ V.I. Kulakov National Medical Research Center for Obstetrics, Gynecology and Perinatology, Moscow

${ }^{5}$ Research Institute of Rheumatology named after V.A. Nasonova, Moscow 
АУДИТ СОСТОЯНИЯ ПРОБЛЕМЫ ОСТЕОПОРОЗА В АРМЕНИИ

( ) В.Н. Бабалян, О.М. Лесняк, Дж. Билезикян

Армянская Ассоциация Остеопороза, Ереван

Цель. Определить заболеваемость, распространенность и социально-экономические последствия остеопороза и переломов в Армении.

Материалы и методы. Анализ публикаций, посвященных вопросам распространенности, факторов риска и последствий остеопороза и остеопоротических переломов, а также состояния организации помощи больным.

На 2018 г. численность населения Армении составляла 3,0 млн. человек. 25\% населения - это люди в возрасте 50 лет и старше. Средняя продолжительность жизни женщин - 77 лет, мужчин - 70 лет. При относительно стабильном прогнозе ООН к 2050 г. доля людей в возрасте 70 лет и старше увеличится практически вдвое. Исследования распространенности остеопороза в Армении не проводились. По данным Армянской ассоциации остеопороза остеопороз в республике могут иметь 150 тыс. женщин и 95 тыс. мужчин в возрасте 50 лет и старше, еще 340 тыс. мужчин и женщин могут находиться в зоне остеопении. Специально спланированное эпидемиологическое исследование [1] подтвердило, что остеопороз и ассоциированные с ним низкоэнергетические переломы представляют важную проблему для здравоохранения Армении. Ежегодная инцидентность перелома проксимального отдела бедренной кости составляет у женщин и мужчин в возрасте 50 лет соответственно 200 и 136 случаев на 100 тыс. населения. Перелом проксимального отдела плечевой кости происходит с частотой 86 случаев на 100 тыс. у женщин и 39 случаев на 100 тыс у мужчин. Соответствующие цифры для перелома дистального отдела предплечья - 176 на 100 тыс. у женщин и 56 на 100 тыс. у мужчин. В целом, по оценочным данным в год в Армении у людей 50 лет и старше происходит около 2000 переломов проксимального отдела бедренной кости, 1200 переломов дистального отдела предплечья и 640 переломов плечевой кости. Существенной проблемой организации травматологической службы в Армении является низкий уровень обращаемости, госпитализации и хирургической активности при низкоэнергетических переломах у людей старшего возраста. Так, 48\% пациентов с переломом дистального отдела предплечья и 49\% - с переломом плечевой кости не получают специализированную медицинскую помощь. 42\% больных с переломом проксимального отдела бедренной кости не госпитализируются. Армения относится к странам с очень высокой распространенностью курения. Так, исследование по оценке работы системы здравоохранения Армении показало, что в 2016 г. курильщики составляли $50 \%$ мужского населения и 25\% женского [2]. По оценкам Национальной статистической службы (НСС) Республики Армения в первом полугодии 2019 г.по сравнению с аналогичным периодом 2015 года объем производства сыра увеличился на 7,4\%, молока - на 2,7\%, сметаны - на 3,1\% [3]. Согласно данным по Обзору рынка молока и молочной продукции государств - членов Евразийского экономического союза за 2010-2015 годы значительно увеличилось по сравнению с 2010 годом потребление молока и молочных продуктов в Армении - на 32 кг до 261 кг, однако это меньше рекомендуемой нормы потребления (337 кг) [3]. Более подробные данные о факторах риска остеопороза и переломов, включая распространенность дефицита витамина D, будут получены в результате проводимого в настоящее время специально спланированного исследования, инициированного Армянской ассоциацией остеопороза. В исследование вошло 1350 женщин из столицы и регионов Армении от 18 лет и старше. Исследование даст возможность понять статус витамина D в Армении, а также состояние проблемы остеопороза в стране. Армения имеет 14 DXA аксиальных денситометров, размещенных в Ереване, а также городах Ванадзор, Капан и Нагорном Карабахе. Обеспеченность этим оборудованием составляет 4,8 на 1 млн. населения Армении. Также есть 4 ультразвуковых костных сонометра. Проведение денситометрического исследования не входит в программу госзаказа, поэтому оплачивается пациентами самостоятельно. Стоимость исследования для пациента составляет от 10 до 30 евро. В Армении зарегистрированы и разрешены к применению следующие препараты для лечения остеопороза: препараты кальция и витамина D, бисфосфонаты (алендронат, ибандронат, ризедронат, золедронат). Существуют дженерики бисфосфонатов, а также разнообразные препараты Са и витамина D. Средняя стоимость годового курса лечения аленронатом составляет около 216 амер. долларов. Государство не покрывает стоимость лечения остеопороза, поэтому пациенты должны покупать препараты самостоятельно. Остеопороз не признан на государственном уровне приоритетной проблемой здравоохранения Армении. Вместе с тем, большую роль в решении проблемы остеопороза в стране играет Армянская ассоциация по остеопорозу и ее лидер профессор Колумбийского Университета США Джон Билезикян. В течение 13 лет в Армении по его инициативе проводится ежегодный Армянский симпозиум по остеопорозу с международным участием, в котором принимают участие до 500 армянских врачей. Большинство имеющихся в стране аппаратов для диагностики остеопороза были предоставлены республике через спонсорство, орагнизованное проф. Дж. Билезикяном. В 2017 г. Джоном Билезикяном был основан Центр Остеопороза с целью организации более системного обучения врачей и пациентов, страдающих этим заболеванием. Кроме столицы, Армянская ассоциация остеопороза организовывает выездные конференции со скринингом на остеопороз в таких городах как Ванадзор, Гюмри, Севан, Эчмиадзин и т.д. В работе с пациентами Армянская ассоциация остеопороза активно использует материалы, 
издаюшиеся Международным фондом остеопороза. Каждый год 20 октября Минздрав размещает информацию о профилактике остеопороза на своем сайте. Армянская ассоциация по остеопорозу стала инициатором проведения Саммита организаций по остеопорозу стран Восточной и Центральной Европы, а также Центральной Азии в октябре 2017 г. в Ереване. В октябре 2019 г. был организован второй Саммит.

Результаты. Имеющиеся эпидемиологические данные свидетельствуют о том, что частота переломов в Армении высока и варьирует в зависимости от возраста популяции. Остеопороз и переломы несут серьезную нагрузку на систему здравоохранения, и в будущем тяжесть проблемы будет только увеличиваться по мере старения населения страны и увеличения доли людей старше 50 лет. Наблюдается низкий уровень госпитализации и хирургической помощи пациентам с переломом шейки бедра, отсутствие льготного обеспечения медикаментами.

Выводы. Результаты аудита должны обратить внимание правительства и органов управления здравоохранением на драматические и нарастающие проблемы, вызванные остеопоротическими переломами. Задачей для всех структур здравоохранения и власти является организация доступной современной хирургической помощи всем пациентам с переломом проксимального отдела бедра. Необходимо продолжать совершенствование профессионального медицинского образования для врачей и хирургов-ортопедов по вопросам остеопороза и ведения больных, информирования населения обо всех аспектах этого заболевания, а также системы льготного обеспечения препаратами для лечения остеопороза и широкого доступа населения к диагностическому оборудованию. Регуляторными органами в Армении должны быть приняты рекомендации по добавкам кальция и витамина D и фортификации ими продуктов питания.

КЛЮЧЕВЫЕ СЛОВА: Остеопороз; переломы; профилактика.

\section{AUDIT OF THE CONDITION OF OSTEOPOROSIS IN ARMENIA}

(c) Babalyan V.N, Lesnyak O.M, Bilezikian J.

Armenian Osteoporosis Association, Yerevan

\section{СПИСОК ЛИТЕРАТУРЫ | REFERENCES}

1. Lesnyak O, Sahakyan S, Zakroyeva A, et al. Epidemiology of fractures in Armenia: development of a country-specific FRAX model and comparison to its surrogate. Archives of Osteoporosis. 2017;12(1). Doi: https://dx.doi.org/10.1007\%2Fs11657-017-0392-6

2. Amoop Media [Internet]. [Cited 2020 Sep 3]. Available from: https://ampop.am/cigarette-smoking-in-armenia/.
3. Евразийская экономическая комиссия. Обзор рынка молока и молочной продукции государств - членов Евразийского экономического союза за 2010-2015 годы. - M.; 2016. iyskaya ekonomicheskayakomissiya. Obzor rynka moloka i molochnoy produktsii gosudarstv - chlenov Evraziyskogo ekonomicheskogosoyuza za 2010-2015 gody. Moscow; 2016. (In Russ.)] 

СМЕШАННОГО ГЕНЕЗА

\author{
( С. М.Б. Бабарина, Е.Г. Пржиялковская, И.Н. Ульянова
}

ФГБУ «Национальный медицинский исследовательский центр эндокринологии» Минздрава России, Москва

Представлено клиническое наблюдение многолетнего лечения остеопороза у пациентки 70 лет.

Пациентка Т. впервые обратилась в ФГБУ «НМИЦ эндокринологии» Минздрава России в марте 2017 года, в возрасте 66 лет с жалобами на выраженные боли в грудном и поясничном отделе позвоночника, снижение в росте с молодости на 15 см, одышку при ходьбе, онемение верхних конечностей преимущественно в ночное время, боли в коленных суставах.

Из анамнеза известно, что у пациентки ранняя менопауза с 45 лет, в 2007 году перенесла переломы ребер при минимальной травме. В августе 2016 года была госпитализирована по поводу бронхиальной астмы, получала терапию глюкокортикоидами в парентеральной форме, после выписки в течении 6 месяцев продолжила принимать преднизолон перорально в дозе 15 мг в сутки.

Из сопутствующей патологии отмечено наличие хронической обструктивной болезни легких, гормон-зависимой формы бронхиальной астмы. Около 30 лет назад проведена гемитиреоидэктомия по поводу многоузлового зоба, в настоящее время функция щитовидной железы не нарушена. Наличие сахарного диабета, мочекаменной болезни, язвенной болезни отрицала.

При осмотре: рост 140 см, вес 38 кг, индекс массы тела 19,4кг/м², обращали внимание выраженный кифоз грудного отдела позвоночника, укорочение туловища по сравнению с длиной нижних конечностей, уменьшение расстояния между реберными дугами и гребнями подвздошных костей, появление расстояния между стеной и затылком при измерении роста. По результатам представленных пациенткой данных: в январе 2017 года по данным магнитно-резонансной томографии позвоночника выявлены множественные компрессионные переломы (C4, C6, Th5, Th11, L2, L5), признаки отека костного мозга Th9, L2-L5. По данным компьютерной томографии грудной клетки, выполненной для исключения экссудативного бронхиолита, выявлена клиновидная деформация Th5, Th7, Th11, Th12, L2. B анализах крови показатели кальций-фосфорного обмена и креатинина в пределах нормы, бета-кросслапс 0,06 (0-1,008) нг/мл, паратгормон 34,6 пг/мл, остеокальцин 33,67 (11-43) нг/мл, ТТГ=2,71 Мед/л, анализ на миеломную болезнь отрицательный. У пациентки выявлен дефицит витамина D (11 нг/мл), рекомендована терапия колекальциферолом и препаратами кальция. По данным рентгеновской денситометрии: Ткрит L1-L4=-5,2, бедро Total=-3,8, бедро Neck=-3,5. Таким образом у пациентки установлен диагноз «Остеопороз смешанного генеза (постменопаузальный, глюкокортикоидный, на фоне дефицита веса и дефицита витамина D) тяжелого течения с множественными компрессионными переломами позвоночника с очень высоким риском переломов». В качестве антиостеопоротической терапии пациентке назначен Деносумаб 60 мг п/к 1 раз в 6 месяцев. Для уменьшения болевого синдрома рекомендовано ношения корсета, расширение физической активности.

На момент повторного обращения в августе 2018 года в анализах крови: показатели кальций фосфорного обмена в пределах нормы, бета- кросслапс 0,17 (0-1,008) нг/мл, остеокальцин 0,55 (11-43) нг/мл, витамин D - 53 нг/мл. Показатели денситометрии: Ткрит L1-L4=-4,6, бедро Total=-3,5, бедро Neck=-3,5. Учитывая сохранение выраженной потери минеральной плотности костной ткани, наличие множественных компрессионных переломов, рекомендовано по жизненным показаниям дополнительно терапия терипаратидом 20 мкг подкожно ежедневно, колекальциферол заменен на альфакальцидол, рекомендовано продолжить прием препаратов кальция.

С декабря 2018 года пациентка начала лечение терипаратидом, переносила лечение удовлетворительно. Для оценки скорости костного обмена выполнены контрольные анализы крови на бета- кросслапс и остеокальцин через 3 месяца лечения терипаратидом, выявлен значительный прирост этих показателей, что свидетельствует об эффективности проводимого лечения.

На фоне лечения пациентка отмечала улучшение самочувствия: уменьшение болей в спине, расширение физической нагрузки. Новых переломов зафиксировано не было. При контрольной денситометрии через год лечения терипаратидом в комбинации с деносумабом: Ткрит L1-L4=-3,9, бедро Total=-3,5, бедро Neck=-3,4.

Таким образом, терипаратид показал высокую эффективность в лечении постменопаузального и глюкокортикоидного остеопороза у пациентки 70 лет в сочетании с деносумабом, обеспечив прибавку минеральной плотности костной ткани и предупреждение новых низкотравматических переломов позвонков.

КЛЮЧЕВЫЕ СЛОВА: Остеопороз; деносумаб; терипаратид.

\title{
EFFECTIVE TERIPARATIDE TREATMENT OF SEVERE OSTEOPOROSIS
}

(c) Babarina M.B, Przhiyalkovskaya E.G., Ulyanova I.N.

Endocrinology Research Centre, Moscow 
Хирургическое лечение деформаций позвоночника - коррекция и фиксация позвоночника с помощью металлоконструкций давно стало рутинной практикой. Часто у пациентов, нуждающихся в оперативном лечении, имеется остеопороз разной степени выраженности. Недостаточность или дефицит витамина D, нарушение гомеостаза кальция, и баланса процессов костеобразования и резорбции (в сторону преобладания резорбции над костеобразованием), приводящее к потере костной массы часто выявляются у пациентов как с идиопатическими (ИС), так и с дегенеративными сколиозами (ДС). Это в значительной мере может влиять как на развитие деформации позвоночника, так и на результаты ее хирургической коррекции и фиксации, на развитие постоперационных осложнений и в первую очередь асептической нестабильности металлоконструкции.

Целью исследования являлось выявление особенностей нарушения метаболизма костной ткани и разработка терапевтической тактики их устранения до и после оперативного лечения у пациентов с ИС и ДС.

Материалы и методы. По программе Центра остеопороза ФГБУ «НМИЦ ТО им Н.Н. Приорова» обследовано две группы пациентов, I группа 49 пациентов (44 женщин и 4 мужчин) 44-75 лет с ИС и II группа 68 человек (63 женщины и 5 мужчин) с ДС 48-79 лет до и/или после оперативного лечения. Всем больным была проведена рентгенография позвоночника, рентгеновская денситометрия шеек бедренных костей (LUNAR, Prodigy), KT и MPT исследовались показатели фосфорно-кальциевого обмена (общий и ионизированный кальций, фосфор, паратгормон (ПтГ) и транспортная форма витамина D - 25(OH)D крови, кальций, фосфор суточной мочи), маркеры костеобразования (щелочная фосфатаза, остеокальцин, P1NP крови), маркеры резорбции кости (beta-CrossLaps крови и ДПИД утренней мочи).

Результаты. Нарушения минерального обмена и витамина D были практически одинаковыми в обеих группах. У 98\% обследованных был выявлен дефицит или недостаточность витамина D от 3 нг/мл до 29 нг/мл. Более чем у 50\% больных отмечалось снижение обеспеченности организма кальцием (по экскреции кальция с мочой), а у 30-32\% пациентов был выявлен повышенный уровнь в крови паратгормона - вторичный гиперпаратиреоз. Все эти нарушения приводили к усилению костной резорбции. Степень потери костной массы по денситометрии была большей у пациентов с ДС, у них в большинстве случаев усиление резорбции наблюдалось на фоне низкого костеобразования, часто встречались единичные или множественные патологические компрессионные переломы тел позвонков, которые в большинстве случаев являлись причиной развития болевого синдрома и обращения в следствии этого за хирургической помощью. На КТ и МРТ-компрессионные переломы тел позвонков, склероз замыкательных пластинок, часто явления спондилодисцитов, жировая дегенерация костного мозга, гемангиомы, выраженные дегенеративные изменения дисков.

У пациентов с ИС потеря МПК по денситометрии была выражена в меньшей степени, и у более половины из обследованных была менее -2,5 SD. У 65\% обследованных нами пациентов были повышены маркеры резорбции при хорошем костеобразовании и практически не выявлялось патологических переломов тел позвонков. На КТ и МРТ отмечалось наличие анте-, ретро-, латеро-спондилолистезов, спондилез, спондилоартроз, дегенеративные изменения межпозвонковых дисков. Причиной обращения за хирургической помощью было прогрессирование деформации позвоночника, нарушение статики и развитие выраженного миофасциального или корешкового болевого синдрома.

На первом этапе подготовки к хирургическому лечению терапевтическая тактика была одинаковой в обеих группах восполнение дефицита витамина D и кальция, устранение вторичного гиперпаратиреоза. У части пациентов этого было достаточно и для нормализации маркеров ремоделирования костной ткани.

На втором этапе - восстановление баланса между процессами костеобразования и резорбции более быстро и предсказуемо проходило у пациентов с ИС. В большинстве случаев препаратами выбора для предоперационной антирезорбтивной терапии являлись препараты золедроновой кислоты, вводимые внутривенно, капельно 1 раз в год.

У пациентов с ДС процесс восстановления баланса ремоделирования костной ткани проходил медленнее и сложнее. В ряде случаев требовалась не только антирезорбтивная, но и/или анаболическая терапия, и не всегда удавалось добиться восстановления маркеров костеобразования до референсного интервала. При применении анаболической терапии у пациентов, готовящихся к оперативному лечению, необходимо учитывать, тот факт, что в след за стимуляцией костеобразования через некоторое время может наблюдаться и повышение резорбции. Поэтому при проведении сочетанной терапии необходимо контролировать показатели как костеобразования, так и резорбции, и при тенденции к повышению резорбции перед операцией после анаболической терапии целесообразно введение антирезорбтивных препаратов (бисфосфонатов) длительного действия. 
В послеоперационном периоде базовую терапию активным метаболитом витамина D альфакальцидолом и препаратами кальция начинали со 2-3 дня после операции. Антирезорбтивная терапия проводилась строго по показаниям, под контролем маркеров ремоделирования кости не ранее чем через 3 месяца после оперативного лечения.

Выводы. Особенности метаболических нарушений при ИС и ДС требуют дальнейших более глубоких изучений на уровне клеточной регуляции для понимания особенностей развития остеопороза, формирования и прогрессирования деформации позвоночника. Пациентов с повышенным риском развития асептической нестабильности необходимо активно выявлять, по возможности устранять имеющиеся у них метаболические нарушения до планируемой операции, наблюдать и проводить превентивную терапию после оперативного лечения. В эту группу входят не только пациенты с повышенными маркерами резорбции до операции, но и пациенты со вторичным гиперпаратиреозом, хроническими воспалительными процессами (в том числе с хронической рецидивирующей герпесвирусной инфекцией), а также коморбидные пациенты с аутоиммунными заболеваниями и новообразованиями, особенно получающие глюкокортикоидные препараты и цитостатики, у которых физиологическое повышение костной резорбции в послеоперационном периоде может значительно превышать костеобразование и наблюдаться более длительный период, являясь причиной развития нестабильности металлоконструкции.

КЛЮЧЕВЫЕ СЛОВА: Витамин D; кальций; сколиоз.

\section{VITAMIN D, CALCIUM HOMEOSTASIS AND MARKERS OF BONE REMODELING IN PATIENTS} WITH IDIOPATHIC AND DEGENERATIVE SCOLIOSIS REQUIRING SURGICAL TREATMENT

(c) Bakhtina E.N., Rodionova S.S.

N.N. Priorov National Medical Research Center of Traumatology and Orthopedics, Moscow 
КОСТНАЯ БОЛЕЗНЬ ПЕДЖЕТА: ОСОБЕННОСТИ ДИАГНОСТИКИ И ПЕРИОПЕРАЦИОННОГО ВЕДЕНИЯ

(с) И.Б. Башкова ${ }^{1,2}$, Н.В. Безлюдная ${ }^{2}$, И.Н. Киселева ${ }^{3}$, Л.Р. Кадырова ${ }^{4}$

'ФГБОУ ВО «Чувашский государственный университет имени И.Н. Ульянова», Чебоксары,

ФГБУ «Федеральный центр травматологии, ортопедии и эндопротезирования» Минздрава России Чебоксары ${ }^{3}$ БУ «Республиканский клинический госпиталь для ветеранов войн» Минздрава России, Чебоксары ${ }^{4}$ ФГБОУ ДПО «Российская медицинская академия непрерывного профессионального образования» Минздрава России, Казань

Цель исследования - провести анализ клинико-анамнестических данных, результатов лабораторно-инструментальных исследований, тактики ведения пациентов с впервые установленным диагнозом костной болезни Педжета (КБП), которым планировалось проведение реконструктивной операции на суставах или позвоночнике в условиях Федерального центра травматологии, ортопедии и эндопротезирования (ФЦТОЭ) г. Чебоксары.

Материал и методы. За период с октября 2011 года по ноябрь 2019 года в условиях ФЦТОЭ (Чебоксары) наблюдались 20 пациентов с впервые установленным диагнозом КБП (из них 10 мужчин) в возрасте от 44 до 79 лет (средний возраст 58,3 11 ,2 года, здесь и далее $М \pm \delta$ ). Все больные были направлены в ФЦТОЭ для проведения тотального эндопротезирования (ТЭП) тазобедренного/коленного суставов или вертебропластики грудного/поясничного позвонков. Результаты и их обсуждение. Диагноз КБП в среднем был установлен через 7,4+5,5 года от момента клинической манифестации костно-суставных проявлений заболевания. «Визитной карточкой» КБП стали следующие клинические проявления: асимметричный характер поражения костей скелета (80\%), постоянные боли в пораженных костях и смежных с ними суставах (100\%), наличие саблевидно-варусной деформации длинных трубчатых костей нижних конечностей в случае их поражения (81\%), болевой синдром и формирование кифосколиотической деформации позвоночника при локализации патологического процесса в позвонках (100\%), локальная гипертермия в случае поражения бедренной и/или большеберцовой костей (75\%).

С одной стороны, большая длительность заболевания до верификации диагноза может быть объяснена бессимптомным течением на начальных этапах болезни, а с другой стороны, недостаточной информированностью врачей первого контакта о клинических проявлениях КБП.

В сыворотке крови выявлено повышение активности щелочной фосфатазы (ЩФ), превышавшее верхнюю границу нормы в 1,5-9,5 раз. Так, среднее значение сывороточного уровня ЩФ составило 838,7士748,7 Ед/л при нормальном

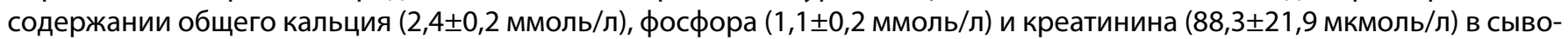
ротке крови.

При проведении рентгеновских инструментальных методов исследования выявлены один/несколько очагов резорбции костей с истончением кортикального слоя со стороны эндоста, разволокнение кортикального слоя, груботрабекулярная и кистовидная перестройка структуры костной ткани.

До постановки диагноза КБП пациенты наблюдались у терапевта, травматолога или ревматолога по месту жительства с диагнозами «остеоартроз с преимущественным поражением суставов нижних конечностей» (9 чел), «тяжелый остеопороз» (2 чел), «остеохондроз поясничного отдела позвоночника» (3 чел), «анкилозирующий спондилит» (1 чел), «ревматоидный артрит» (1 чел), «хронический склерозирующий остеомиелит Гарре» (1 чел), «надрыв и растяжение сухожилий сгибателей бедра» (1 чел), «посттравматическая остеоартропатия» (1 чел), «гиперпаратиреоидная остеоартропатия» (1 чел).

Среди коморбидных заболеваний наиболее часто диагностировались гипертоническая болезнь (60\%), поражение желудочно-кишечного тракта и желчевыводящих путей (40\%), хронический пиелонефрит (40\%), хроническая обструктивная болезнь легких (35\%), варикозная болезнь вен нижних конечностей (20\%), ишемическая болезнь сердца (15\%). Случаи развития нефролитиаза отмечены нами только у 3 чел. Индекс массы тела в среднем составил $27,4 \pm 5,0 \mathrm{kг} / \mathrm{M}^{2}$.

В 17 из 20 случаев (85\%) диагностирована полиоссальная форма КБП, и только у 3 пациентов (15\%) - монооссальная форма заболевания. Чаще поражались кости таза (32,6\%), бедренная (37,2\%) и большеберцовая (14,0\%) кости, нижнегрудной и поясничный отделы позвоночника (14,0\%). Поражение плечевой кости, костей предплечья, мозгового черепа были выявлено в единичных случаях (7,0\%). В 75\% случаев число патологических очагов составляло 4 и менее. Стадия уплотнения (промежуточная) установлена у 15 чел, груботрабекулярной перестройки (стабилизации) у 5 чел.

По данным рентгеновской остеоденситометрии (Lunar DPX) остеопороз выявлен в 78,6\% случаев. У каждого второго пациента с КБП (50\%) в анамнезе имелось указание на наличие патологических переломов (компрессионные переломы тел позвонков (5 чел), переломы проксимального отдела бедренной кости (5 чел), костей таза (1 чел), хирургической шейки плечевой кости (1 чел). Необходимо подчеркнуть, что у 5 из 10 пациентов с низкоэнергетическими переломами в анамнезе последние носили множественный характер. В одном случае через 2 года после проведенного 
ранее ТЭП развилась асептическая нестабильность бедренного компонента эндопротеза. Вторичный кокс- и/или гонартроз III рентгенологической стадии выявлены у 16 больных (80\%), что явилось показанием для проведения ТЭП суставов нижних конечностей, однако во всех случаях операция была отложена до достижения стойкой нормализации лабораторных маркеров ремоделирования костной ткани и до достижения стадии стабилизации. Проведение вертебропластики грудного/поясничного позвонков предполагалось у 4 пациентов, что также было отложено.

Патогенетическая терапия бисфосфонатами рекомендована всем пациентам с КБП. Патогенетически обоснованное лечение КБП направлено, с одной стороны, на ограничение или полное прекращение усиленной резорбции костной ткани, с другой - на создание условий для восстановления нарушенного ремоделирования костной ткани и ее микроархитектоники. Назначение бисфосфонатов при КБП широко практикуется и перед проведением ортопедических операций не только с целью ограничения патологической резорбции костной ткани, но и подавления повышенной васкуляризации соответствующей области кости и устранения высокого риска послеоперационной кровопотери. У 11 пациентов, явившихся на этап катамнеза, достигнута стадия стабилизации, позволившая восстановить опорно-двигательную функцию в достаточном объеме у 4 пациентов, и в одном случае провести ТЭП тазобедренного сустава.

Выводы. Диагноз КБП устанавливается крайне поздно, чаще на стадии уплотнения или груботрабекулярной перестройки, когда уже развились осложнения данного заболевания (вторичный остеоартроз, вторичный остеопороз с патологическими переломами). Соотношение пациентов с монооссальной и полиоссальной формами заболевания составило как 1:5,7. Определение активности ЩФ впервые было проведено только в условиях ФЦТОЭ, во всех случаях уровень данного биохимического показателя оказался повышенным.

Своевременная диагностика КБП может позволить вовремя назначить эффективную консервативную терапию для подавления усиленного метаболизма костной ткани и создавать предпосылки в будущем для предупреждения прогрессирования заболевания, развития вторичных остеоартрозов, патологических переломов, снижения послеоперационных осложнений при проведении ортопедических операций.

КЛЮЧЕВЫЕ СЛОВА: Болезнь Педжета; остеопороз; бисфосфонаты.

\section{PAGET'S DISEASE: FEATURES OF DIAGNOSIS AND PERIOPERATIVE MANAGEMENT}

(c) Bashkova I.B. ${ }^{1,2}$, Bezlyudnaya N.V. ${ }^{2}$, Kiseleva I.N. ${ }^{3}$, Kadyrova L.R. ${ }^{4}$

${ }^{1}$ Chuvash State University named after I.N. Ulyanov, Cheboksary,

${ }^{2}$ Federal Centre of Traumatology, Orthopedics and Endoprosthetics, Cheboksary

${ }^{3}$ Republican Clinical Hospital for War Veterans, Cheboksary

${ }^{4}$ Russian Medical Academy of Continuous Professional Education, Kazan 
() Ж.Е. Белая, С.А. Гронская, Т.А. Гребенникова, Е.О. Мамедова, Е.А. Пигарова, Е.Г. Пржиялковская, Л.Я. Рожинская, Г.А. Мельниченко

ФГБУ «Национальный медицинский исследовательский центр эндокринологии» Минздрава России, Москва

Гипопаратиреоз и псевдогипопаратиреоз - это заболевания, характеризующиеся гипокальциемией, связанной с низким уровнем паратиреоидного гормона (ПТГ) или нечувствительностью рецепторного аппарата к ПТГ, которое может оказывать негативное воздействие на множество органов и систем, ухудшая качество жизни и прогноз. Эпидемиологические аспекты изучены недостаточно, особенно мало исследований в этой области в России.

Цель исследования: Оценить этиологию, современные аспекты течения заболевания, диагностики и особенности подходов к лечению. В ФГБУ «НМИЦ Эндокринологии» была создана база данных пациентов с гипо- и псевдопаратиреозом, прототипом которой послужил Итальянский регистр (Флорентийский университет), с целью последующего совместного анализа полученных результатов.

Материалы и методы: В регистр вошло 200 человек с гипо- и псевдогипопаратиреозом, наблюдавшихся в ФГБУ НМИЦ Эндокринологии в течение 2017-2019 годов.

Результаты: Согласно полученным данным, гипопаратиреоз чаще всего встречался среди женщин среднего и пожилого возраста, перенесших хирургические операции на передней области шеи (82,5\%). В остальных случаях был зарегистрирован идиопатический гипопаратиреоз (10\%), наследственные формы гипопаратиреоза (4,5\%) и резистентность к действию ПтГ (3\%). Касательно лечения, большинству пациентов было достаточно приема препаратов кальция и активных форм витамина Д для поддержания нормокальциемии. Однако в некоторых случаях (n=8) назначался терипаратид, т.к. другими способами не удалось достичь компенсации заболевания.

Вывод: В данной работе описана этиологическая и клинико-диагностическая структура гипопаратиреоза. Продемонстрирована необходимость лечения терипаратидом для некоторых пациентов с гипопаратиреозом. Кроме того, представленная база данных будет полезна для определения потенциальной необходимости в заместительной терапии ПТГ 1-34 в России.

КЛЮЧЕВЫЕ СЛОВА:Гипопаратиреоз; псевдогипопаратиреоз; регистр.

\section{REGISTER OF ADULT PATIENTS WITH HYPOPARATHYROIDISM AND}

\section{PSEUDOHYPOPARATHYROIDISM: ETIOLOGY, CURRENT ASPECTS OF THE DISEASE,} TREATMENT APPROACHES

(c) Belaya Zh.E., Gronskaya S.A., Grebennikova T.A., Mamedova E.O., Pigarova E.A., Przhiyalkovskaya E.G., Rozhinskaya L.Ya., Melnichenko G.A.

Endocrinology Research Centre, Moscow 


\section{( Беленький И.Г., ${ }^{1,4}$, Кочиш А.Ю. ${ }^{3}$ Зайцева Т.Е. ${ }^{4}$, Майоров Б.А. ${ }^{1,2}$}

'ФГБОУ ВПО «Первый Санкт-Петербургский медицинский университет им. Академика И.П. Павлова» Министерства здравоохранения Российской Федерации, Санкт-Петербург

гГБУЗЛО «Всеволожская КМБ», Всеволожск

${ }^{3}$ ФГБУ «Российский ордена Трудового Красного Знамени научно-исследовательский институт травматологии и ортопедии им. Р.Р. Вредена» Министерства здравоохранения Российской Федерации, Санкт-Петербург ${ }^{4}$ СПб ГБУЗ «Александровская больница», Санкт-Петербург

Введение. Актуальность проблемы лечения низкоэнергетических переломов костей на фоне остеопороза обусловлена все возрастающим количеством подобных травм и их тяжелыми последствиями у пациентов старших возрастных групп. Эта тенденция обусловлена, прежде всего, повышением средней продолжительности жизни населения Российской Федерации, а также возрастным снижением минеральной плотности и, соответственно, прочности костной ткани. Известно, что на количество остеопорозных переломов влияют социально-экономические факторы. Так, относительно невысокий уровень пенсионного обеспечения не позволяет пожилым людям обеспечить необходимый для поддержания нормальной минеральной плотности кости рацион питания, а также должный уровень лекарственного обеспечения для профилактики и лечения остеопороза. При этом пациенты с остеопорозными переломами поступают для оказания специализированной травматологической помощи в экстренном порядке в травматологические пункты или городские многопрофильные стационары, где им оказывается помощь зачастую без учета механизмов получения травмы и сниженных качественных характеристик костной ткани. Кроме того, у них не всегда проводятся необходимые мероприятия по профилактике повторных остеопорозных переломов костей.

Цель исследования: Посредством анализа данных медицинской статистики одного из многопрофильных городских стационаров Санкт-Петербурга изучить структуру пациентов с остеопорозными переломами костей конечностей наиболее типичных локализаций.

Материалы и методы. На основании изучения официальных статистических отчетов, составленных на базе МКБ10, был проведен анализ структуры пациентов с низкоэнергетическими переломами костей конечностей наиболее типичных для остеопороза локализаций, проходивших лечение в СПб ГБУЗ «Александровская больница» в 2018 году и определены виды оказанной им специализированной травматологической помощи.

Результаты. В 2018 году в двух травматологических отделениях СПб ГБУЗ «Александровская больница» было пролечено 325 пациентов с низкоэнергетическими переломами проксимального отдела плечевой кости с кодом МКБ-10 S42.2. Из них 140 больным были выполнены различные модификации остеосинтеза, а в 7 случаях было произведено эндопротезирование плечевого сустава. Оперативная активность составила 45,2\%.

Количество больных с низкоэнергетическими переломами дистального сегмента костей предплечья с кодами МКБ S52.5 и S52.6 составило 230 пациентов. Из них оперативным путем были пролечены 56 больных, а оперативная активность составила $24,3 \%$.

За изученный период в стационар поступило 235 больных с медиальными переломами шейки бедренной кости (код МКБ S72.0). Из них 190 больным выполнены операции, а оперативная активность составила 80,9\%. Количество больных с латеральными переломами вертельной области (коды МКБ S72.1 и S72.2) в 2018 году достигло 271 пациента. Из них операции были проведены в 198 случаях, а оперативная активность составила 73,1\%.

Обсуждение. Анализ стационарного потока пациентов с низкоэнергетическими переломами костей конечностей типичных для остеопороза локализаций показал их значительное количество (1061 случай), составившее долю в 14\% от всех пострадавших с переломами костей, поступивших в многопрофильный городской стационар в 2018 году. При этом оперативная активность при лечении переломов проксимального отдела плечевой кости (45,2\%) и дистальных отделов костей предплечья (24,3\%) может, на наш взгляд, считаться вполне обоснованной и адекватной. Однако доли оперативных вмешательств, проведенных профильным пациентам с остеопорозными медиальными и латеральными переломами проксимального отдела бедренной кости (соответственно 80,9\% и 73,1\%) является явно недостаточными с учетом требований современных клинических рекомендаций. Кроме того, требуется разработка и внедрение в клиническую практику комплекса мероприятий по маршрутизации пациентов с обсуждаемыми переломами после оказания им специализированной травматологической помощи для дальнейшего терапевтического лечения остеопороза и предупреждения повторных низкоэнергетических переломов костей.

Заключение. Число профильных пациентов (1061) и доля типичных остеопорозных переломов (14\%) в потоке пострадавших с переломами костей конечностей в многопрофильном городском стационаре мегаполиса являются достаточно высокими, а оперативная активность при низкоэнергетических переломах проксимального отдела бедренной кости требует увеличения. Кроме того, необходимо внедрять в клиническую практику систему профилактики 
повторных остеопорозных переломов. В плане дальнейшего изучения обсуждаемой проблемы требуется проведение целенаправленного анализа видов оперативных вмешательств, времени их выполнения, использованных хирургических технологий и имплантатов, а также исходов лечения пациентов с остеопорозными переломами костей.

КЛЮЧЕВЫЕ СЛОВА: Остеопороз; переломы; профилактика.

\section{ANALYSIS OF PATIENT STREAM WITH OSTEOPOROTIC FRACTURES, HOSPITALIZED IN A MULTIDISCIPLINARY HOSPITAL}

(c) Belenky I.G. ${ }^{1,4}$, Kochish A.Yu. ${ }^{3}$, Zaitseva T.E. ${ }^{4}$, Mayorov B.A. ${ }^{1,2}$

${ }^{1}$ First St. Petersburg State Medical University named after I.P. Pavlov, Saint Petersburg

${ }^{2}$ Vsevolozhskaya Clinical Hospital, Vsevolozhsk

${ }^{3}$ R.R. Vreden Russian Order of the Red Banner of Labor Research Institute of Traumatology and Orthopedics, Saint Petersburg

${ }^{4}$ «Alexander»s Hospital», Saint Petersburg 
Актуальность: одной из актуальных проблем современной травматологии остается лечение переломов проксимального отдела бедра (ППОБ), количество которых ежегодно увеличивается во всем мире. Причем пострадавшими являются лица пожилого и старческого возраста, среди которых преобладают женщины. В настоящий момент не вызывает сомнений преимущество оперативного лечения ППОБ, но по-прежнему остаются нерешенными вопросы организации лечебного процесса от момента получения травмы до выписки из стационара.

По нашему мнению, все лица с ППОБ должны быть прооперированы в кратчайшие сроки после получения травмы, поскольку, несмотря на высокий риск, единственная возможность спасти пациента - это как можно быстрее «поставить его на ноги». Но, несмотря на внедрение оперативного лечения, как основного способа оказания помощи при ППОБ, сохраняется высокий уровень внутрибольничной летальности, что требует корректировки основных тактических подходов к лечению этих больных.

За последнее десятилетие нами были проанализированы и внедрены в повседневную клиническую практику рекомендации, сформулированные на основании результатов рандомизированных контролируемых исследований и мета-анализов случаев оказания помощи пациентам старше 50 лет с неметастатическими низкоэнергетическими ПпОБ, основным из ключевых пунктов которых является максимально быстрое оперативное лечение (в течение 48 часов с момента травмы), позволяющее избежать развитие гиподинамических осложнений.

Цель: оценить влияние организационных изменений в виде внедрения 48-часового протокола на последствия низкоэнергетических ППОБ у пациентов 50 лет и старше.

Материалы и методы: Для оценки результатов внесенных организационных изменений нами был проведен сравнительный анализ лечения пациентов в ГАУЗ ЯО «Клиническая больница скорой медицинской помощи имени Н.В. Соловьева» с низкоэнергетическими ППОБ за два периода: первый 2010-2011гг. (до внедрения 48-часового протокола); второй 2013-2015 гг. (после внедрения 48-часового протокола). На базе отделения статистики больницы создан автоматизированный регистр пациентов с ППОБ, позволяющий производить ввод, хранение, обработку данных и формирование отчетов.

Результаты: в 2010-2011 гг. по результатам сплошного исследования оказалось, что в большинстве случаев (71,23\%) проводилось оперативное лечение, при этом средний койко-день составил 22,02 суток. Общая летальность в стационаре оказалась 9,97\%, в течение 2-х суток был прооперирован только 1 (0,31\%) пациент, большая часть больных получила оперативное лечение позднее 5 суток - 269 (84,33\%) наблюдений, то есть практически во всех случаях можно говорить о существенной задержке сроков операции по сравнению с рекомендуемыми. Полученные результаты заставили пересмотреть подходы к лечению этой сложной группы пациентов и внедрить международные рекомендацию по лечению ППОБ.

В процессе внедрения рекомендаций потребовалось организовать транспортировку пациентов из районных больниц в течение 24 часов и круглосуточное обследование госпитализированных больных (необходимое минимальное лабораторное обследование, УЗИ вен ног; по показаниям - консультации узких специалистов, КТ, ЭХО-КС, рентгенограмма груди, УЗИ любой локализации), добиться бесперебойного обеспечения всеми необходимыми расходными материалами, включая конструкции для остеосинтеза и эндопротезы, за счет средств ОМС; наладить быстрое и эффективное взаимодействие с кардиологическим и терапевтическими отделениями, ввести в штатное расписание травматологического отделения ставки терапевта и инструктора ЛФК.

Для оценки результатов лечения за период 2013-2015 гг. был произведен экспорт данных в регистр из базы статистического подразделения ГАУЗ ЯО «Клиническая больница скорой медицинской помощи имени Н. В. Соловьева». Проанализированы данные по 1745 пациентам. Хирургические операции проводились у 1504 пациентов (88,52\%). Средняя длительность пребывания в стационаре составила 8,57 дней. Наиболее часто выполнялся остеосинтез $(60,72 \%)$, тотальное замещение тазобедренного сустава $(21,44 \%)$, гемиартропластика (12,32\%). При этом в первые сутки были оперированы 466 больных (33,26\%), в течение 48 часов - 781 (55,75\%), 72 часов - 999 (71,31\%). Внутрибольничная летальность составила 2,77\%. Среди умерших больных не были оперированы 15 человек (дооперационная летальность 0,88\%), из них почти половина умерли на первые-вторые сутки, что свидетельствует об их крайне тяжелом исходном состоянии. Послеоперационная летальность составила 1,8\%. Летальность в зависимости от возраста закономерно увеличивалась и была наибольшей у пациентов старше 80 лет (в 3,6 раза по сравнению с предыдущей возрастной группой).

Наилучших результатов удалось добиться у пациентов с переломом шейки бедренной кости, что связано с внутренним распорядком в ГАУЗ ЯО КБ СМП им. Н.В. Соловьёва. Так, в 2018 г. оперативная активность у этих пациентов 
составила 92,3\%, в течение 48 часов были прооперированы 81,7\% пациентов. Внутрибольничная летальность при этом составила 1,44\%.

Обсуждение: внедрение в практику современных рекомендаций, базирующихся на принципах доказательной медицины, позволили повлиять на исходы лечения пациентов с низкоэнергетическими ППОБ. В частности, значительно уменьшился срок нахождения в стационаре с 22,02 суток в 2010-2011 гг. до 8,57 в 2013-2015 г, причем в основном за счет предоперационного койко-дня: так, в 2010 г. он составлял 10,22 дня, а в 2015 достиг 2,47. При оценке показателя оперативной активности следует отметить, что в г. Ярославле в 2010-2011 гг. он уже составлял 71,23\%, тем не менее, его удалось повысить до 88,52\% в 2013-2015 гг. Внутрибольничная летальность за указанный период снизилась в 3,5 раза (с $9,66 \%$ до 2,77\%).

Вывод: Результаты проведённого исследования показывают положительный эффект внедрения 48-часового протокола лечения низкоэнергетических ППОБ, приводящего к сокращению предоперационного койко-дня, увеличению оперативной активности и снижению внутрибольничной летальности у пациентов в возрасте старше 50-ти лет.

КЛЮЧЕВЫЕ СЛОВА: Остеопороз; перелом шейки бедра; оперативное лечение.

\section{EXPERIENCE IN THE EARLY SURGICAL TREATMENT OF PATIENTS WITH PROXIMAL FEMUR} FRACTURES, ASSOCIATED WITH OSTEOPOROSIS

๑ Belov M.V., Degtyarev A.A., Ershova O.B., Klyuchevsky V.V., Belova K.Yu., Kalyaginov P.S.

Clinical Hospital for Emergency Medical Care named after N.V. Solovyov, Yaroslavl

Yaroslavl State Medical University, Yaroslavl 


\author{
○ К.Ю. Белова', А.А. Марусина', И.В. Марусина', О.Б. Ершова', Х.Г. Горджеладзе ${ }^{3}$
}

ФГБОУ ВО «Ярославский государственный медицинский университет» Минздрава России, Ярославль

${ }^{2}$ ОГБУЗ «Городская больница г. Кострома», Кострома

${ }^{3}$ ГАУЗ «Клиническая больница скорой медицинской помощи имени Н.В. Соловьева», Ярославль

Цель исследования: оценить распространенность факторов риска, влияющих на развитие костной ткани в детском и подростковом возрасте.

Материалы и методы: Было проведено двухцентровое одномоментное сплошное исследование в средних образовательных учреждениях г. Ярославле (центр №1) и г. Кострома (центр №2). Сплошным методом проведен опрос 1362 школьников со 2-го по 11-й классы, дети самостоятельно заполняли предлагаемую анкету, включившую вопросы по питанию и образу жизни. В г. Ярославле в исследование вошли 901 человек (440 (48,83\%) мальчиков и 461 (51,17\%) девочек), В г. Костроме - 461 ребенок (215 мальчиков (46,64\% мальчиков и 246 девочек (53,36\%). В г. Костроме часть параллелей не была опрошена (дети 3-го, 4-го и 9-го классов) в связи с организационными трудностями. Средний

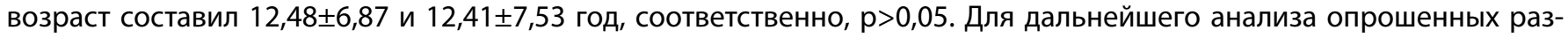
делили на три группы: ученики начальной школы (2-4 класс, возраст 7-11 лет), среднего звена (5-8 класс, 11-15 лет) и старших классов (9-11 класс, 15-18 лет). Потребление кальция в сутки рассчитывалось как сумма суточного потребления кальция из молочных продуктов (в мг) и 250 мг кальция, приходящегося на все другие продукты (Лесняк О.М., с соавт., Научно-практическая ревматология, 2015). Норма потребления кальция для детей в Российской Федерации составляет: в возрасте 4-10 лет - 1100 мг/сут, старше 10 лет - 1200 мг/сут (Щеплягина Л.A., Moиceeва T.Ю. Consilium medicum. 2003). Для статистической обработки был применен однофакторный дисперсионный анализ с использованием критерия Фишера.


В г. Костроме - 1300,39 487,40 мг (р>0,05). В целом среди опрошенных детей в центре №1 нормальное количество кальция употребляли 393 (43,62\%) школьника, более половины суточной нормы (50-99\%) - 381 (42,29\%) ребенок, менее 50\% - 127 (14,10\%) детей. В центре №2 соответствующие показатели составили 208 (45,12\%), 191 (41,43\%) и 62 (13,48\%) человека, р>0,05. Таким образом, в целом каждый шестой ребенок потребляет ежедневно менее половины суточной нормы кальция, еще почти половина детей - меньше нормы, необходимой для данного возраста. Анализ между группами исследования показал, что среднее потребление кальция составило у школьников 2-4 класса 1459,08 мг/сут в первом центре и 1712,99 мг/сут - во втором, у детей 5-8 классов - 1198,06 мг/сут и 1233,46 мг/сут соответственно, в 9-11 классах - 1085,28 мг/сут и 1152,90 мг/сут, достоверные различия не были выявлены ни в одной возрастной группе. При этом доля детей с нормальным потреблением кальция снижалась с возрастом (с 55,51\% в начальной школе до 38,47\% в старших классах, p>0,05). Следует отметить, что с увеличением возраста количество потребляемого кальция должно возрастать в связи с ростом скелета и повышенными потребностями в данном микроэлементе для обеспечения формирования пиковой костной массы, а по данным проведенного опроса его поступление прогрессивно уменьшалось. Это связано, вероятно, с тем, что в начальной школе прием молочным продуктов у детей контролируется родителями, а в дальнейшем они употребляют недостаточное количество продуктов, богатых кальцием, руководствуясь своими вкусовыми предпочтениями.

Для косвенной оценки статуса витамина D в анкетирование были включены вопросы по виду, длительности и регулярности инсоляции. Оказалось, что в летние месяцы $\geq 5$ часов в день бывают на открытом воздухе 592 (43,47\%) школьника (344 (38,18\%) в центре №1 и 248 (53,80\%) в центре №2, р>0,05), 3-4 часа - еще 661 (48,53\%) ребенок (468 (51,94\%) и 193 (41,87\%) в центрах исследования соответственно, р>0,05). Однако при этом не отдыхают за городом 846 (62,11\%) детей $(651$ (72,25\%) в г. Ярославле и 195 (42,30\%), ребенок, проживающий в г. Костроме (р>0,05)), в течение года не ездят на юг 563 (41,34\%) школьника (соответственно 363 (40,29\%) и 200 (43,38\%), р>0,05).

Таким образом, несмотря на то, что летом почти 90\% детей бывают на улице более 3-4 часов в день, большинство из них проводят лето в городе, где образование витамина D в коже ограничено из-за городского смога. Также можно отметить, что в почти 40\% детей не отдыхают летом за городом (при этом оказалось, что таких детей в г. Костроме достоверно больше), и почти 60\% не ездят на юг. По-видимому, данные опроса позволяют сделать вывод, что у большинства детей имеет место недостаточная инсоляция и высока вероятность дефицита витамина D.

Регулярные физические нагрузки более 5 часов в неделю отметили 519 (38,11\%) школьников: 381 (42,29\%) в 1-ом центре и 138 (29,93\%) - во 2-ом; 2-4 часа в неделю - 639 (46,91\%): 394 (43,73\%) и 245 (53,15\%) детей соответственно. В зависимости от возраста доля детей, занимающихся в спортивных или хореографических секциях регулярно, составляет: во 2-4 классах - 268 (71,27\%), по центрам это составило 208 (70,27\%) и 60 (75,00\%) детей, р>0,05, в 5-8 классах - 540 (78,95\%), соответственно 326 (82,12\%) и 214 (74,83\%), р>0,05, в 9-11 классах - 247 (81,25\%), в центрах эти показатели соответствовали 182 (86,60\%) и 65 (69,15\%), р>0,05. При этом только в школе занимаются физкультурой 
171 (12,56\%): 51 (5,56\%) школьник в центре №1 и 120 (26,03\%) в центре №2, р<0,05. Таким образом, оказалось, что большая доля опрошенных детей занимается спортом регулярно, и занятия только в рамках школьной программы отметили около 12\% детей, однако при этом в г. Костроме таких детей было в 5 раз больше, чем в г. Ярославле.

Всего переломы костей в анамнезе отметили 260 (28,86\%) детей в центре №1 и 117 (25,38\%) детей в центре №2 (всего 377 (27,68\%) человек), при этом один перелом произошел в целом у 222 (16,30\%) детей, два - у 110 (8,08\%), три и более перелома отметили в анамнезе 45 (3,30\%) школьников. Следует отметить достаточно большую частоту встречаемости переломов - более чем у четверти детей, при этом почти у половины из них имелись повторные переломы, что требует поиска и дальнейшего анализа причин.

Выводы: Было проведено исследование для оценки распространенности различных факторов, влияющих на здоровье костной ткани, среди школьников 2-11 классов. Оказалось, что только половина детей употребляет достаточно кальция с пищей, и их число уменьшается с возрастом. Более 90\% детей ежедневно более 3-4 часов бывают летом на улице, но при этом 72,25\% детей проводят лето преимущественно в городе, и 40,29\% школьников вообще не ездят на юг. Лишь небольшое количество детей не занимаются регулярно физкультурой, спортом или танцами. Около 29\% детей отмечали наличие переломов костей в анамнезе, более одного перелома отметили 11,38\% школьников.

КЛЮЧЕВЫЕ СЛОВА: Костная ткань; развитие; кальций.

\section{STUDY OF FACTORS AFFECTING ON BONE FORMATION IN CHILDREN AND ADOLESCENTS:} RESULTS OF THE STUDY IN TWO CENTERS

(c) Belova K.Yu. ${ }^{1}$, Marusina A.A. ${ }^{1}$, Marusina I.V. ${ }^{2}$, Ershova O.B. ${ }^{1}$, Gorjeladze H.G. ${ }^{3}$

${ }^{1}$ Yaroslavl State Medical University, Yaroslavl

${ }^{2}$ Kostroma City Hospital, Kostroma

${ }^{3}$ Clinical Hospital for Emergency Medical Care named after N.V. Solovyov, Yaroslavl 


\section{() К.Ю. Белова, О.Б. Ершова, А.А. Дегтярев}

ФГБОУ ВО «Ярославский государственный медицинский университет» Минздрава России, Ярославль ГАУЗ «Клиническая больница скорой медицинской помощи имени Н.В. Соловьева», Ярославль

Цель исследования: изучить частоту проведения оценки риска последующих переломов и назначения антиостеопоротических препаратов у пациентов, включенных в службу профилактики повторных переломов (СППП), и выявить основные причины, повлиявшие на отсутствие проведения данных оценок и/или инициации терапии.

Материалы и методы: Было проведено сплошное когортное исследование с вмешательством по оценке эффективности работы (СППП) на базе областного центра остеопороза больницы скорой медицинской помощи им. Н.В. Соловьева. В службу включали всех пациентов 50 лет и старше, поступивших на лечение в стационар с переломами проксимального отдела бедренной, плечевой кости и тел позвонков. Работа службы была организована с наличием выделенного координатора-медсестры, за время пребывания в стационаре пациентов консультировали врачи-ревматологи, специализирующиеся по проблеме остеопороза. В течение 6-ти месяцев в больницу поступили 534 пациента с данными переломами. Из них не были включены в дальнейшее обследование и наблюдение в службе 50 (9,36\%) пациентов: 30 (5,62\%) больных отказались от госпитализации, 9 (1,68\%) имели перелом на фоне опухоли или метастаза, и у 11 (2,06\%) при опросе был выявлен высокоэнергетический перелом. В дальнейший анализ вошли 484 пациента.

Результаты: Оценка риска последующих переломов (с выявлением значимых клинических факторов риска и расчетом 10-летнего абсолютного риска переломов по FRAX) не была выполнена у 89 (18,39\%) пациентов. Причины: летальный исход - у 11 (12,36\%) человек, тяжелое состояние пациента и/или деменция - 34 (38,20\%), отказ пациента - 3 (3,37\%) пациента. У 41 (46,07\%) пациента имели место административные причины, так как эти больные были выписаны ранее проведения оценок.

После беседы с пациентом и оценки факторов риска медсестра-координатор обеспечивает выполнение лабораторного обследования для выявления причин вторичного остеопороза, а также проведение денситометрии. Двухэнергетическая рентгеновская абсорбциометрия (DXA) у пациентов, госпитализированных в стационар и не имеющих критериев исключения из программы, была выполнена лишь у 180 (37,19\%) человек. Среди причин, по которым она не была проведена, наиболее частым оказались тяжелое состояние пациента (включая наличие значительного снижения ментального статуса, что делало проведение обследования нецелесообразным) и летальный исход (соответственно у 177 (58,22\%) и 17 (5,6\%) больных). Из них пациенты с переломом проксимального отдела бедренной кости составили основную долю (186 (95,88\%) человек). Еще 25 (8,22\%) пациентов отказались от выполнения денситометрии, и у 85 (27,96\%) имели место административные причины, по которым не было возможности организовать ее проведение.

В целом были проконсультированы врачом 310 (64,05\%) больных. Среди тех, кто не получил консультацию специалиста, умерли 17 (9,77\%) человек, крайне тяжелое состояние и деменция отмечены у 58 (33,33\%), не получили необходимого лабораторного обследования 7 (4,02\%), отказались от консультации 11 (6,32\%), были выписаны ранее получения консультации 81 (46,55\%) пациент.

Среди тех больных, которые получили консультацию врача-специалиста, препараты кальция и/или витамина D были назначены 288 (92,90\%) пациентам. У остальных не были выполнены анализы, или в них отмечалась гиперкальциемия, повышение уровня паратиреоидного гормона в сочетании с гиперкальциемией или имела место тяжелая мочекаменная болезнь, требующая дополнительного обследования для принятия решения о назначении указанных препаратов.

Патогенетические антиостеопоротические препараты были назначены 219 (70,65\%) консультированным больным. Среди причин, по которым не была инициирована терапия, были следующие: наличие тяжелого состояния пациента или деменции - 14 (15,38\%), отказ пациента - 4 (4,40\%), выявление отклонений в анализах, требующих дополнительного обследования или коррекции (гипокальциемия, гиперпаратиреоз и прочие) - 63 (69,23\%), а также выявленный низкий риск последующих переломов - 10 (10,99\%).

Обсуждение: Таким образом, в ходе организации работы СППП следует учитывать отдельные аспекты, которые могут помешать провести оценку риска последующих переломов или назначить лечение. В первую очередь, необходимо четко определить критерии включения пациентов с переломами в программу, так как она предполагает выявление больных с низкоэнергетическими переломами на фоне остеопороза. Кроме того, при сплошном включении пациентов с переломами некоторые из них неизбежно будут находиться в тяжелом состоянии, иметь деменцию, что не позволит начать у них лечение остеопороза. В таких случаях необходимо максимально привлекать к организации помощи таким больным родственников, социальные службы, обеспечить передачу данных в первичное звено, чтобы 
впоследствии, в случае улучшения состояния больного, он смог получать необходимую терапию. У ряда больных могут быть выявлены противопоказания к назначению лечения непосредственно во время нахождения в стационаре, что потребуют дальнейшего наблюдения с проведением обследования и подбором терапии. Наконец, существуют больные, которые отказываются от помощи в рамках службы профилактики повторных переломов. Здесь возникает необходимость привлечения других медицинских работников, в первую очередь травматологов, авторитетное мнение которых может изменить отношение больного к данной проблеме. Кроме того, важно проводить школы для пациентов. Что касается причин административного характера, они требуют проведения анализа различных составляющих оказания помощи пациентам с последующей их оптимизацией.

Выводы: Проведенное исследование по анализу оказания помощи в рамках СППП позволяет проанализировать причины, по которым пациенты не получают обследование и/или лечение, и в тех случаях, когда это зависит не от состояния самого пациента, а обусловлено особенностями организации, следует выявлять возможные недостатки и оптимизировать процесс оказания медицинской помощи.

КЛЮЧЕВЫЕ СЛОВА: Остеопороз; профилактика переломов; FRAX.

\section{FREQUENCY OF EXAMINATION AND APPOINTMENT OF ANTI-OSTEOPOROTIC THERAPY IN PATIENTS INCLUDED IN THE PROGRAM OF PREVENTION OF REPEATED FRACTURES}

(c) Belova K.Yu., Ershova O.B., Degtyarev A.A.

Yaroslavl State Medical University, Yaroslavl

Clinical Hospital for Emergency Medical Care named after N.V. Solovyov, Yaroslavl 


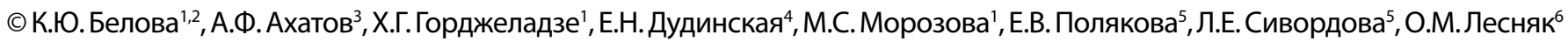

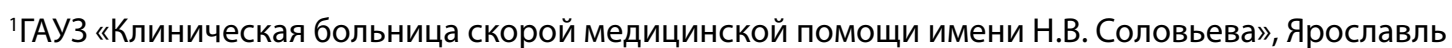

${ }^{2}$ ФГБОУ ВО «Ярославский государственный медицинский университет» Минздрава России, Ярославль

${ }^{3} \mathrm{OOO}$ «Барсмед», Казань

${ }^{4}$ ФГАОУ ВО «Российский национальный исследовательский медицинский университет имени Н.И. Пирогова»

Минздрава России, Москва

${ }^{5}$ ФГБНУ «Научно-исследовательский институт клинической и экспериментальной ревматологии имени

А.Б. Зборовского», Волгоград

${ }^{6}$ ФГБОУ ВО «Северо-западный государственный медицинский университет им. И.И. Мечникова», Санкт-Петербург

Актуальность: для профилактики повторных переломов во многих странах мира сегодня создаются службы профилактики повторных переломов (СППП). В Российской Федерации на сегодня создано 16 таких служб. Для получения единых данных и анализа оказания помощи, а также основных исходов у этих пациентов необходимо создавать единые национальные базы данных.

Цель: разработать регистр пациентов с низкоэнергетическими переломами, включенными в СПпП, и проанализировать первые результаты его работы.

Материалы и методы: Российской Ассоциацией по остеопорозу в июне 2019 года был инициирован проект по созданию регистра пациентов с низкоэнергетическими переломами, включенными в СППП, названный «Прометей». Была создана информационная система для хранения, поиска, обработки информации, на платформе Quinta (свидетельство о государственной регистрации программы ЭВМ № 2016615129 «Универсальный программный комплекс для сбора, обработки и управления территориально распределенными клинико-эпидемиологическими данными в режиме удаленного доступа «Quinta», правообладатель АО «Астон Консалтинг») в режиме удалённого доступа (в on-line). Разработана регистрационная карта, проведены рабочие совещания с руководителями СППП. В настоящее время принимают участие во внесении данных о пациентах в регистр 4 СППП. Внесение пациентов было начато с 08 октября 2019 г.

Результаты: на сегодняшний день в регистр поступили данные о 107 пациентах, средний возраст их составил $71,77 \pm 11,16$ лет. Информация о переломе, по поводу которого пациенты были включены в регистр, не была введена у 3 (2,8\%). Из оставшихся наибольшее число пациентов были с переломами проксимального отдела бедра 64 (61,54\%), проксимального отдела плеча 24 (23,08\%), у оставшихся были выявлены переломы тел позвонков 14 (13,46\%) и дистального отдела предплечья 20 (19,23\%). Переломы в анамнезе отмечали 58 (54,21\%) пациентов. Денситометрия была выполнена у 37 (34,58\%) пациентов, не было проведено исследование преимущественно у больных, получивших перелом проксимального отдела бедренной кости и позвонков, ввиду тяжести их состояния во время госпитализации. Оценка риска последующих переломов выполнена у 100\% включенных пациентов. Оценка риска падений проводилась также всем, высокий риск падений отмечен у 97 (90,65\%) пациентов. Лабораторное обследование для поиска причин вторичного остеопороза было выполнено у 100 (93,46\%) больных. У 28 (28,00\%) при этом была выявлена гипокальциемия, что является противопоказанием к немедленному назначению патогенетической терапии. У 2 (2,00\%) отмечена гиперкальциемия. Препараты кальция и витамина D были назначены у 103 (96,26\%) больных, патогенетические препараты - у 62 (57,94\%). Выводы: таким образом, в России начато создание Всероссийского регистра пациентов с остеопоротическими переломами, включенных в СППП. Следует продолжать сбор данных и увеличивать количество центров, принимающих участие в работе регистра, для улучшения оказания помощи при остеопоротических переломах.

Благодарности и конфликт интересов: регистр «Прометей» поддерживается грантом компании Амджен.

КЛЮЧЕВЫЕ СЛОВА: Профилактика переломов; регистр; остеопороз.

\section{FIRST RESULTS FROM THE RUSSIAN REGISTRY OF THE PATIENTS INCLUDED IN THE OSTEOPOROSIS REFRACTURE PREVENTION SERVICES}

(c) Belova K.Yu. ${ }^{1,2}$, Akhatov A.F. ${ }^{3}$, Gorjeladze H.G. ${ }^{1}$, Dudinskaya E.N. ${ }^{4}$, Morozova M.S. ${ }^{,}$, Polyakova E.V. ${ }^{5}$, Sivordova L.E. ${ }^{5}$, Lesnyak O.M. ${ }^{6}$

${ }^{1}$ Clinical Hospital for Emergency Medical Care named after N.V. Solovyov, Yaroslavl

${ }^{2}$ Yaroslavl State Medical University, Yaroslavl

${ }^{3}$ LLC «Barsmed», Kazan

${ }^{4}$ Russian National Research Medical University named after N.I. Pirogov, Moscow ${ }^{5}$ Institute of Clinical and Experimental Rheumatology named after A.B. Zborovsky, Volgograd

${ }^{6}$ North-Western State Medical University named after I.I. Mechnikov, Saint Petersburg 
ОСТЕОПЕНИЧЕСКИЙ СИНДРОМ У УЧАСТНИКОВ ЛИКВИДАЦИИ ПОСЛЕДСТВИЙ АВАРИИ НА ЧЕРНОБЫЛЬСКОЙ АЭС

\section{(с) Е.В. Белогурова, И.И. Шантырь, С.В. Дударенко}

ФГБУ Всероссийский центр экстренной и радиационной медицины имени А.М. Никифорова МЧС России, СанктПетербург

По данным эпидемиологических исследований, проводимых в России (денситометрическое исследование лиц в возрасте пятьдесят лет и старше в соответствии с критериями ВОЗ) остеопороз выявляется у каждой третьей женщины и каждого пятого мужчины. По данным Всемирной организации здравоохранения, остеопороз занимает четвертое место среди неинфекционных заболеваний после болезней сердечно-сосудистой системы, онкологических заболеваний и сахарного диабета, а частота переломов, связанных с остеопорозом, во всем мире имеет тенденцию к увеличению.

Социальная значимость остеопороза определяется его последствиями - переломами позвонков и трубчатых костей. Наиболее тяжелые медико-социальные последствия обусловлены переломами проксимального отдела бедренной кости.

В настоящее время известно, что развитие остеопороза также может быть обусловлено дефицитом микроэлементов. Так, при ограниченном поступлении в организм магния тормозится образование фосфата кальция. Марганец входит в состав ферментов, необходимых для обмена веществ в хряще и соединительной ткани. Существенное значение для обмена в соединительной и костной тканях имеет медь. Она необходима для ковалентной поперечной связи пептидных цепей в коллагеновых и эластических волокнах соединительной ткани. При дефиците меди описано развитие остеопороза, вызывавшего спонтанные переломы у недоношенных детей. При дефиците железа отмечаются изменения в костной ткани, напоминающие талассемию, что формирует выраженный с расширением костномозговых пространств и деформацией скелета. Возможной причиной остеопороза при дефиците железа может служить гиперплазия костного мозга вследствие неэффективного эритропоэза.

Известно, что ионизирующее излучение, которому подверглись участники ликвидации последствий аварии на Чернобыльской АЭС вызывает не только непосредственные биологические эффекты, но может также приводить к возникновению заболеваний в течение всей последующей жизни человека. В отдаленном периоде патология костно-мышечной системы занимает одно из ведущих мест в структуре заболеваемости участников ликвидации последствий аварии на Чернобыльской АЭС. Изучение клинических симптомов показало, что наряду с остеоартрозом, осеохондрозом позвоночника у ликвидаторов нередко имеются признаки системного заболевания скелета - метаболической остеопатии.

Патогенез остеопороза представляет во многом нерешенную проблему. Учитывая многочисленные этиологические факторы у данной категории больных, способствующие развитию остеопороза, можно думать о гетерогенном характере данного заболевания, сложном многоступенчатом развитии патологического процесса, что предполагает комплексный подход к диагностике и раннему выявлению данного заболевания.

В связи с этим возрастает необходимость и важность микроэлементного анализа как метода ранней диагностики остеопенического синдрома и своевременного начала профилактики развития остеопороза.

КЛЮЧЕВЫЕ СЛОВА: Остеопения; остеопороз; Чернобыльская АЭС.

\section{OSTEOPENIA IN LIQUIDATORS OF THE CHERNOBYL DISASTER CONSEQUENCES}

(c) Belogurova E.V., Shantyr I.I., Dudarenko S.V.

Russian Center of Emergency and Radiation Medicine named after A.M. Nikiforov, Saint Petersburg 
АНАЛИЗ СОДЕРЖАНИЯ 25(ОН) ВИТАМИНА D В СЫВОРОТКЕ КРОВИ У БОЛЬНЫХ С МЯГКИМИ ФОРМАМИ ГИПЕРПАРАТИРЕОЗА

(с Л.Н. Боева ${ }^{1,2}$, Е.В. Капустина ${ }^{1,2,3}$, Е.П. Ключникова², В.С. Мордовский ${ }^{1,2,3}$, Т.Ю. Большакова ${ }^{1,3}$

'ФГБОУ ВО «Красноярский государственный медицинский университет имени профессора В.Ф. Войно-Ясенецкого» Минздрава России, Красноярск

${ }^{2}$ КГБУЗ Краевая клиническая больница, Красноярск

${ }^{3}$ КГБУЗ «Красноярская межрайонная клиническая больница № 20 им. И. С. Берзона», Красноярск

В клинической практике вызывает затруднение постановка диагноза у пациентов с мягкими формами первичного гиперпартиреоза (ПГПТ), нормокальциемическим вариантом ГПТ в отсутствие визуализации аденомы ОЩЖ и вторичного гиперпаратиреоза в результате недостаточности витамина D.

Цель: Оценить содержание в крови 25(OH)D и его взаимосвязи с другими показателями фосфорно-кальциевого обмена у пациентов с мягкими формами гиперпаратиреоза.

Материалы и методы. Проведен ретроспективный анализ 215 электронных амбулаторных карт пациентов эндокринного центра КГБУЗ «Красноярская краевая клиническая больница», обследованных с целью исключения ПГПТ. Среди обратившихся было 97\% женщин. Пациенты разделены на 3 группы: первая группа - 25 человек с уровнем ПТГ (Ме) 160,08 [111,9; 239,7] пг/мл в возрасте (Ме) 62 [54; 65] года; вторая - 55 человек с уровнем ПТГ 99 [85,2; 123,25] пг/мл в возрасте 62 [48; 67] года; третью (контрольную) группу составили 50 человек с нормальным уровнем ПтГ 52,8 [42,4; 61,1] пг/мл в возрасте 51 [38,58,25] лет.

У всех пациентов исследовалось содержание в крови 25 (ОН) D (тест-система «Architect»), ПтГ, общего кальций, фосфора, щелочной фосфатазы. Оценивались ИМТ, сопутствующие заболевания (в том числе мочекаменная болезнь, язвенная болезнь), а также случаи переломов; проводилась денситометрия с оценкой МПКТ, УЗИ околощитовидных желез. Из данных групп исключены лица с уровнем сывороточного кальция выше 2,9 ммоль/л, СКФ <60 мл/мин/1,73 м², с наличием патологическими переломами в анамнезе.

Результаты: Содержание 25(OH)D в первой и второй группах с разной степенью повышения ПтГ в крови не раз-

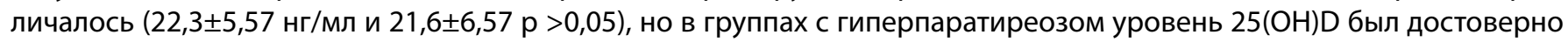
ниже, чем в группе с нормальным уровнем ПТГ $(26,1 \pm 7,17$ нг/мл ( $<<0,00)$. Выявлена слабая отрицательная корреляционная связь между содержанием 25(OH)D и ПТГ в крови у всех обследованных $(-0,192$ p <0,05). Уровень общего кальция в первой ГПТ группе был достоверно выше (Ме) 2,66 ммоль/л [2,39; 2,77]. Во второй группе содержание кальция 2,39 ммоль/л $[2,36 ; 2,48]$ не отличалось от контрольной группы.

Во всех группах уровень 25(ОН)D отрицательно коррелировал с ИМТ $(-0,163, \mathrm{p}<0,05)$ и возрастом $(-0,208, \mathrm{p}<0,05)$. Выявлена положительная корреляционная взаимосвязь паратгормона с возрастом $(0,263, p<0,01)$. 3начимых различий с другими лабораторными показателями в нашем исследовании не выявлено.

Выводы: Уровень 25 (OH) D сыворотки крови был достоверно ниже у больных с гиперпаратиреозом, но значимой разницы между первой и второй группами не выявлено, что определяет необходимость для дифференциальной диагностики ГПТ проведение функциональных проб.

КЛЮЧЕВЫЕ СЛОВА: Гиперпаратиреоз; витамин D; кальций.

\section{SERUM 25(OH)D LEVELS IN PATIENTS WITH MILD FORMS OF HYPERPARATHYROIDISM}

(c) Boeva L.N. ${ }^{1,2}$, Kapustina E.V. ${ }^{1,2,3}$, Klyuchnikova E.P. ${ }^{2}$, Mordovsky V.S. ${ }^{1,2,3}$, Bolshakova T.Yu. ${ }^{1,3}$

${ }^{1}$ Krasnoyarsk State Medical University named after professor V.F. Voino-Yasenetsky, Krasnoyarsk

${ }^{2}$ Regional Clinical Hospital, Krasnoyarsk

${ }^{3}$ Krasnoyarsk Interdistrict Clinical Hospital No. 20 named after I.S. Berzon, Krasnoyarsk 


\section{() Т.В. Буйлова}

Национальный исследовательский Нижегородский государственный университет им. Н.И. Лобачевского, Нижний Новгород

Современная концепция медицинской реабилитации, которая внедряется в России и уже доказала свою эффективность во всех странах Европы и мира за последние 60 лет, предполагает «устранение нарушений для облегчения функционирования пациентов, увеличения их активности и участия в общественной жизни, а также улучшения качества жизни в целом», базируется на принципах раннего начала, непрерывности, преемственности, последовательности, комплексности, обоснованности, индивидуального подхода, мультидисциплинарности и длительности до сохранения положительной динамики. [White Book on Physical and Rehabilitation Medicine in Europe. Introduction, Executive Summary and Methodology. Eur J Rehabil Med. 2018 Apr; 54(2):125-155.] Краеугольным камнем современной концепции является: использование мультидисциплинарного подхода, международной классификации функционирования (МКФ) при постановке реабилитационного диагноза и разработке реабилитационной программы, обязательное формулирование реабилитационных целей и применение шкал, тестов и опросников, позволяющих оценить реабилитационный потенциал, а также изменение состояния пациента на всех уровнях его функционирования.

Современные подходы к восстановительному лечению пациентов с остеопорозом полностью соответствуют данной концепции медицинский реабилитации. Для постановки реабилитационного диагноза (по МКФ) необходимо оценить состояние пациента на уровне «структуры и функции», а также на уровне «активности и участия». Для анализа состояния пациента с остеопорозом на уровне «структуры и функции», по МКФ, проводится оценка «структур и функций, связанных с движением - блок №7», а также «сенсорных и боли - блок №2». Реабилитационный диагноз больных с остеопорозом должен включать в себя домены МКФ, отражающие состояние костной, мышечной тканей, баланса, ходьбы, возможностей передвижения, самообслуживания, активности в повседневной жизни и др. Для анализа выраженности болевого синдрома у пациентов с остеопорозными переломами применяется визуально-аналоговая шкала (ВАШ) боли. Для оценки мышечной силы используется мануальное мышечное тестирование по 6-балльной системе, тест на выносливость мышц спины и живота к статической нагрузке, тест на выносливость мышц спины и живота к динамической нагрузке, динамометрия и тензодинамометрия. Для оценки риска падений и функции баланса применяются усложненный тест Ромберга, тест «Встань и иди», шкала равновесия Берга, тест устойчивости стояния, шкала Тинетти (ориентированная на выполнение задания оценка мобильности), шкала эффективности падений и стабилометрия. Для оценки возможностей передвижения применяются тесты с регистрацией времени и расстояния (10-метровый тест ходьбы, 400-метровой тест ходьбы, тест 4-минутной ходьбы), а также подометрия. Для оценки выраженности психо-эмоциональных нарушений применяется шкала депрессии Бека, шкала Спилбергера-Ханина, Госпитальная шкала тревоги-депрессии. Для анализа жизнедеятельности и факторов окружающей среды применяются Канадская Оценка Выполнения Деятельности (COPM) и шкала эрготерапевта для оценки окружения. Для оценки качества жизни и общего уровня здоровья у пациентов с ОП применяется несколько опросников. Наиболее используемый опросник оценки качества жизни пациентов с переломами позвонков на фоне остеопороза - QUALEFFO-41 (Quality of Life questionnaire of the European Foundation for Osteoporosis). Для оценки общего уровня здоровья применяются опросники SF-36 (Short Form-36 Health Survey) и EQ-5D (European Quality of Life instrument). Реабилитационные мероприятия считаются эффективными, если достигнуты реабилитационные цели и есть положительная динамика по доменам МКФ реабилитационного диагноза. Мультидисциплинарная реабилитационная бригада (МДБ) при остеопорозе включает в себя: врача физической и реабилитационной медицины (ФРМ), специалиста по физической реабилитации (физического терапевта), специалиста по эргореабилитации (эрготерапевта), клинического психолога, медсестру ФРМ, социального работника. Члены МДБ работают в тесном контакте с другими врачами-специалистами: ревматологом, геронтологом, эндокринологом, акушером-гинекологом, неврологом, терапевтом, офтальмологом. Важнейшее значение в реабилитации пациентов с остеопорозными переломами имеет правильная трехэтапная маршрутизация.

Данная модель реабилитации апробирована в нашем реабилитационном центре Нижегородского филиала ФГУП «Московское ПрОП». При первичном осмотре пациентов с ОП ставился реабилитационный диагноз, формулировались реабилитационные цели и составлялась реабилитационная программа, которая включала в себя различные методы: физические упражнения, механотерапию, тренажерную гимнастику, физиотерапию, бальнеотерапию, рефлексотерапию, эрготерапию, психотерапию, медикаментозное лечение и ортезирование. Основным методом лечения больных с остеопорозом была физическая терапия, доля которой составляла 70-90\% в структуре реабилитационной программы. В процессе реабилитации пациентов с ОП особое внимание уделялось тренировке баланса и уменьшению риска падений. Разработанная нами программа реабилитации включала в себя: лечебную гимнастику 
(в т.ч. с использованием методики проприоцептивного нейромышечного проторения), обучение правильной ходьбе (в т.ч. по лестнице), обучение правильному падению и вставанию, подбор и обучение пользованию техническими средствами реабилитации (дополнительными средствами опоры, ортезами и брейсами), стабилотренинг виброплатформе Galileo, а также нестабильной биомеханической платформе IMOOVE, многоканальную миостимуляцию во время ходьбы, а также психотерапию, направленную на уменьшение страха падений. При завершении курса реабилитации члены МДБ оценивали динамику реабилитационного диагноза (по МКФ), а также результаты решения задач и достижения целей реабилитации. Пациент-ориентированный, мультидисциплинарный подход с использованием МКФ был апробирован в процессе реабилитации 58 пациентов с остеопорозом.

КЛЮЧЕВЫЕ СЛОВА: Остеопороз; реабилитация; профилактика.

MODERN APPROACHES TO REHABILITATION OF PATIENTS WITH OSTEOPOROSIS. INTERNATIONAL CLASSIFICATION OF FUNCTIONING AND REHABILITATION DIAGNOSIS

(c) Builova T.V.

Nizhny Novgorod State University named after N.I. Lobachevsky, Nizhny Novgorod 
РЕЗУЛЬТАТЫ ПРИМЕНЕНИЯ АСФОТАЗЫ АЛЬФА У ВЗРОСЛОГО ПАЦИЕНТА С ДЕТСКОЙ ФОРМОЙ ГИПОФОСФАТАЗИИ

\author{
( Ю.В. Буклемишев, С.С. Родионова
}

ФГБУ «НМИЦ ТО им. Н.Н. Приорова» Минздрава России, Москва

Гипофосфатазия (ГФФ) - редкое генетическое медленно прогрессирующее заболевание, обусловленное мутациями в гене ALPL, кодирующем неспецифический тканевой изофермент щелочной фосфатазы TNSALP, проявляющееся нарушениями в минерализации костей скелета и зубов, неврологической патологией, вторичными системными осложнениями.

Патогенетической терапией при ГФФ является пожизненная фермент-заместительная терапия асфотазой альфа. Применение данного препарата (согласно инструкции) у пациентов детского возраста с ГФФ позволяет значительно улучшить качество жизни пациентов. Опыт использования препарата асфотазы альфа у взрослых в мире крайне ограничен.

Хотим представить опыт лечения взрослого пациента с детской формой ГФФ, осложненной перестроечными переломами бедренных костей которому диагноз ГФФ был поставлен через 39 лет от появления первых симптомов и назначено патогенетическое лечение.

Пациент Б., 1978 г.р., обратился на консультацию в КДЦ, научно-клинический центр остеопороза ФГБУ «НМИЦ ТО им. Н.Н. Приорова» МЗ РФ 21.12.2017 с жалобами на прогрессирующие боли в области правого бедра в в/3, деформацию нижних конечностей, слабость. При сборе анамнеза, со слов пациента и его родителей, выяснено что начало заболевания отмечено в возрасте 1,1 года, когда появилась вальгусная деформация нижних конечностей, хромота. Выпадение молочных зубов с корнями началось с 1,2 года.

Диагностирован рахит, однако консервативное лечение, включающее витамин Д, эффекта не принесло. Деформации продолжали прогрессировать.

В возрасте 2-7 лет пациенту неоднократно проводилось протезирование молочных зубов.

В 9 лет в отделении костной патологии детского возраста ЦИТО, в сентябре 1986 года проведены операции: подмыщелковые корригирующие остеотомии обеих большеберцовых костей по Ренке, остеотомия малоберцовых костей. В связи с рецидивом деформации в октябре 1989 года проведена операция: подмыщелковая остеотомия костей обеих голеней с фиксацией гипсовыми повязками. Спустя 4 года в (1993 году) выявлен рецидив деформации нижних конечностей за счет бедренных сегментов. В марте 1993 года проведены операции: надмыщелковые остеотомии обеих бедренных костей с фиксацией спицами и гипсовыми повязками.

Со слов родителей пациента, формирование костных мозолей в послеоперационные периоды происходило в более поздние сроки, в связи с чем, приходилось проводить гипсовую иммобилизацию более длительное время по сравнению с обычными сроками консолидации.

Впервые уровень ЩФ был определен в 1993 г. и составлял - 264 (448-896) нмоль\сл., что было в два раза ниже возрастной нормы. Однако эти данные не были приняты во внимание.

Коренные зубы появлялись в срок, были плохого качества с тонкой эмалью, желтоватого цвета, хрупкие. С 20 лет потеря постоянных зубов, с корнями, оставшиеся 12 фиксированы за счет слизистой, и внешних конструкций.

Повторное обращение в НМИЦ ТО в декабре 2017 г. с жалобами на прогрессирующие боли в области в 3 левого бедра, слабость. Боли появились постепенно, без предшествующей травмы начиная с июня 2017 г.

Выявленное в 1993 году снижение уровня ЩФ крови - 03.03 .1993 г.: снизилось до цифр ЩФ - 5 (40-135) Е\л в 2017 г.

Рентгенологически, по данным КТ, МРТ, КТ-скеаграмм выявлены перестроечные переломы обеих бедренных костей (правой бедренной кости в в 3 , левой бедренной кости

По данным рентгеновской денситометрии не выявлено снижение минеральной костной плотности. QST - MПК превышает возрастную норму.

Проведен генетический анализ крови пробанда и его родственников на мутацию ALP. У пациента, его матери, и сына выявлена мутация (MIM 171760 транскрипт RefSeq:NM000478), болезнь гипофосфатазия (OMIM 146300). Выявлен вариант нуклеотидной последовательности с.182 G>A (p.G61E) в гетерогенном состоянии в 4 экзоне. Проведен биоинформатический анализ предсказания патогенности замены p.Gly61Glu: программы Mutation Taster, PolyPhen-2, SIFT, PROVEAN - патогенный вариант.

Кроме того у пробанда и его отца выявлена мутация (MIM 171760 транскрипт RefSeq:NM_000478)), болезнь гипофосфатазия (OMIM 146300).

Вариант нуклеотидной последовательности c.571 G>A (p.Glu191lys) в гетерогенном состоянии в 6 экзоне описан в базах данных ALPL-SESEP и HGMD (CM920019).

У сестры пациента и дяди по отцовской линии мутаций гена ALP не вывялено.

Исходя из анамнеза заболевания, уровня ЩФ крови, наличия перестроечных переломов бедренных костей, данных генетических анализов крови - был верифицирован диагноз - Гипофосфатазия, детская форма, осложненная 
перестроечными переломами обеих бедренных костей. Варусная деформация нижних конечностей.

С февраля 2019 г. пациент начал получать препарат для заместительной терапии асфотаза альфа 80 мг. 0,8 мл. в комбинации с альфакальцидолом и диетой богатой кальцием.

Результаты: Начиная с месячного курса терапии у пациента отмечено прогрессирующее улучшение самочувствия, увеличение толерантности к нагрузкам, скорости ходьбы.

При контрольном обследовании на срок 8 мес. терапии выявлено практически полная консолидация перестроечных переломов в/3 диафиза правой бедренной кости и н/3 диафиза левой бедренной кости.

Выводы: Показана высокая эффективность лечения патогенетической фермент-замещающей терапии при ГФФ, несмотря на длительный срок течения заболевания от начала появления первых симптомов до начала лечения.

КЛЮЧЕВЫЕ СЛОВА: Гипофосфатазия; асфотаза альфа; фосфор.

\section{RESULTS OF USING ASFOTASE ALFA IN AN ADULT PATIENT WITH CHILDHOOD HYPOPHOSPHATASIA}

(c) Buklemishev Yu.V., Rodionova S.S.

N.N. Priorov National Medical Research Center of Traumatology and Orthopedics, Moscow 
ТРУДНОСТИ В ЛЕЧЕНИИ АТИПИЧНЫХ ПЕРЕЛОМОВ БЕДРЕННОЙ КОСТИ (ОПИСАНИЕ КЛИНИЧЕСКОГО СЛУЧАЯ)

\author{
(с) Ю.В. Буклемишев, С.С. Родионова, М.С. Криворотько
}

ФГБУ «НМИЦ ТО им. Н.Н.Приорова» Минздрава России, Москва

Бисфосфонаты (БФ) являются одними из наиболее часто назначаемыми препаратами для лечения остеопороза и других метаболических заболеваний костной ткани, так же эти препараты применяются для профилактики и лечения метастатического поражения костной ткани, используется в комплексном лечении ряда гематологических заболеваний. Вопросы этиологии и патогенеза, а также причины появления и развития атипических переломов бедренной кости оказываются спорными. Ряд клинических исследований нашли прямую зависимость между длительным назначением азотсодержащих БФ и атипичными переломами. После анализа данных FDA в 2010 году не нашла связи атипичных переломов с приемом БФ.

Приводим следующее наблюдение. Пациентка С., 1938 г.р., 78 лет. в ноябре 2016 г. Заочно консультирована в КДЦ ФГБУ «НМИЦ ТО им.Н.Н. Приорова» Минздрава России.

С августа 2016 г. без травмы появились и стали постепенно нарастать боли в области с\3 правого бедра. В октябре для дополнительной опоры больная стала использовать трость, затем ходунки. Пациентка неоднократно обследовалась в различных ЛПУ г. Москвы, проводились рентгенография, МРТ-томография, КТ-томография бедра, исключена неврологическая патология и патология пояснично-крестцового отдела позвоночника, тазобедренного сустава.

Выявлено, что пациентка наблюдается с диагнозом остеопороз в течение 3 лет, когда при обследовании в связи с болями в области поясницы были выявлены компрессионные переломы тел позвонков Th7, Th11, L2, L4. Наследственность отягощена: у матери пациентки множественные переломы тел позвонков. Пациентка 2 года находилась на терапии бисфосфонатами (ибандроновая кислота таблетированная форма - 150 мг. - 1 раз в месяц) в сочетании с холекальциферолом 400 мг и препаратами кальция. Показанием к назначению лечения и контроль эффективности проводимой терапии остеопороза, основывался данными денситометрии. При ретроспективном анализе медицинской документации и данных лучевых методов диагностики пациентке был поставлен диагноз: Постменопаузальный остеопороз, осложненный множественными переломами тел позвонков. Атипичный неполный перелом диафизов бедренных костей с 2-х сторон. 05.12.2016 находясь на госпитализации для реабилитационного лечения, при ходьбе с ходунками, пациентка развернулась с упором на правую ногу и почувствовала боль в области средней трети бедра. После рентгенографии заподозрен патологический перелом правой бедренной кости на фоне опухоли, учитывая отсутствие адекватной травмы. 16.12 .2016 проведено оперативное вмешательство: открытая биопсия и экскохлеация опухоли. Репозиция и малоинвазивный остеосинтез бедренной кости пластиной под ЭОПом. При гистологическом исследовании - биоптате фрагменты остеосаркомы низкой степени злокачественности с признаками инвазивного роста в поперечнополосатую мышечную ткань. Гистологические материалы пересмотрены в РОНЦ РАН и институте ревматологии, 62 ГКБ - морфологическая картина (с учетом данных лучевой диагностики) более всего соответствует перелому с репарацией разной степени давности, выраженным реактивным остеогенезом, повреждением окружающих мягких тканей. Имеются признаки, наблюдаемые при остеопорозе. При повторной консультации в научно-клиническом центре остеопороза ФГБУ «НМИЦ ТО им Н.Н. Приорова» Минздрава России, выявлено резкое снижение маркера костеобразования (остеокальцина). Назначена терапия: альфакальцидол 1 мкг/сутки, диета с повышенным содержанием кальция (до 1200 мг/сутки), оссеин-гидроксиапатитный комплекс, дозированная ходьба с помощью ходунков, ортез на бедро. Отменен прием бисфосфонатов.

Несмотря на неудовлетворительное стояние отломков, большой размер диастаза между костными фрагментами, патогенетически обоснованная консервативная терапия (по результатам маркеров костного ремоделирования), привела к практически полной консолидации перелома в срок 3 года.

Выводы: Наличие длительного болевого синдрома в бедренных костях у пациентов принимающих бисфосфонаты в течение длительного времени, особенно без адекватного приема кальция и витамина Д, требует дополнительного обследования на формирующиеся атипичные переломы длинных трубчатых костей (рентгенография, а для более ранней диагностики применяется МРТ).

Таким пациентам следует отменять лечение бисфосфонатами и назначать активные метаболиты витамина Д в сочетании с оссеин-гидроксиапатитным комплексом или препаратами кальция.

КЛЮЧЕВЫЕ СЛОВА: Атипичный перелом; остеопороз; витамин D.

DIFFICULTIES IN TREATMENT OF ATYPICAL FEMORAL FRACTURES (CLINICAL CASE)

(c) Buklemishev Yu.V., Rodionova S.S., Krivorotko M.S.

N.N. Priorov National Medical Research Center of Traumatology and Orthopedics, Moscow 


\author{
() В.Е. Бялик, М.А. Макаров, Е.И. Бялик, С.А. Макаров, В.А. Нестеренко, М.Р. Нурмухаметов
}

Федеральное Государственное Бюджетное Научное Учреждение «Научно-Исследовательский Институт Ревматологии им. В.А. Насоновой», Москва

Цель исследования: оценить эффективность внутрисуставного введения препаратов гиалуроновой кислоты (ГК) с различной молекулярной массой (ММ) и в сочетании с хондроитин сульфатом (ХС) в лечении больных остеоартритом (ОА) коленного сустава (КС).

Материалы и методы: В отделении травматологии-ортопедии ФГБНУ НИИР им. В. А. Насоновой за период с сентября 2017 года по июнь 2019г внутрисуставные инъекции (ВИ) препаратов ГК были выполнены 160 пациентов. Среди пациентов преобладали женщины, в соотношении 2,5:1. Средний возраст больных составил 43,5 $\pm 8,7$ лет,

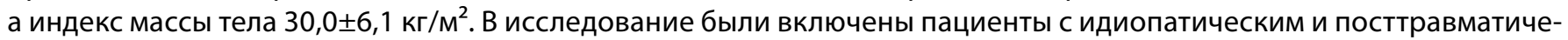
ским ОА КС с интенсивностью боли, оцененной по визуальной аналоговой шкале (ВАШ), в 40 мм и более.

Больные, включенные в исследование, были распределены на 4 группы, в зависимости от вводимого им препарата ГК. В первую группу были включены 80 пациентов, которым вводили гексадециламидное производное ГК с ММ 500-730 кДа, во вторую - 20 пациентов, получивших ВИ препаратом ГК с ММ 1500-2000 кДа, в третью - 30 пациентов, прошедших курс инъекции ГК с ММ 3500 кДа и четвертую - 30 больных, которым внутрисуставно вводили ГК с ХС. Курс ВИ составил для ГК с ММ 500-730 кДа, 3500 кДа и ГК с ХС 2 инъекции, для ГК с ММ 1500-2000 кДа - 3. Инъекции выполняли с интервалом в 1 неделю. В последующем осуществляли контрольные осмотры по прошествии 1, 3 и 6 месяцев со дня последней инъекции.

Оценку результатов лечения осуществляли в соответствии с изменением боли по ВАШ в мм. Результат был оценен как отличный при снижении боли по ВАШ до 0-19 мм, хороший: боль по ВАШ равна 20-39 мм; удовлетворительный: ВАШ 40-59 мм (интенсивность боли становилась слабее, чем до курса ВИ, либо как минимум не усиливалась). Критерием неудовлетворительного результата лечения было усиление боли по ВАШ выше исходных значений, либо интенсивность боли 60 мм и более.

Результаты: у пациентов, пролеченных ГК с ММ 500-730 кДа при I стадии ОА КС, было отмечено снижение боли, в среднем, на 30,5 мм уже к 1 месяцу после ВИ ГК, которое сохранилось вплоть до финальной точки исследования. При II стадии исходный уровень боли не отличался от пациентов с I стадией, однако результат через 1 месяц был хуже

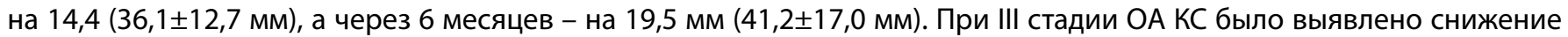

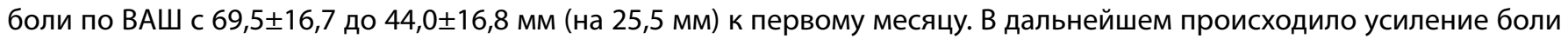

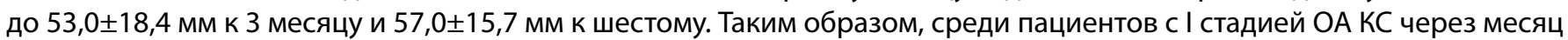
после ВИ ГК было 86,3\% отличных и хороших результатов, через 3 месяца - 69\%, а к 6 месяцам - 65,6\%. Применение препарата ГК с ММ 500-730 кДа на II стадии ОА КС через месяц после ВИ позволило достичь отличных и хороших результатов в 41,5\% случаев. Данный результат сохраняется до 3 месяцев, а к 6 снижается до 26,9\%. У больных с III стадией ОА КС через месяц после курса лечения хорошие и отличные результаты были получены в 40\% случаев, однако уже к 3 месяцу пациентов с улучшением в данной группе не осталось.

Лечение пациентов с ОА КС ІІ стадии препаратом ГК с ММ 1500-2000 кДа позволило снизить боль по ВАШ к 1 ме-

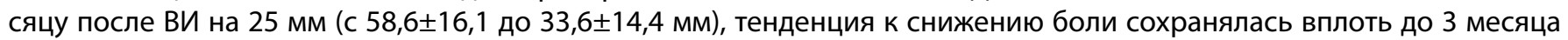
$(32,1 \pm 15,2$ мм), однако к 6 было выявлено усиление боли по ВАШ до 43,6 29,5 мм. При III стадии ОА КС также отмечали

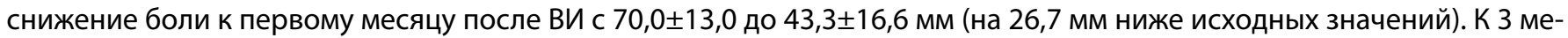
сяцу после ВИ было выявлено резкое усиление боли (до 61,7士23,3 мм), которое сохранилось вплоть до 6 месячного контроля (58,3 229,9 мм). Применение ГК с ММ 1500-2000 кДа при II стадии ОА КС к первому месяцу дает возможность добиться отличных и хороших результатов в 57,2\% случаев. Результат сохраняется до 3 месяцев, после чего ухудшается в 2 раза (до 28,6\%). В случае внутрисуставного введения данного препарата пациентам с III стадией ОА КС отличный и хороший результат удается получить в 33,4\% случаев. При этом полученный результат сохраняется до 6 месяцев. У единственной пациентки с I стадией ОА КС, пролеченной ГК с ММ 3500 кДа боль по ВАШ, снизилась на 30 мм уже через месяц (с 40 до 10 мм). К 3 месяцу боли не было, к 6 - она не превышала 10 мм. Применение данного препарата

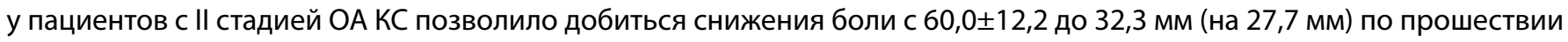

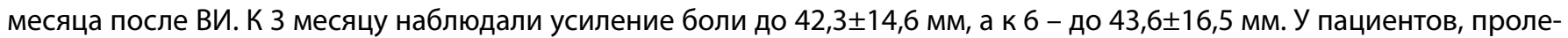

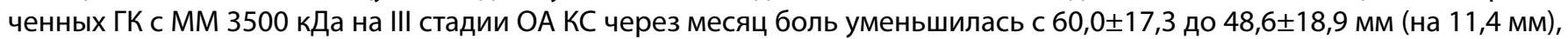

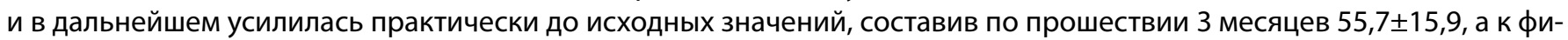
нальной точке исследования - 55,7士17,2 мм. В случае применения ГК с ММ 3500 кДа для лечения ОА КС І стадии отличный результат сохранился до конца исследования. Внутрисуставное введение ГК с ММ 3500 кДа при II стадии ОА КС позволило получить 59,1\% отличных и хороших результатов через месяц после курса инъекций. Однако, к 3 месяцу 
было выявлено снижение процента отличных и хороших результатов до 27,3\%. Данный результат сохранился до конца исследования. В случае лечения пациентов, страдающих ОА КС III стадии, через месяц было диагностировано лишь 28,6\% отличных и хороших результатов. К 3 месяцам результат ухудшился в 2 раза (до 14,3\%), а к 6 не осталось ни одного пациента с III стадией ОА КС, имеющих отличный или хороший результат.

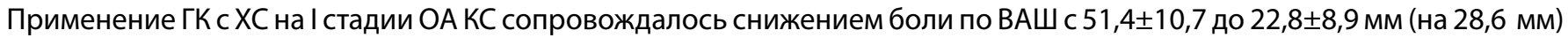

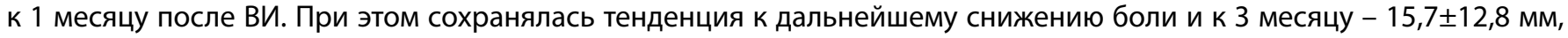
но к 6 месяцам после ВИ ГК было отмечено усиление боли до 18,6士12,1 мм. У пациентов с II стадией ОА КС, пролеченных ГК с ХС, боль по ВАШ до курса ВИ была равна 50,0 14,1 мм, и через месяц после лечения уменьшилась до 22,8土14,3 мм (на 27,2 мм). Однако, в отличие от пациентов с I стадией, к 3 месяцу боль уменьшилась на 1,4 мм

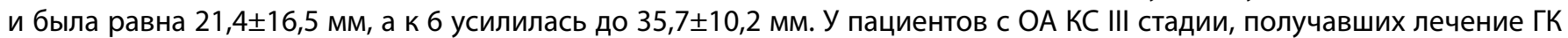

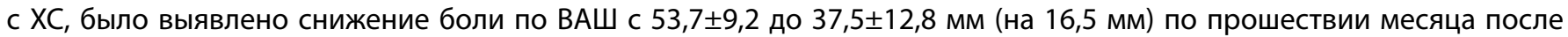
курса ВИ. Тенденция к уменьшению боли сохранялась и через 3 месяца (33,7士11,6 мм), но к 6 месяцам после лечения боль вновь усилилась и была равна 40,0土15,1 мм. У пациентов, пролеченных ГК с ХС при I стадии ОА КС, отличный и хороший результаты через месяц после курса лечения были получены в 71,5\% случаев. К 3 месяцам $100 \%$ пациентов имеют отличный и хороший результаты, но к 6 месяцам этот процент снизился до 85,8\%. Пациенты, пролеченные ГК с XС на II стадии ОА, через месяц после курса лечения имели 78,6\% отличных и хороших результатов. К 3 месяцу число отличных и хороших результатов увеличилось до 92,9\%, а к 6 месяцам снизилось до 50\%. Применение ГК с ХС при III стадии ОА КС привело через месяц после курса лечения к отличным и хорошим результатам в 55,6\% случаев. В дальнейшем число отличных и хороших результатов уменьшилось до 44,4\% (3 месяца), а затем до 22,2\% (к 6 месяцу). Выводы: При I стадии ОА КС, через месяц после ВИ, независимо от применяемой ГК, можно добиться уменьшения боли по ВАШ на 28,6-30,5 мм. ГК в сочетании ХС наиболее эффективна при применении на II стадии ОА КС и позволяет сохранить отличный и хороший результат по прошествии 6 месяцев у 50\% больных. На III стадии ОА КС, через 6 месяцев после ВИ, препараты ГК имеют сопоставимые результаты и эффективны лишь у 16,2\% пациентов.

КЛЮЧЕВЫЕ СЛОВА: Остеоартрит; гиалуроновая кислота; коленный сустав.

\section{THE EFFECTIVENESS OF HYALURONIC ACID WITH DIFFERENT MOLECULAR WEIGHT} IN TREATMENT OF PATIENTS WITH STAGE I-III KNEE JOINT OSTEOARTHRITIS

(c) Byalik V.E., Makarov M.A., Byalik E.I., Makarov S.A., Nesterenko V.A., Nurmukhametov M.R.

Research Institute of Rheumatology named after V.A. Nasonova, Moscow 
(с) В.А. Васильева, Л.А. Марченкова, В.Н. Сергеев

Национальный медицинский исследовательский центр реабилитации и курортологии Минздрава России, Москва

Цель исследования: сравнить эффективность трех методов исследования состава тела - биоимпедансометрии (БИМ), воздухозамещающей бодиплетизмографии (ВБПГ) и рентгенденситометрии по программе вce тело (DXA Total Body) в верификации признаков саркопении (снижение массы скелетной мускулатуры) у пациентов с ожирением.

Материалы и методы: Исследуемую группу составили 95 пациентов в возрасте от 21-69 лет (средний возраст

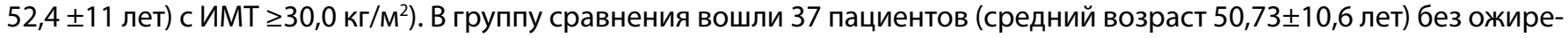
ния - ИМТ 20,0-29,9 кг/м². Все пациентам проводили исследование состава тела методами БИМ, BБПГ и DXA Total Body с определением количества (кг) и \% жировой, тощей и мышечной массы.

Результаты: По данным БИМ группы отличались только количеством жировой ткани (ЖТ) - 42,75 [4,8; 6,3] против 33,15 $[28,4 ; 35,5]$ кг; p=0,036 и не отличались (p>0,05) количеством тощей (TT) и мышечной ткани (MT) и \% ЖТ и скелетно-мышечной ткани (СМТ). По данным ВБПГ исследуемые группы достоверно отличалась по количеству ЖТ - 3,4 [36,81; 69,94] против 31,02 [23,22; 38] кг, p=0,007, \% ЖТ - 45,4 [42,1; 53,8] против 37,7 [28,6; 41,1], p=0,003 и \% МТ - 54,6 [46,2; 57,9] против 62,3 [58,9; 71,4], p=0,003 при статистически равнозначных значениях количества ТТ $55[49,48 ; 67,77]$ против 40,36 [33,12; 49,06], p=0,19. По данным DXA Total Body выявлены статистически значимые различия ( $<<0,05)$ между группами в количестве и \% ЖТ всех исследуемых отделов тела (руки, ноги, туловище, все тело), но не отмечено всего количество жира $(p=0,009)$ было выявлено увеличение количества ЖТ и \% жТ, но не было выявлено существенной разницы (р>0,05) в \% и количестве МТ и ТТ между группами ни в одном участке тела.

Обсуждение: известно, что при саркопеническом ожирении выявляется избыточное накопление жировой ткани, при снижении мышечной массы и силы, причем уже в возрасте старше 30 лет. Современные методы диагностики имеют свои недостатки для постановки диагноза саркопенического ожирения. Поэтому, более широкое применение метода ВБПГ может улучшить качество и своевременность диагностики признаков саркопении у пациентов с ожирением, что в итоге будет способствовать более раннему целевому назначению лечения саркопении и улучшить ее прогноз. Не смотря на относительно высокую стоимость и трудоемкость исследования с помощью ВБПГ, метод может быть рекомендован для применения в комплексе диагностики саркопенического ожирения.

Выводы: Из трех методов оценки состава тела (БИМ, ВБПГ и DXA Total Body) наиболее чувствительным методом диагностики признаков саркопении у пациентов с ожирением является ВБПГ. Этот метод показывает, что пациенты с ожирением имеют значительно меньшую мышечную массу по сравнению с пациентами с избыточной массой тела.

КЛЮЧЕВЫЕ СЛОВА: Саркопения; ожирение; состав тела.

\section{EFFECTIVENESS OF THREE METHODS OF BODY COMPOSITION ASSESSMENT IN DIAGNOSING SIGNS OF SARCOPENIA IN PATIENTS WITH OBESITY}

(c) Vasilyeva V.A., Marchenkova L.A., Sergeev V.N.

National Medical Research Center of Rehabilitation and Balneology, Moscow 
(с) А.А. Волков, Н.Н. Белосельский, Ю.Н. Прибытков, А.Ю. Прибытков

ФГБОУ ВО «Ярославский государственный медицинский университет» Минздрава РФ, Ярославль

Цель исследования: Изучить однородность минерализации трабекулярной и кортикальной кости поясничных позвонков у женщин.

Материалы и методы: Были изучены результаты количественной компьютерной томографии 2, 3, 4 поясничных позвонков 127 условно здоровых женщин различного возраста, полученных на РКТ Siemens и аналитической программы OSTEO. Толщина срезов составляла 1,0 см, срезы проводились через центральные отделы тел параллельно замыкательным пластинам. В качестве показателя однородности минерализации использовался «Плотностный интервал губчатой и кортикальной кости (ПИГ и ПИК)», определяемый как арифметическая разница между наиболее и наименее минерализованными участками трабекулярной и кортикальной кости в зоне сканирования.

Результаты и обсуждение: Согласно рекомендациям ISCD, нормальная минеральная плотность тел позвонков, определяемая QCT, оставляет более 120 мг/мл, величина 80-120 мг/мл соответствует остеопении, менее 80 остеопорозу; T, Z критерии в QCT не учитываются. На первом этапе исследования все пациентки были разделены на возрастные группы с интервалом 9 лет от 50 лет и младше до 70 лет и старше. Получено ожидаемое уменьшение с возрастом минеральной плотности кортикальной кости от нормальных значений до значений, соответствующих остеопорозу. При этом отмечено сокращение ПИГ на 4,8\% в возрастной группе 50-59 лет, где средняя плотность губчатой кости составила 111,4 мг/мл (начальная остеопения) по сравнению с самой младшей возрастной группой. Последующее сокращение ПИГ на 34,8\% (до 81,0 мг/мл) от предыдущего значения определялась в группе 60-69 лет, где средняя минеральная плотность губчатой кости составила 81,8 мг/мл (выраженная остеопения). В самой старшей возрастной группе, где минеральная плотность соответствовала остеопорозу (69,9 мг/мл) плотностной интервал увеличивался на 8,9\%. ПИК с возрастом неравномерно возрастал от 204 мг/мл до 249 мг/мл.

На следующем этапе результаты были разделены на группы в зависимости от величины средней минеральной плотности губчатой кости (125+, 100-125, 75-99, 50-74, -50 мг/мл). Наибольшее сокращение ПИГ (-38,5\% до 81,6 мг/мл) отмечено при переходе плотности губчатой кости от значения умеренной остеопении до выраженной остеопении и начальному остеопорозу, средний возраст пациенток в этих группах составил 60,7 и 62,7 лет соответственно. При более низких значениях плотности губчатой кости наибольшее сокращение ПИГ не превышало 6,4\%. В свою очередь уменьшение плотности корткикальной кости происходило неравномерно, наибольшая потеря - $17 \%$ отмечена при переходе от нормальным значение плотности губчатой кости к значению, соответствующему начальной остеопении. Дальнейшее сокращение плотности кортикальной кости составило -7\%, -5\%, -12\% от предыдущих значений. Наибольшее уменьшение ПИГ выявлено в группах с умеренной остеопенией - начальным остеопорозом и умеренным остеопорозом, в среднем составило -5\%, средний возраст в этих группах 60,7, 62,7 и 67,6 лет соответственно.

Таким образом, подтверждены известные данные о разной скорости возрастного и патологического снижения минеральной плотности губчатой и кортикальной кости. Определено «критическое» значение ПИГ в 81 мг/мл, последующее уменьшение которого свидетельствует о тенденции к патологическому снижению минеральной плотности. Кроме того, полученные результаты указывают на роль плотности кортикальной кости в общей минерализации тел позвонков.

Выводы: Для ранней диагностики остеопороза целесообразно раздельно исследовать минеральную плотность и однородность минерализации губчатой и кортикальной кости тел позвонков.

КЛЮЧЕВЫЕ СЛОВА: Остеопороз; минерализация; поясничные позвонки.

\section{HOMOGENEITY OF TRABECULAR AND CORTICAL BONE MINERALIZATION OF LUMBAR VERTEBRAE IN DIAGNOSIS OF OSTEOPOROSIS IN WOMEN}

(c) Volkov A.A., Beloselsky N.N., Pribytkov Yu.N., Pribytkov A.Yu.

Yaroslavl State Medical University, Yaroslavl 
ФГБОУ ВО «Ярославский государственный медицинский университет» Минздрава РФ, Ярославль

Цель: Изучить однородность минерализации кортикальной и губчатой костной ткани тел поясничных позвонков у женщин с разной величиной минеральной плотности кости и с разной степенью выраженности остеохондроза.

Материалы и методы: В качестве абсорбциометрии использовалась количественная компьютерная томография 2, 3, 4 поясничных позвонков, выполненная на компьютерном томограф Siemens с аналитической программой OSTEO, с толщиной срезов 1 см, проведенных через середины тел параллельно замыкательным пластинам. Однородности минерализации кортикальной и губчатой кости характеризовалась арифметической разницей между наиболее и наименее минерализованными участками костной ткани в зоне сканирования - плотностный интервал (ПИК и ПИГ). Оценка степени выраженности остеохондроза производилась по боковым рентгенограммам грудного и поясничного отделов позвоночного столба, выполненных по единым правилам. Минимальные горизонтальные остеофиты оценивались в 1 балл, остеофиты до 0,5 см в 2 балла, более 0,5 см в 3 балла; при наличии подобных изменения в 2-3 сегментах к оценке добавлялся 1 балл, в 4-5 сегментах - 2 балла, в 6 и более - 3 балла. Таким образом оценка выраженности и распространенности остеохондроза могла составить от 0 до 6 баллов. В исследовании принимало участие 127 условно здоровых женщин, у двух из которых рентгеновских проявлений остеохондроза зарегистрировано не было.

Результаты и обсуждение: в группе пациенток с минимальными проявлениями остеохондроза в 1-2 балла (n 30, средний возраст 62,1 лет) минеральной плотность губчатой кости составила 84,8 мг/мл, что согласно рекомендациям, ISCD соответствует выраженной остеопении, значение ПИГ в этой группе 78,4 мг/мл. В группах с умеренным остеохондрозом 3-4 балла (n 59, средний возраст 61,3 года) и выраженным остеохондрозом 5-6 баллов (n 36, средний возраст 63,7 года) плотность губчатой костной ткани балы больше на 15,8\% и так же соответствовала остеопении. ПИГ равномерно увеличился на 19,8\%. В свою очередь, увеличение плотности кортикальной кости и увеличение ПИК на 15\% отмечено только в группе с выраженными проявлениями остеохондроза. При распределении результатов в зависимости от величины минеральной плотности губчатой кости в группах 75-99 (n 40, средний возраст 62,7 года), 50-74 (n 27 средний возраст 67,6 года) и менее 50 мг/мл (n 14, средний возраст 69,5 лет) оценка степени выраженности и распространенности остеохондроза составила 3,7; 2,8 и 3,7 балла соответственно ПИГ равномерно уменьшался с 84,6 до 72,6 мг/мл. Плотность кортикальной кости неравномерно сокращалась с 252,1 до 203,1мг/мл, ПИК с 219,2 до 204,6 мг/мл. В группе со средней минеральной плотностью губчатой кости 100-124мг/мл (n 23, средний возраст 60,7 года) средняя оценка остеохондроза составила 3,2 балла, однако ПИГ был существенно выше 113,0 мг/мл (+38,5\%), плотность кортикальной кости и ПИК больше на 8\% и 5,1\% соответственно.

Таким образом, по мере прогрессии остеохондроза наибольшие преобразования претерпевает губчатая кость, она становилось более плотной, а ее минерализация более неоднородной. Аналогичные изменения кортикальной кости в меньшем объеме происходят при формирования выраженного остеохондроза. Патологическое снижение минеральной плотности может происходить на фоне умеренного остеохондроза, однако в этом случае минерализация губчатой кости становится менее однородной.

Выводы: При умеренном и выраженном остеохондрозе с целью ранней диагностики патологического снижения минеральной плотности целесообразно исследовать плотностные интервалы кортикальной и губчатой кости.

КЛЮЧЕВЫЕ СЛОВА: Остеохондроз; минерализация; поясничные позвонки.

\section{THE EFFECT OF OSTEOCHONDROSIS ON THE HOMOGENEITY OF MINERALIZATION IN CORTICAL AND TRABECULAR BONE LUMBAR VERTEBRAE IN WOMEN}

(c) Volkov A.A., Beloselsky N.N., Pribytkov Yu.N., Pribytkov A.Yu.

Yaroslavl State Medical University, Yaroslavl 
ФАКТОРЫ РИСКА ОСТЕОПОРОЗА И ОСТЕОПОРОТИЧЕСКИХ ПЕРЕЛОМОВ У МУЖЧИН С ИШЕМИЧЕСКОЙ БОЛЕЗНЬЮ СЕРДЦА

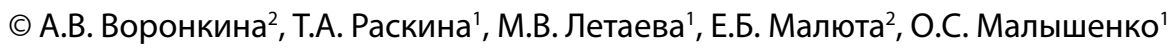

'ФГБОУ ВО «Кемеровский государственный медицинский университет» Минздрава России, Кемерово 2ГАУЗ КО «Областная клиническая больница скорой медицинской помощи им. М.А. Подгорбунского», Кемерово

Обоснование. Воздействие на общие факторы риска ишемической болезни сердца (ИБС) и остеопороза (ОП) позволит предупредить тяжелые осложнения обоих заболеваний. Целью настоящей работы явилось изучение факторов риска ОП и остеопоротических переломов у мужчин с ИБС.

Методы. Факторы риска ОП и остеопоротических переломов изучали у 102 мужчин в возрасте 51-75 лет (медиана возраста - 61 (55; 65) лет) с ИБС, верифицированной методом коронароангиографии. На основании результата двухэнергетической абсорбциометрии по Т-критерию поясничного отдела позвоночника и шейки бедра у всех пациентов оценивалась минеральная плотность кости (МПК) следующим образом: нормальная МПК (Т-критерий $\geq-1)$, остеопения (Т-критерий от -1 до -2,5) и ОП (Т-критерий $\leq-2,5)$. Для оценки риска основных остеопоротических переломов и перелома проксимального отдела бедра в ближайшие 10 лет использовали калькулятор FRAX.

Результаты. По индексу массы тела (ИМТ) больные распределились следующим образом: нормальный ИМТ отмечен

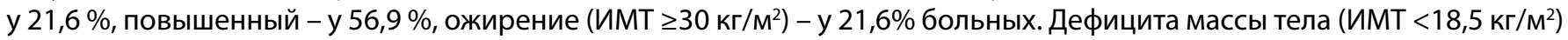
у пациентов не обнаружено. Из всех обследуемых больных 61,7 \% мужчин курили. Предшествующие переломы зафиксированы в 21,6\% случаев, анамнез перелома бедра у родителей - в 6,9\%. По состоянию МПК большинство пациентов (79,4 \%) имели остеопенический синдром (ОПС), в структуре которого остеопения встречалась у 47,0\% пациентов, а ОП - у 32,4\%. Высокий риск основных переломов по FRAX выявлен у 10,8\%, высокий риск переломов бедра у 3,9 \% больных. Корреляционный анализ показал достоверную отрицательную корреляцию между ИМТ и риском перелома бедра по шкале $\operatorname{FRAX}(r=0,23 ; p=0,020)$.

Выводы. Значительная распространенность ОПС демонстрирует высокую долю сочетания атеросклеротического процесса с низкой МПК среди мужчин с ИБС в возрасте 51-75 лет. Повышенный риск перелома бедра по шкале FRAX ассоциируется со снижением ИМТ у мужчин с ИБС старше 50 лет.

КЛЮЧЕВЫЕ СЛОВА: Остеопороз; перелом; ишемическая болезнь сердца.

\section{RISK FACTORS FOR OSTEOPOROSIS AND OSTEOPOROTIC FRACTURES IN MEN WITH CORONARY HEART DISEASE}

(c) Voronkina A.V. ${ }^{2}$, Raskina T.A. ${ }^{1}$, Letaeva M.V. ${ }^{1}$, Malyuta E.B. ${ }^{2}$, Malyshenko O.S. ${ }^{1}$

${ }^{1}$ Kemerovo State Medical University, Kemerovo

${ }^{2}$ Regional Clinical Hospital of Emergency Medical Care named after M.A. Podgorbunsky, Kemerovo 
РЕЗУЛЬТАТЫ АУДИТА СОСТОЯНИЯ ПРОБЛЕМЫ ОСТЕОПОРОЗА В РЕСПУБЛИКЕ КАЗАХСТАН

(с) Г.Х. Габдулина' , Б.Г. Исаева' , С.М. Исаева' ${ }^{1}$ О.М. Лесняк²

${ }^{1} \mathrm{HAO}$ «Казахский национальный медицинский университет им. С.Д. Асфендиярова», Алматы

${ }^{2}$ Северо-Западный государственный медицинский университет им. И.И. Мечникова, Санкт-Петербург

Цель Аудита. Изучение заболеваемости, распространенности остеопороза (ОП) и остеопорозных переломов, организации медицинской помощи пациентам с ОП в Республике Казахстан (РК).

Материалы и методы. Проанализированы публикации, посвященные вопросам распространенности ОП и остеопорозных переломов, факторов риска и последствий ОП и остеопорозных переломов, а также организации медицинской помощи больным в РК.

Результаты и обсуждение. На 1 января 2018 г. население Республики Казахстан составляло 18,403,860 чел, из них мужчин - 8 913,485, женщин - 9 490,375 чел. Численность населения старше 50 лет составляла 4 130,892 чел. (22,4\% от общего населения), старше 70 лет - 795,304 чел. (4,3\% от общего населения). По прогнозам при росте населения республики к 2035 г. на 13,4\% и к 2050 г. на 24,8\% доля населения старших возрастных групп будет увеличиваться значительно быстрее. Так, к 2035 г. население старше 50 лет вырастет на 35\%, старше 70 лет - на $95 \%$. К 2050 г. прирост составит 64\% 152\% соответственно.

ОП еще довольно редко регистрируется в официальной статистике. Однако изучение показателей официальной статистики по Казахстану за 2012-2016 гг. показало динамику прироста как общей заболеваемости на 39,5\% (1129 и 1575 соответственно), так и впервые установленного диагноза на 23,7\% (307 и 395 соответственно).

Проведенное в 2015-2017 гг. эпидемиологическое исследование остеопорозных переломов в г.Талдыкорган позволило впервые получить цифры инцидентности основных остеопорозных переломов и на этой основе построить модель FRAX, специфическую для Казахстана. Если экстраполировать эпидемиологические данные, полученные в Талдыкоргане, на всю территорию страны, то число переломов проксимального отдела бедренной кости в 2015 г. должно было составить 11690 (3815 у мужчин и 7875 у женщин 50 лет и старше). То есть, ежедневно в стране происходит 32 перелома проксимального отдела бедра.

К 2050 г. в Казахстане ожидается увеличение количества пациентов с переломом бедра на 140\%. Из-за выраженной зависимости частоты этих переломов от возраста наибольшие темпы прироста будут отмечаться у женщин (153\% у женщин против 112\% у мужчин). Вероятность до конца жизни перенести перелом проксимального отдела бедренной кости у жителей Казахстана в возрасте 50 лет и старше составляет 7,7\% у женщин и 4,3\% у мужчин.

К 2050 г. прогнозируется практически двукратный рост числа пациентов с переломами дистального отдела предплечья и проксимального отдела плечевой кости.

Распространенность компрессионных переломов позвонков в Республике Казахстан не изучена.

Исследование, проведенное в г. Талдыкорган, показало, что оказание оперативной травматолого-ортопедической помощи при переломах проксимального отдела бедренной кости в республике зачастую не соответствует международным стандартам. Так, уровень госпитализации пациентов с переломом этой локализации составил только 76\%. Причем с увеличением возраста пациента эта цифра снижалась. Среди госпитализированных в стационар хирургическое лечение получили лишь 77\% больных: операция эндопротезирования тазобедренного сустава произведена в 33\%, остеосинтез - в 67\% случаев. Специализированных реабилитационных отделений для пациентов, перенесших перелом бедра, нет. В целом, 41\% пациентов с переломом проксимального отдела бедренной кости не получили специализированной медицинской помощи либо велись консервативно.

Продолжительность стационарного лечения пациента с переломом бедра составляет 9,6 койко-дня. Средняя стоимость операции тотального эндопротезирования тазобедренного сустава - 898196 тенге (2089 евро), остеосинтеза интрамедуллярным имплантом - 336697 тенге (783 евро). Стоимость реабилитации составляет 124242 тенге (289 евро). Реабилитационные мероприятия получает в среднем 28\% пациентов, выписанных из травматологического стационара после перелома проксимального отдела бедренной кости.

B PK для диагностики остеопороза используются как двухэнергетическая рентгеновская абсорбциометрия (DXA), так и количественная ультрасонометрия. В настоящее время в республике имеется 15 рентгеновских аксиальных денситометров (DXA), из них в государственной системе здравоохранения работают 7, в частных медицинских учреждениях - 8 денситометров.

Обеспеченность рентгеновскими денситометрами составляет 0,83 на 1 млн. населения от 0 лет и старше. Стоимость исследования в среднем двух зон (поясничный отдел позвоночника и проксимальный отдел бедра) составляет 16-22 евро (7000-9500 тенге).

Показатель плотности рентгеновских денситометров на 1000000 человек составил 0,7, что в 2,5 раза выше, чем в 2010 г. 
В РК зарегистрированы все основные лекарственные препараты для терапии остеопороза (алендронат, ризедронат, ибандронат, золедроновая кислота, деносумаб, терипаратид, альфакальцидол). Существуют также разнообразные формы менопаузальной заместительной терапии и препаратов кальция и витамина D.

Лечение остеопороза доступно не всем пациентам, которые приобретают лекарства самостоятельно.

Выводы. ОП представляет собой важную проблему здравоохранения РК. С учетом прогнозов по увеличению доли пожилых людей в ближайшие десятилетия будет отмечаться рост числа переломов, ассоциированных с этим заболеванием. Уже сейчас в Республике Казахстан необходимо разработать Национальный регистр остеопорозных переломов проксимального отдела бедра и предоставить в Республиканский центр по развитию здравоохранения Республики Казахстан для внедрения в стране. Для совершенствования знаний медицинских работников по вопросам диагностики и профилактики остеопороза необходимо создание центров по остеопорозу в областных центрах. Важно дальнейшее внедрение в систему здравоохранения служб профилактики повторных переломов. В Республике Казахстан необходимо проведение исследований по изучению фармакоэкономической эффективности лечения остеопороза, приверженности пациентов к лечению остеотропными препаратами.

КЛЮЧЕВЫЕ СЛОВА: Остеопороз; здравоохранение; эпидемиология.

\section{OSTEOPOROSIS IN KAZAKHSTAN REPUBLIC: RESULTS OF THE AUDIT}

(c) Gabdulina G.H. ${ }^{1}$, Isaeva B.G. ${ }^{1}$, Isaeva S.M. ${ }^{1}$, Lesnyak O.M. ${ }^{2}$

${ }^{1}$ Kazakh National Medical University named after S.D. Asfendiyarov, Almaty

${ }^{2}$ North-Western State Medical University named after I.I. Mechnikov, Saint Petersburg 


\author{
() О.А. Ганерт ${ }^{1}$, О.Б. Ершова ${ }^{2,3}$, К.Ю. Белова ${ }^{2,3}$, М.А. Романова ${ }^{2,3}$
}

1ГАУЗ Ярославской области «Клиническая больница №9», Ярославль

${ }^{2}$ ФГБОУ ВО «Ярославский государственный медицинский университет» Минздрава России, Ярославль

${ }^{3}$ ГАУЗ Ярославской области «Клиническая больница скорой медицинской помощи имени Н.В. Соловьева», Ярославль

Актуальность. Переломы проксимального отдела бедренной кости относятся к наиболее тяжелым осложнениям остеопороза. Летальность при этом переломе достигает 16,5-27,3\% через год после его получения (Кates S. L. et al., 2010; Kang H. Y. et al., 2010) и 34,5-39,0\% через два года (Ngobeni R. S. et al., 2010; Hu F. et al., 2012).

Цель: определение факторов, влияющие на повышение вероятности развития летального исхода у пациентов в возрасте 50 лет и старше, получивших низкоэнергетический перелом проксимального отдела бедренной кости.

Материалы и методы. Проведено сплошное проспективное двухгодичное наблюдательноео исследование, включившее всех пациентов - жителей г. Ярославля, с низкоэнергетическими переломами проксимального отдела бедренной кости. Было выявлено 446 человек, из них 112 мужчин (25,11\%) и 334 женщины (74,89\%), средний воз-

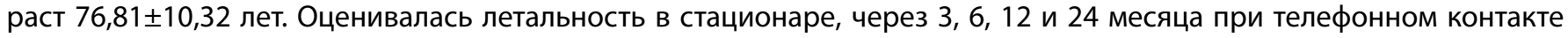
с больным или его родственниками, в ряде случаев (при невозможности связи с пациентом) - через поликлинику по месту жительства. Статистический анализ выполнен с помощью пакета прикладных программ StatSoft, Inc. (2014) STATISTICA (data analysis software system), version 12, MedCalc Statistical Software version 15.8 (MedCalc Software bvba, Ostend, Belgium; 2015). Оценка взаимосвязи различных факторов с уровнем летальности проводилась с вычислением коэффициента ранговой корреляции т-Kendall и $\gamma$ ).

Результаты. В ходе проведенного исследования общая летальность в стационаре составила 9,66\%, через три месяца - 21,75\%, через шесть месяцев - 26,46\%, 12 месяцев - 29,82\%, 24 месяца - 34,53\%.

Проведенный корреляционный анализ показал достоверную связь летальности в стационаре с возрастом и наличием инвалидности во всех периодах наблюдения. Из других факторов, связанных с летальностью, были отмечены: наличие шока при поступлении, более высокие показатели шкалы ASA, развитие психоза в стационаре, наличие тромботических осложнений (тромбоз по УзДГ, применение лечебных доз антикоагулянтов, развитие осложнений антикоагулянтной терапии, выполнение операций на сосудах). Кроме этого, связь с частотой развития летального исхода отмечена при хронических заболеваниях, имевшихся у больного до перелома: сахарный диабет и прием сахароснижающих препаратов, ишемическая болезнь сердца, прием мочегонных препаратов, дисциркуляторная энцефалопатия, острое нарушение мозгового кровообращение в анамнезе и наличие его последствий, хроническая почечная недостаточность, заболевания крови, оперированный желудок. Помимо этого, через 12 и 24 месяца летальность оказалась связана с показателями шкалы MMSE при выявлении у больного выраженного снижения когнитивной функции, через 6, 12, 24 месяца - с частотой падений, наличием нарушений зрения, через 12 месяцев с паркинсонизмом. Из показателей физической активности пациентов на всех этапах наблюдения установлена связь с длительностью ходьбы до перелома и степенью восстановления подвижности за время госпитализации и после выписки из стационара.

Выводы. Таким образом летальность пациентов после перелома оказалась напрямую связан с тяжестью их состояния при поступлении и развитием осложнений за время госпитализации (делирий, тромбоз глубоких вен ног и его лечение), с наличием тяжелой сопутствующей патологии на момент получения перелома, в первую очередь это сердечно-сосудистые заболевания и снижение когнитивной функции. Кроме того, на повышение риска летального исхода влиял уровень физической активности пациента до и после перелома и целый ряд факторов, повышающих риск падений (включая нарушение зрения, паркинсонизм, повторные падения).

КЛЮЧЕВЫЕ СЛОВА: Перелом; летальность; остеопороз.

\title{
FACTORS ASSOCIATED WITH MORTALITY IN ELDER GROUPS OF PATIENTS WITH PROXIMAL FEMORAL FRACTURES
}

(c) Ganert O.A. ${ }^{1}$, Ershova O.B. ${ }^{2,3}$, Belova K.Yu. ${ }^{2,3}$, Romanova M.A. ${ }^{2,3}$

${ }^{1}$ Clinical hospital No. 9, Yaroslavl

${ }^{2}$ Yaroslavl State Medical University, Yaroslavl

${ }^{3}$ Yaroslavl Emergency Medical Care Hospital named after N.V. Solovyov, Yaroslavl 
ОРГАНИЗАЦИЯ ПОМОЩИ ПАЦИЕНТАМ С ОСТЕОПОРОЗОМ В РЕСПУБЛИКЕ БАШКОРТОСТАН

() И.Р. Гафаров ${ }^{1,4}$, Ф.С. Мусина ${ }^{3,4}$, Р.З. Нурлыгаянов ${ }^{2}$

'ГБУЗ РКБ им Г.Г. Куватова, Уфа

2ГБУЗ ГКБ № 21, Уфа

${ }^{3}$ ФГБОУ ВО «Башкирский государственный медицинский университет», Уфа

${ }^{4} \mathrm{AHO} \mathrm{ДПО} \mathrm{«Институт} \mathrm{профессионального} \mathrm{развития} \mathrm{в} \mathrm{сфере} \mathrm{здравоохранения} \mathrm{и} \mathrm{социального} \mathrm{развития»,} \mathrm{Уфа}$

Ежегодно увеличивается количество пациентов, которые обращаются с остеопорозом в медицинские организации. Внедрение Клинических рекомендаций по остеопорозу внесло ясность для дальнейшего проведения эффективных лечебно-диагностических и профилактических работ на этапе первичного звена здравоохранения. Однако, все еще сохраняется недостаточное понимание проблемы остеопороза, отсутствуют регистр по остеопорозу в единой базе медицинских организаций, стандарты ведения пациентов, что затрудняет возможность полностью раскрыть задачи и перспективы службы.

Цель: формирование регистра пациентов с остеопорозом для сбора и анализа унифицированных данных в системе практического здравоохранения, выявление распространенности заболевания и возможность оказания адекватной медицинской помощи

Материалы и методы: За основу медицинского программного обеспечения была выбрана «Медико-информационно аналитическая система «МИАЦ»», в которой формируется регистр по регистрации пациентов с остеопорозом и переломом проксимального отдела бедренной кости на фоне низкоэнергетической травмы у населения Республики Башкортостан. В первичном звене здравоохранения с предварительно установленным диагнозом «остеопороз» вводятся данные пациента в систему «МИАЦ», которые формируют: эндокринолог, терапевт, хирург, травматолог и ортопед. Все данные о пациентах передаются в Республиканский Центр профилактики и лечения остеопороза для статистического анализа с последующим методическим руководством с медицинскими организациями. Сохраненные данные о пациенте с остеопорозом в системе «МИАЦ» отображается на приеме у врача первичного звена здравоохранения с обратной связью с координатором Центра остеопороза Республики Башкортостан.

Результаты: В результате внедрения регистра по остеопорозу на этапе старта были получены достоверные данные о пациентах в рутинной клинической практике на территории Республики Башкортостан, выстроена маршрутизация пациентов, что позволило проводить оценку качества назначенной терапии, маршрутизацию пациентов, а также расчеты на оказание медицинских услуг в системе ОМС. В перспективе необходимо осуществлять мониторинг и контроль пациентов с остеопорозом, определить потребность в специализированной и высокотехнологичной медицинской помощи пациентов с переломом проксимального отдела бедренной кости. Регистр по остеопорозу позволит проводить эпидемиологические исследования, которые могут быть основой для планирования лечебно-диагностических мероприятий, лекарственного обеспечения, а также медико-экономической оценки заболеваемости в регионе.

Выводы: Регистр позволит оценить реальный уровень распространенности остеопороза, проводить лечебнопрофилактическую работу, улучшить исходы заболевания и повысить качество жизни пациентов с остеопорозом.

КЛЮЧЕВЫЕ СЛОВА: Остеопороз; регистр; здравоохранение.

\section{ORGANIZATION OF PATIENT CARE FOR PATIENTS WITH OSTEOPOROSIS IN BASHKORTOSTAN REPUBLIC}

(c) Gafarov I.R. ${ }^{1,4}$, Musina F.S. ${ }^{3,4}$, Nurlygayanov R.Z. ${ }^{2}$

${ }^{1}$ Republican Hospital named after G.G. Kuvatov, Ufa

${ }^{2}$ City Clinical Hospital No. 21, Ufa

${ }^{3}$ Bashkir State Medical University, Ufa

${ }^{4}$ Institute of Professional Development in the Field of Health and Social Development, Ufa 
1ГБУЗ РКБ им Г.Г. Куватова, Уфа

2ГБУЗ ГКБ № 21, Уфа

${ }^{3}$ ФГБОУ ВО «Башкирский государственный медицинский университет», Уфа

${ }^{4} \mathrm{AHO} \mathrm{ДПО} \mathrm{«Институт} \mathrm{профессионального} \mathrm{развития} \mathrm{в} \mathrm{сфере} \mathrm{здравоохранения} \mathrm{и} \mathrm{социального} \mathrm{развития»,} \mathrm{Уфа}$

Последние десятилетия фармакотерапия остеопороза значительно претерпела изменения, накопился большой опыт кураций пациентов с остеопорозом различной степени тяжести, особенно у пациентов с коморбидной патологией, стероидным остеопорозом или на фоне низкоэнергетического перелома проксимального отдела бедренной кости, компрессионного перелома тел позвонков и перелома типа Колиса.

Важную роль в терапии остеопороза играет приверженность пациента и практический опыт врача, занимающегося остеопорозом, которому необходимо знать новые подходы диагностики, терапии остеопороза и своевременно проводить профилактику осложнении остеопороза. Известно, что фармакокоррекция остеопороза прежде всего направлена на коррекцию параметров минерального обмена и для снижения риска низкоэнергетических переломов, поэтому бисфосфонаты рекомендуются в качестве первой линии лечения остеопороза, однако, незначительная доля пациентов недостаточно отвечает на проводимую фармакокоррекцию из-за внешних или внутренних причин, что и стало предметом ведения пациентов с установленным диагнозом тяжелый остеопороз.

Цель исследования: оценить современные возможности фармакотерапии остеопороза с учетом ступенчатого подхода и наиболее эффективной и безопасной преемственности.

Материалы и методы. В регистре Республиканского центра профилактики и лечения остеопороза за 2019 год наблюдаются более 983 пациента с остеопорозом, значительную долю составляют лица старше 60 лет, в $78 \%$ составляет женский пол и в 12\% остеопорозом страдают мужчины. В соответствии классификации РАОП на первичный остеопороз приходится 84\%, другие формы - 16\%. По данным регистра Центра остеопороза Республики Башкортостан тяжелой формой остеопороза страдают 32 пациента, которые прошли курс антирезорбтивной терапии по месту жительства согласно рекомендациям Центра остеопороза и недостаточно ответили на проводимую терапию.

Были проведены клинико-лучевые методы обследования пациентов, согласно клиническим рекомендациям РАОП. Доступность и объем медицинской помощи в регионе по данной патологии полностью обеспечивается. На основе полученных данных был произведен статистический анализ регистра для оценки эффективности проводимой терапии.

Результаты и обсуждения. В результаты проведенного анализа лечения пациентов с тяжелой формой остеопороза у 32 пациентов выявлено, что у 8 пациентов в анамнезе имело место наличия стероидного остеопороза, в 13 случаях подтверждалась патология желудочно-кишечного тракта и у 11 пациентов был зарегистрирован недостаточный ответ на проведенную антирезорбтивную терапию, которая связана была с синильной формой остеопороза. Параметры качества жизни у пациентов данных групп не доходили до средних статистических цифр в возрастных диапазонах по России, а результаты минеральной плотности кости по данным остеоденситометрии по центральным сегментам значимо снижались. Анализ двух параметров выявил положительную корреляцию. По показаниям на основании этих данных 23 пациентам было предложено костно-анаболическая терапия на два года согласно клиническим рекомендациям РАОП. На фоне проводимой терапии на 6-м месяце параметры качества жизни достигли средних значений по возрасту у 17 пациентов, положительный ответ на проводимую фармакотерапию через 12 месяцев регистрирован у 20 пациентов, в двух случаях динамика ответа на проводимую терапию была недостаточной в связи с приемом кардиопротекторов и клиническими проявлениями в виде одышки и боли в области грудной клетки, а также повышения лабораторных показателей Са ${ }^{2+}$ что потребовало коррекции этого показателя в связи воздействием препарата на кальций-фосфорный обмен.

Заключение. Таким образом, при тяжелой форме остеопороза оправдано назначение терипаратида после применения бисфосфонатов, особенно при неэффективности предшествующей терапии остеопороза.

КЛЮЧЕВЫЕ СЛОВА: Тяжелый остеопороз; терапия; регистр.

\section{MAINTAINING THE MOST EFFECTIVE AND SAFE CONTINUITY OF THERAPY FOR PATIENTS WITH SEVERE OSTEOPOROSIS}

(c) Gafarov I.R. ${ }^{1,4}$, Musina F.S. ${ }^{3,4}$, Nurlygayanov R.Z. ${ }^{2}$

${ }^{1}$ Republican Hospital named after G.G. Kuvatov, Ufa

${ }^{2}$ City Clinical Hospital No. 21, Ufa

${ }^{3}$ Bashkir State Medical University, Ufa

${ }^{4}$ Institute of Professional Development in the Field of Health and Social Development, Ufa 
ТЯЖЕЛЫЙ ОСТЕОПОРОЗ У МУЖЧИН В РОССИЙСКОЙ ФЕДЕРАЦИИ (ИССЛЕДОВАНИЕ ОСТЕО-РФ)

() Е.Н. Гладкова ${ }^{1,2}$, О.М. Лесняк ${ }^{1,2}$, Н.О. Александров ${ }^{3}$, Н.В. Безлюдная ${ }^{4}$, Ж.Е. Белая ${ }^{5}$, Т.А. Гребенникова ${ }^{5}$, А.В. Древаль $^{6}$, О.Б. Ершова7, К.Ю. Белова7, С.О. Мазуренко ${ }^{8}$, И.В. Крюкова ${ }^{6}$, О.В. Добровольская ${ }^{9}$ Д.В. Приймак ${ }^{3}$, Л.Я. Рожинская ${ }^{5}$, Р.Р. Самигуллина' ${ }^{1}$ Н.В. Торопцова ${ }^{9}$

'ФГБОУ ВО «Северо-Западный государственный медицинский университет имени И.И. Мечникова» Минздрава России, Санкт-Петербург

${ }^{2}$ СПб ГБУЗ «Клиническая ревматологическая больница № 25», Санкт-Петербург

${ }^{3} \mathrm{OOO}$ «Лилли Фарма», Москва

${ }^{4}$ ФГБУ «Федеральный центр травматологии, ортопедии и эндопротезирования» Минздрава России, Чебоксары

5ФГБУ «Национальный медицинский исследовательский центр эндокринологии» Минздрава России, Москва

бГБУЗ МО «МОНИКИ им. М.Ф. Владимирского», Москва

${ }^{7}$ ФГБОУ ВО «Ярославский государственный медицинский университет» Минздрава России, Ярославль

${ }^{8}$ ФГБОУ ВО «Санкт-Петербургский государственный университет», Санкт-Петербург

${ }^{9}$ ФГБНУ «НИИ ревматологии им. В.А. Насоновой», Москва

Популяционные исследования, проведенные в России, показали, что 33,8\% женщин и 26,9\% мужчин в возрасте 50 лет и старше имеют остеопороз (ОП). При этом, несмотря на тот факт, что ОП чаще встречается среди женщин, каждый третий новый перелом переносят мужчины. Зачастую ОП у мужчин не диагностируется и не лечится, даже при наличии переломов и высоком риске новых переломов. Наряду с этим для мужчин характерны более тяжелые последствия переломов. В России ранее не изучался вопрос тяжелого ОП у мужчин, что и обусловило актуальность проведенного исследования.

Цель исследования. Проанализировать клинические характеристики и подходы к лекарственной терапии тяжелого ОП у мужчин в специализированных медицинских организациях Российской Федерации.

Материалы и методы. Данное исследование выполнено в рамках многоцентровой программы «Ретроспективное социально-экономическое исследование статуса лечения пациентов с тяжёлым остеопорозом в Российской Федерации» (ОСТЕО-РФ), организованной Российской ассоциацией по остеопорозу и Лигой содействия клиническим исследованиям. В семи крупных российских центрах, специализирующихся на оказании помощи пациентам с ОП, проводился ретроспективный анализ первичной документации пациентов с тяжелым ОП, обратившихся на консультацию в период с 01 января 2014 г. по 31 декабря 2015 г. Пациенты включались в исследование при наличии тяжелого ОП при наличии не менее двух описанных в первичной медицинской документации визитов к врачу исследовательского центра и наблюдения в центре не менее 1 года. В анализ включались клинико-демографические данные, результаты исследования МПК при проведении двуэнергетической рентгеновской абсорбциометрии (DXA денситометрии) и данные по перенесенным переломам, в том числе, в процессе наблюдения за пациентом.

Результаты и обсуждение. Демографическая, социальная и клиническая характеристика пациентов

В исследование включено 1000 пациентов: 955 женщин и 45 мужчин в возрасте от 35 до 95 лет, медиана возраста составила 69,0 (62,0-76,0) лет. Сроки наблюдения пациентов в центрах колебались от 12 до 168 мес. с кратностью наблюдения от 2 до 7 визитов. Общая длительность наблюдения пациентов в центрах составила 2864,5 человеко-лет. Нами было проведено сравнение группы мужчин и женщин с тяжелым ОП. Мужчины были моложе женщин в среднем на 10 лет: медиана возраста соответственно 59 (50,0-69,0) против $69(63,0-76,0)$, p=0,000003.

На момент установления диагноза более трети женщин (36\%) и 40\% мужчин уже были официально признаны инвалидами по заболеванию. Несмотря на то, что исходно достоверных различий в доле лиц, признанных инвалидами, не отмечалось, в динамике увеличение доли лиц, имеющих группу инвалидности, среди мужчин достигала 57,5\% и была достоверно выше, чем среди женщин, $\mathrm{p}=0,03$.

В большинстве случаев (95,6\%) ОП у мужчин диагностирован после перенесенного низкоэнергетического перелома. Диагноз первичного ОП был установлен у 37 мужчин, вторичного - у 8 чел. (17,0\%), у женщин частота выявления вторичного ОП составила 13,9\%, р>0,05. Наиболее частой причиной вторичного ОП у мужчин был прием глюкокортикоидов: в структуре вторичного ОП его доля составляла 75,0\%.

Минеральная плотность костной ткани (МПКТ)

ОП по денситометрии с наибольшей частотой определялся в поясничном отделе позвоночника (78,6\%). За период наблюдения доля лиц с низкой МПК хотя бы в одном из отделов скелета снижалась, однако к концу наблюдения она продолжала оставаться высокой, составляя 65,4\%.

\section{Характеристика переломов}

В анализ были включены следующие типы переломов: переломы позвонков, проксимального отдела бедренной кости (ПОБ), дистального отдела предплечья, верхнего конца плечевой кости, дистального отдела голени, ребер. Переломы костей стоп и кистей, костей таза и др. типы переломов, произошедшие у пациентов при низком уровне 
травмы, были объединены в группу «другие локализации». Наиболее частой локализацией невертебральных переломов у мужчин с тяжелым ОП был перелом ПОБ (у 15\% мужчин) и переломы «других локализаций» (15\%). Наибольший прирост новых случаев переломов наблюдался для перелома проксимального отдела бедренной кости, который составил $28,8 \%$.

На момент начала наблюдения в центре частота переломов позвонков была выше у мужчин (80,9\%) по сравнению с женщинами (57,9\%), p=0,0018. Мужчины на момент диагностики первых переломов позвонков были на 8,3 года мо-

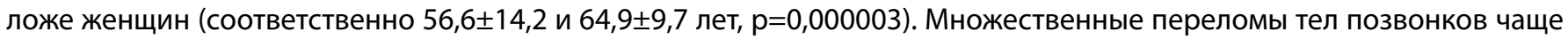
встречались у мужчин (84,6\% -2 и более перелома), при этом три и более переломов позвонков имели 61,5\% мужчин. Аналогичные показатели у женщин составили $68,2 \%$ и $38,2 \%$ соответственно, $\mathrm{p}<0,05$.

В целом, в течение наблюдения в центрах количество переломов позвонков выросло на 24,8\% и к концу наблюдения на одного пациента составило 2,68 ( $\mathrm{p=0,002}$ по сравнению с первым визитом в центры), у женщин - 2,6, у мужчин 3,6 переломов соответственно ( $p=0,000004)$.

Выводы. Проведенное исследование показало, что остеопороз у мужчин остается недооцененной проблемой, при этом клинические проявления ОП у мужчин более тяжелые по сравнению с женщинами. Обращает на себя внимание и тот факт, что доля пациентов с вторичным остеопорозом не отличается от таковой у женщин, что говорит о недостаточном обследовании пациента даже на уровне специализированный медицинский организаций. Тяжелые клинические проявления ОП у мужчин развиваются раньше и сопровождаются более выраженным ограничением трудоспособности. Полученные данные демонстрируют потребность в разработке алгоритмов обследования мужчин с остеопорозом, обязательного назначения патогенетической терапии ОП, ее длительного применения, подбора лекарственных препаратов, имеющих доказанную эффективность для снижения риска переломов.

КЛЮЧЕВЫЕ СЛОВА: Тяжелый остеопороз; остеопороз у мужчин; переломы.

\section{SEVERE OSTEOPOROSIS IN MEN IN RUSSIAN FEDERATION (OSTEO-RF STUDY)}

( ) Gladkova E.N. ${ }^{1,2}$, Lesnyak O.M. ${ }^{1,2}$, Alexandrov N.O. ${ }^{3}$, Bezlyudnaya N.V. ${ }^{4}$, Belaya Zh.E. ${ }^{5}$, Grebennikova T.A. ${ }^{5}$, Dreval A.V. ${ }^{6}$, Ershova O.B. ${ }^{7}$, Belova K.Yu. ${ }^{7}$, Mazurenko S.O. ${ }^{8}$, Kryukova I.V. ${ }^{6}$, Dobrovolskaya O.V. ${ }^{9}$, Priymak D.V. ${ }^{3}$, Rozhinskaya L.Ya. ${ }^{5}$, Samigullina R.R. ${ }^{1}$, Toroptsova N.V. ${ }^{9}$

${ }^{1}$ North-Western State Medical University named after I.I. Mechnikov, Saint Petersburg

${ }^{2}$ Clinical rheumatology hospital No. 25, Saint Petersburg

${ }^{3}$ LLC «Lilly Pharma», Moscow

${ }^{4}$ Federal Center of Traumatology, Orthopedics and Endoprosthetics, Cheboksary

${ }^{5}$ Endocrinology Research Centre, Moscow

${ }^{6}$ Moscows regional research clinical institute n.a. M.F. Vladimirskiy, Moscow

${ }^{7}$ Yaroslavl State Medical University, Yaroslavl

${ }^{8}$ Saint Petersburg State University, Saint Petersburg

${ }^{9}$ Research Institute of Rheumatology named after V.A. Nasonova, Moscow 

ПЕРЕЛОМОВ С ИСПОЛЬЗОВАНИЕМ КАЛЬКУЛЯТОРА FRАХ

( Е.Н. Гладкова ${ }^{1,2}$, О.М. Лесняк ${ }^{1,2}$, И.В. Забежинская ${ }^{3}$, Ю.М. Илюшин ${ }^{4}$, М.Ю. Колбин ${ }^{3}$, В.Г. Танаев ${ }^{3}$, М.И. Бондаренко ${ }^{3}$

'ФГБОУ ВО «Северо-Западный государственный медицинский университет имени И.И. Мечникова» Минздрава

России, Санкт-Петербург

${ }^{2}$ СПб ГБУЗ «Клиническая ревматологическая больница № 25», Санкт-Петербург

${ }^{3}$ СПб ГБУЗ «Городская поликлиника № 25 Невского района», Санкт-Петербург

${ }^{4}$ Администрация Невского района Санкт-Петербурга, Санкт-Петербург

В России остеопорозом болеют каждая третья женщина и каждый четвертый мужчина в возрасте старше 50 лет. Переломы, вызванные остеопорозом, сопровождаются тяжелыми последствиями в виде снижения качества жизни, больших финансовых затрат, а зачастую и смертности. В связи с этим выявление пациентов с высоким риском переломов является приоритетной задачей здравоохранения.

Целью данного исследования было оценить эффективность скрининга на выявление пациентов с высоким риском переломов с использованием калькулятора FRAX на примере городской поликлиники Санкт-Петербурга.

Материал и методы: Данное исследование выполнено в рамках совместного проекта Российской ассоциации по остеопорозу, администрации Невского района Санкт-Петербурга и Законодательного Собрания СанктПетербурга. Реализация проекта осуществлялась с 2017 по 2019 годы. В рамках исследования врачи первичного звена городской поликлиники №25 Невского района Санкт-Петербурга (ГП№25) были обучены выявлению пациентов с высоким риском переломов с использованием калькулятора FRAX. Для реализации цели исследования подсчет риска переломов осуществлялся у всех пациентов, обратившихся на прием к врачу по любому поводу, в возрасте 50 лет и старше. После проведения подсчёта сведения о риске переломов фиксировались в амбулаторной карте пациента и медицинской информационной системе для последующего анализа. Пациенты высокого риска (превышающего порог терапевтического вмешательства) были направлены на консультацию врача-ревматолога районного центра остеопороза. В рамках данного проекта ГП №25 Невского района была обеспечена золедроновой кислотой для лечения пациентов с тяжелыми проявлениями остеопороза (перенесших перелом проксимального отдела бедра, переломы тел позвонков или множественные переломы костей периферического скелета) или наличием противопоказаний для терапии пероральными бисфосфонатами. По итогам работы поликлиники была проведена оценка количества пациентов с высоким риском переломов, выявленных врачами первичного звена, а также показатели общей и первичной заболеваемости остепорозом по ГП №25 Невского района.

Результаты и обсуждение: Выявление пациентов с высоким риском переломов путем скрининга населения врачами первичного звена было начато в 2018 году. По состоянию на 01.01 .2020 года охвачено скринингом 11157 человек, из них определен риск, превышающий порог терапевтического вмешательства, у 1138 человек. Доля пациентов, охваченных скринингом за 2018-2019 годы реализации проекта, составила 1/3 от всех подлежащих скринингу. Пациенты с высоким риском переломов были консультированы в районном центре остеопороза, с последующим назначением терапии. Пациенты, которым было рекомендовано лечение пероральными бисфосфонатами, направлялись под наблюдение врачей-терапевтов. С 2017 года в дневном стационаре по направлению районного центра остеопороза было проведено 766 инфузий золедроновой кислоты (95 в 2017 году, 229 в 2018 году и 442 в 2019).

В результате проводимой работы по выявлению пациентов высокого риска отмечалось изменение статистических показателей по городской поликлинике №25 Невского района Санкт-Петербурга. Показатель общей заболеваемости остеопорозом у населения, прикрепленного к ГП №25, до начала исследования составлял 703,4 на 100 тыс. населения, первичной заболеваемости - 28,3 на 100 тыс. При этом аналогичные показатели в Санкт-Петербурге за тот же период (2017 год) составили 283 и 29,4 на 100 тыс. населения соответственно, в РФ - 135 и 20 на 100 тысяч. За первый год работы по выявлению пациентов с высоким риском переломов первичная заболеваемость остеопорозом у населения, прикрепленного к ГП№25, выросла в 11,8 раз и составила 333,1 на 100 тыс. населения. Эта же тенденция сохранялась и в 2019 году, в результате внедрения мероприятий по осуществлению скрининга пациентов с использованием алгоритма FRAX показатель общей заболеваемости остеопорозом достиг 1456,9 на 100 тыс. населения, а первичная заболеваемость - 565,6 на 100 тыс.

Выводы: Таким образом, меры по выявлению пациентов высокого риска позволяют идентифицировать и лечить целевую группу пациентов, предотвращая тяжелые проявления остеопороза, требующие дорогостоящего лечения, а также могут оказывать влияние на снижение показателей смертности в популяции лиц 50 лет и старше.

КЛЮЧЕВЫЕ СЛОВА: Остеопороз; риск переломов; FRAX. 
EFFECTIVENESS OF SCREENING OF PATIENTS AT HIGH RISK OF FRACTURES USING FRAX

\section{CALCULATOR}

(C) Gladkova E.N. ${ }^{1,2}$, Lesnyak O.M. ${ }^{1,2}$, Zabezhinskaya I.V. ${ }^{3}$, Ilyushin Yu.M. ${ }^{4}$, Kolbin M.Yu. ${ }^{3}$, Tanaev V.G. ${ }^{3}$, Bondarenko M.I. ${ }^{3}$

${ }^{1}$ North-Western State Medical University named after I.I. Mechnikov, Saint Petersburg

${ }^{2}$ Clinical rheumatology hospital No. 25, Saint Petersburg

${ }^{3}$ Nevsky District Polyclinic No. 25, Saint Petersburg

${ }^{4}$ Administration of the Nevsky District, Saint Petersburg 
() Е.Н. Гладкова ${ }^{1,2}$, О.М. Лесняк ${ }^{1,2}$, О.Б. Ершова ${ }^{3}$, И.А. Скрипникова ${ }^{4}$, О.Н. Аношенкова ${ }^{5,6}$, Ю.Р. Ахвердян ${ }^{7}$, К.Ю. Белова ${ }^{3}$, И.Б. Белоусова ${ }^{8}$, Е.В. Большакова ${ }^{3}$, А.В. Древаль ${ }^{9}$, Б.В. Заводовский, М.В. Ильин ${ }^{3}$, О.В. Косматова ${ }^{4}$, И.В. Крюкова9 А.Ф. Ахатов ${ }^{10}$, А.А. Латфуллин ${ }^{10}$, Е.А. Лейкаускене ${ }^{11}$, Н.В. Леонова ${ }^{11}$, Ю.В. Максимова ${ }^{5}$, М.А. Мягкова ${ }^{4}$ В.Е. Новиков ${ }^{4}$, А.Р. Нуриев ${ }^{10}$, Е.Ю. Полякова9 ${ }^{9}$ Ю.В. Полякова ${ }^{7}$, Л. Е. Сивордова7, В.А. Тавлуев ${ }^{5}$, Л.Р. Шавалиева ${ }^{10}$

'ФГБОУ ВО «Северо-Западный государственный медицинский университет имени И.И. Мечникова» Минздрава России, Санкт-Петербург

${ }^{2}$ СПб ГБУЗ «Клиническая ревматологическая больница № 25», Санкт-Петербург

${ }^{3}$ ФГБОУ ВО «Ярославский государственный медицинский университет» Минздрава России, Ярославль

${ }^{4}$ ФГБУ «Национальный медицинский центр профилактической медицины» Минздрава России, Москва

${ }^{5} \mathrm{OOO}$ «Макс и К» Медицинский центр «Максимум здоровья», Томск

${ }^{6}$ ФГБОУ ВО «Сибирский государственный медицинский университет» Минздрава России, Томск

7ФГБНУ «Научно-исследовательский институт клинической и экспериментальной ревматологии

им. А.Б. Зборовского», Волгоград

${ }^{8}$ Клиническая больница № 101 филиал Федерального государственного бюджетного учреждения «Северо-

Кавказский федеральный научно-клинический центр Федерального медико-биологического агентства», Лермонтов ${ }^{9}$ ГБУЗ МО «МОНИКИ им. М.Ф. Владимирского», Москва

${ }^{10} \mathrm{OOО}$ «БАРСМЕД», Казань

${ }^{11}$ ООО Медицинская многопрофильная клиника «Антуриум», Барнаул

В России остеопорозом (ОП) болеют каждая третья женщина и каждый четвертый мужчина в возрасте старше 50 лет. В связи с этим выявление пациентов с высоким риском переломов является приоритетной задачей здравоохранения. Разработанный ВО3 и используемый в мировой практике с 2008 г. алгоритм расчета 10-летнего абсолютного риска остеопорозных переломов FRAX ${ }^{\circledR}$ (http://www.shef.ac.uk/FRAX) позволяет определить вероятность возникновения перелома у конкретного пациента с учетом его возраста, сопутствующих состояний, наличия клинических факторов риска с использованием МПК шейки бедренной кости или без нее. В зависимости от особенностей системы здравоохранения, распространенности остеопороза и связанных с ним переломов, а также желания государства оплачивать лечение остеопороза для предупреждения его осложнений в каждой стране принимается так называемый «порог терапевтического вмешательства». В Российской Федерации используется возраст-зависимый порог терапевтического вмешательства. Немногочисленные оценки эффективности его использования продемонстрировали недостаточную удовлетворенность исследователей.

Таким образом, необходимо продолжить анализ различных порогов терапевтического вмешательства для выбора наиболее оптимальных для России с клинической и организационной точек зрения, что и определило цель настоящего исследования.

Цель исследования. Провести анализ использования для российской популяции фиксированных порогов терапевтического вмешательства, предложенных Национальным Фондом остеопороза США (National Osteoporosis Foundation, NOF).

Материалы и методы. Нами проведено многоцентровое одномоментное исследование женщин в постменопаузе, не получавших антиостеопорозной терапии. Материалом для исследования послужили выборки, приближенные к популяционным, предоставленные шестью медицинскими организациями различных регионов Российской Федерации. Для того, чтобы невероятностная выборка была максимально приближена к популяционной, в исследование включались те центры, где есть оборудование DXA денситометрии, и куда пациенты обращаются для диагностики остеопороза без предварительного осмотра специалиста, преимущественно самостоятельно или по направлению врача поликлиники. В исследование были включены женщины в постменопаузе в возрасте 50 лет и старше при наличии результата исследования МПК в шейке бедра (Т-критерий) по результатам денситометрии на DXA аппарате компаний Hologic, GE Lunar или Norland и информации по всем вопросам анкеты FRAX, ответы на которые учитываются при подсчете FRAX. На указанной выборке были применены фиксированные пороги терапевтического вмешательства 20\% для основных остеопоротических переломов (ООП) и 3\% для перелома проксимального отдела бедра (ППОБ), предложенные Национальным Фондом остеопороза США. При применении порога рассчитывалась доля женщин, превышавших интервенционный порог, в целом и отдельно по возрастным группам с 5-летним интервалом.

Результаты и обсуждение. В исследование включено 3866 женщин в постменопаузе в возрасте от 50 до 90 лет. Подсчет FRAX используется в США и Канаде в качестве дополнения к клинической информации и результатам денситометрии. FRAX подсчитывается только у пациентов без указания на перенесенные в анамнезе перелом проксимального отдела бедренной кости и/или позвонка, у которых по денситометрии выявляется не остеопороз (являющийся самостоятельным показанием к началу лечения), а остеопения. 
При применении фиксированных порогов в 20\% по ООП и 3\% по ППОБ на российской популяции женщин в контексте клинических рекомендаций NOF общая доля женщин, подлежащих лечению, составила 47,8\%. При этом обращало на себя внимание увеличение с возрастом процента женщин, идентифицированных для терапии от 29,6\% в 50-54 г. и $39,3 \%$

в 55-59 лет до максимального - 81,3\% в возрастной группе 80-84 года, с небольшим снижением доли подлежащих терапии до 80,6\% в возрасте 85 лет и старше.

При этом следует иметь в виду, что использование Т-критерия $\leq-2,5$ СО в качестве интервенционного порога, постулируемое обеими рекомендациями, подвергается серьезной критике. Основным ее доводом является тот факт, что риск перелома при определенном значении МПК зависит от возраста, поэтому Т-критерий всегда необходимо рассматривать в возрастном аспекте, а, следовательно, при подсчете FRAX, а не отдельно от него. Некорректность использования Т-критерия для инициации лечения остеопороза без учета других клинических факторов риска демонстрирует реанализ данных NHANES, проведенный Kanis и соавт., показавших, что средний 10-летний риск ООП у пациентов с Т-критерием в зоне остеопороза составлял 17,3\%, что ниже, чем у пациентов, перенесших переломы (19\%). В нашем исследовании соответствующие цифры были 16,6\% и 19,1\%, что подтверждает выводы о том, что Т-критерий $\leq-2,5$ СО является диагностическим порогом, но не обязательно - интервенционным.

При анализе числа больных, которых необходимо пролечить для предупреждения одного перелома (ЧБНЛ), использование фиксированных порогов NOF в сочетании с данными денситометрии оказалось недостаточно эффективным: вероятность переломов у лиц, превысивших порог вмешательства, составила 18,7\%, а ЧБНЛ - 18.

Выводы: Использование интервенционных порогов, рекомендованных NOF, США, в российской популяции, показало недостаточную эффективность в связи с идентификацией большого количества пациентов для терапии, особенно в старших возрастных группах.

КЛЮЧЕВЫЕ СЛОВА: Остеопороз; порог терапевтического вмешательства; FRAX.

\section{FIXED THRESHOLDS FOR THERAPEUTIC INTERVENTION BASED ON THE FRAX MODEL IN THE RUSSIAN POPULATION}

(c) Gladkova E.N. ${ }^{1,2}$, Lesnyak O.M. ${ }^{1,2}$, Ershova O.B. ${ }^{3}$, Skripnikova I.A. ${ }^{4}$, Anoshenkova O.N. ${ }^{5,6}$, Akhverdyan Yu.R. ${ }^{7}$, Belova K.Yu. ${ }^{3}$, Belousova I.B. ${ }^{8}$, Bolshakova E.V. ${ }^{3}$, Dreval A.V. ${ }^{9}$, Zavodovsky B.V. ${ }^{7}$, Ilyin M.V. ${ }^{3}$, Kosmatova O.V. ${ }^{4}$, Kryukova I.V. ${ }^{9}$, Akhatov A.F. ${ }^{10}$, Latfullin A.A. ${ }^{10}$, Leykauskene E.A. ${ }^{11}$, Leonova N.V. ${ }^{11}$, Maksimova Yu.V. ${ }^{5}$, Myagkova M.A. ${ }^{4}$, Novikov V.E. ${ }^{4}$, Nuriev A.R. ${ }^{10}$, Polyakova E.Yu. ${ }^{9}$, Polyakova Yu.V. ${ }^{7}$, Sivordova L.E. ${ }^{7}$, Tavluev V.A. ${ }^{5}$, Shavalieva L.R. ${ }^{10}$

${ }^{1}$ North-Western State Medical University named after I.I. Mechnikov, Saint Petersburg

${ }^{2}$ St. Petersburg State Medical Institution «Clinical Rheumatology Hospital No. 25», Saint Petersburg

${ }^{3}$ Yaroslavl State Medical University, Yaroslavl

${ }^{4}$ National Medical Research Center for Preventive Medicine, Moscow

${ }^{5}$ Maximum Health Medical Center, Tomsk

${ }^{6}$ Siberian State Medical University, Tomsk

${ }^{7}$ Research Institute of Clinical and Experimental Rheumatology named after A.B. Zborovsky, Volgograd

${ }^{8}$ Clinical Hospital No. 101 branch of the North Caucasus Federal Research and Clinical Center, Lermontov

${ }^{9}$ Moscows regional research clinical institute n.a. M.F. Vladimirskiy, Moscow

${ }^{10}$ LLC «BARSMED», Kazan

${ }^{11}$ LLC Medical Multidisciplinary Clinic «Anturium», Barnaul 
() Е.Н. Гладкова ${ }^{1,2}$, О.М. Лесняк ${ }^{1,2}$, Н.О. Александров ${ }^{3}$, Н.В. Безлюдная ${ }^{4}$, Ж.Е. Белая ${ }^{5}$, Т.А. Гребенникова ${ }^{5}$, А.В. Древаль ${ }^{6}$, О.Б. Ершова7, К.Ю. Белова7, С.О. Мазуренко ${ }^{8}$, И.В. Крюкова ${ }^{6}$, О.В. Добровольская ${ }^{9}$ Д.В. Приймак ${ }^{3}$, Л.Я. Рожинская ${ }^{5}$, Р.Р. Самигуллина' ${ }^{1}$ Н.В. Торопцова ${ }^{9}$

'ФГБОУ ВО «Северо-Западный государственный медицинский университет имени И.И. Мечникова» Минздрава России, Санкт-Петербург

${ }^{2}$ СПб ГБУЗ «Клиническая ревматологическая больница № 25», Санкт-Петербург

${ }^{3} \mathrm{OOO}$ «Лилли Фарма», Москва

${ }^{4}$ ФГБУ «Федеральный центр травматологии, ортопедии и эндопротезирования» Минздрава России, Чебоксары

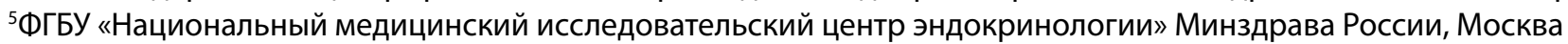

бГБУЗ МО «МОНИКИ им. М.Ф. Владимирского», Москва

${ }^{7}$ ФГБОУ ВО «Ярославский государственный медицинский университет» Минздрава России, Ярославль

${ }^{8}$ ФГБОУ ВО «Санкт-Петербургский государственный университет», Санкт-Петербург

${ }^{9}$ ФГБНУ «НИИ ревматологии им. В.А. Насоновой», Москва

Тяжелый остеопороз (ОП), в соответствии с классификацией ВОЗ, определяется как снижение минеральной плотности костной ткани (МПКТ) (Т-критерий равен или ниже -2,5 стандартных отклонений) в сочетании с низкотравматичным переломом. Пациенты с низкоэнергетическими переломами требуют дополнительных ресурсов не только для лечения самих переломов. В связи с высоким риском повторных переломов они нуждаются в адекватном медикаментозном лечении повышенной хрупкости скелета. Вместе с тем, очевидно, что тактика, интенсивность и результаты лечения у пациентов с множественными низкоэнергетическими переломами могут отличаться от тех, у кого переломов еще не было или кто перенес только один перелом. Выделение когорты пациентов с тяжелым остеопорозом и выбор оптимального терапевтического подхода для этой популяции больных позволит предупредить наиболее фатальные осложнения этого заболевания.

Цель исследования. Анализ особенностей лекарственного лечения и его результатов у пациентов с тяжелым остеопорозом в специализированных медицинских учреждениях Российской Федерации.

Материал и методы. Данное исследование выполнено в рамках многоцентровой программы «Ретроспективное социально-экономическое исследование статуса лечения пациентов с тяжёлым остеопорозом в Российской Федерации» (ОСТЕО-РФ), организованной Российской ассоциацией по остеопорозу и Лигой содействия клиническим исследованиям. В семи крупных российских центрах, специализирующихся на оказании помощи пациентам с ОП, проводился ретроспективный анализ первичной документации пациентов с тяжелым ОП, обратившихся на консультацию в период с 01 января 2014 г. по 31 декабря 2015 г. Пациенты включались в исследование, если они имели тяжелый остеопороз. Для целей данного исследования определение тяжелого остеопороза, данное ВОЗ, было расширено наличием у пациента низкоэнергетического перелома проксимального отдела бедренной кости или 2 и более переломов позвонков или других костей скелета, даже если остеопороза по данным DXА денситометрии не было. Помимо указанного критериями включения пациента в исследование были наличие не менее двух описанных в первичной медицинской документации визитов к врачу исследовательского центра и наблюдение в центре не менее 1 года.

Результаты и обсуждение. В исследование включено 1000 пациентов: 955 женщин и 45 мужчин в возрасте от 35 до 95 лет, медиана возраста составила 69,0 (62,0-76,0) лет. Сроки наблюдения пациентов в центрах колебались от 12 до 168 мес. с кратностью наблюдения от 2 до 7 визитов. Общая длительность наблюдения пациентов в центрах составила 2864,5 человеко-лет.

В соответствии с имеющейся в Российской Федерации медико-социальной системой 36,3\% пациентов (301 чел.) из числа тех, у кого было известно о нетрудоспособности, на момент установления диагноза уже были официально признаны инвалидами по заболеванию. В динамике наблюдалось увеличение этой доли до 40,8\% (p>0,05).

На момент диагностики остеопороза более $90 \%$ пациентов нашей группы имели в анамнезе хотя бы один перелом, у 70\% больных переломы позвонков были множественными. За период наблюдения в центрах новые переломы произошли у 23,9\% больных, прирост случаев переломов проксимального отдела бедренной кости составил 28,8\%, переломов позвонков - 24,8\%. В терапии остеопороза исходно чаще назначались пероральные и парентеральные бисфосфонаты (55\% и 30,2\% соответственно). У 48,3\% пациентов препараты патогенетического действия заменялись или отменялись. Причинами чаще всего были низкая эффективность, плохая переносимость и отсутствие у пациента возможности оплатить лечение. Наиболее часто отменялись пероральные бисфосфонаты (71,3\%). Спектр лекарственной терапии исходно и в конце наблюдения существенно различался для всех группах препаратов. Так, доля пероральных бисфосфонатов снижалась, а доля парентеральных бисфосфонатов, деносумаба и терипаратида к концу наблюдения увеличивалась ( $<<0,0001)$. На дату последнего наблюдения в структуре терапии в центрах преобладали парентеральные бисфосфонаты (42,8\%) и деносумаб (36,6\%). Анаболическую терапию (терипаратид) получали 
более 5\% пациентов с тяжелым остеопорозом. Мы дополнительно проанализировали результаты лечения у тех пациентов, у которых сразу после диагностики остеопороза начиналось лечение более мощными парентеральными антирезорбтивными препаратами (золедроновая кислота или деносумаб) или костно-анаболическим препаратом терипаратид, и они получили курс достаточной продолжительности, чтобы можно было оценить эффективность лечения (золедроновую кислоту не менее 3 раз [3 года лечения], деносумаб или терипаратид - не менее 1 года). Всего в эту группу вошло 172 чел. Указанная группа характеризовалась более низкими показателями МПК во всех участках скелета на момент диагностики остеопороза. Однако к концу наблюдения статистически значимой разницы между группами не было по МПК в позвоночнике и шейке бедра. Важно, что к концу наблюдения у пациентов с изначально более агрессивной терапией отмечена меньшая частота новых переломов любой локализации, включая переломы позвонков и проксимального отдела бедренной кости.

Выводы. Таким образом, наше исследование показало, что пациенты с тяжелым остеопорозом - это сложная для курации категория больных. Более активная терапия, инициированная с момента диагностики этого заболевания, существенно улучшает результаты лечения и может быть более эффективной для предупреждения повторных переломов на фоне лечения.

КЛЮЧЕВЫЕ СЛОВА: Тяжелый остеопороз; переломы; лечение.

\section{AN AGGRESSIVE TREATMENT STRATEGY IS NEEDED FOR SEVERE OSTEOPOROSIS. RESULTS OF MULTICENTER STUDY «OSTEO-RF»}

(c) Gladkova E.N. ${ }^{1,2}$, Lesnyak O.M. ${ }^{1,2}$, Alexandrov N.O. ${ }^{3}$, Bezlyudnaya N.V. ${ }^{4}$, Belaya Zh.E. ${ }^{5}$, Grebennikova T.A. ${ }^{5}$, Dreval A.V. ${ }^{6}$, Ershova O.B. ${ }^{7}$, Belova K.Yu. ${ }^{7}$, Mazurenko S.O. ${ }^{8}$, Kryukova I.V. ${ }^{6}$, Dobrovolskaya O.V. ${ }^{9}$, Priymak D.V. ${ }^{3}$, Rozhinskaya L.Ya. ${ }^{5}$, Samigullina R.R. ${ }^{1}$, Toroptsova N.V. ${ }^{9}$

${ }^{1}$ North-Western State Medical University named after I.I. Mechnikov, Saint Petersburg

${ }^{2}$ St. Petersburg State Medical Institution «Clinical Rheumatology Hospital No. 25», Saint Petersburg

"«Lilly Pharma», Moscow

${ }^{4}$ Federal Center of Traumatology, Orthopedics and Endoprosthetics, Cheboksary

${ }^{5}$ Endocrinology Research Centre, Moscow

${ }^{6}$ Moscows regional research clinical institute n.a. M.F. Vladimirskiy, Moscow

${ }^{7}$ Yaroslavl State Medical University, Yaroslavl

${ }^{8}$ Saint Petersburg State University, Saint Petersburg

${ }^{9}$ Research Institute of Rheumatology named after V.A. Nasonova, Moscow 


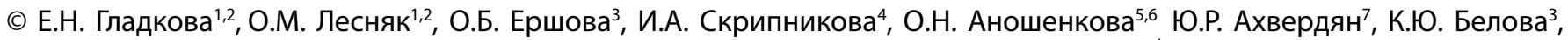
И.Б. Белоусова ${ }^{8}$, Е.В. Большакова ${ }^{3}$, А.В. Древаль ${ }^{9}$, Б.В. Заводовскийㄱ, М.В. Ильин ${ }^{3}$, О.В. Косматова ${ }^{4}$, И.В. Крюкова ${ }^{9}$, А.Ф. Ахатов ${ }^{10}$, А.А. Латфуллин ${ }^{10}$, Е.А. Лейкаускене ${ }^{11}$, Н.В. Леонова ${ }^{11}$, Ю.В. Максимова ${ }^{5}$, М.А. Мягкова ${ }^{4}$, В.Е. Новиков ${ }^{4}$, А.Р. Нуриев ${ }^{10}$, Е.Ю. Полякова9 ${ }^{9}$ Ю.В. Полякова ${ }^{7}$, Л.Е. Сивордова ${ }^{7}$, В.А. Тавлуев ${ }^{5}$, Л.Р. Шавалиева ${ }^{10}$

'ФГБОУ ВО «Северо-Западный государственный медицинский университет имени И.И. Мечникова» Минздрава России, Санкт-Петербург

${ }^{2}$ СПб ГБУЗ «Клиническая ревматологическая больница № 25», Санкт-Петербург

${ }^{3}$ ФГБОУ ВО «Ярославский государственный медицинский университет» Минздрава России, Ярославль

${ }^{4}$ ФГБУ «Национальный медицинский центр профилактической медицины» Минздрава России, Москва

${ }^{5} \mathrm{OOO}$ «Макс и К» Медицинский центр «Максимум здоровья», Томск

${ }^{6}$ ФГБОУ ВО «Сибирский государственный медицинский университет» Минздрава России, Томск

7ФГБНУ «Научно-исследовательский институт клинической и экспериментальной ревматологии

им. А.Б. Зборовского», Волгоград

${ }^{8}$ Клиническая больница № 101 филиал Федерального государственного бюджетного учреждения «Северо-

Кавказский федеральный научно-клинический центр Федерального медико-биологического агентства», Лермонтов

9ГБУЗ МО «МОНИКИ им. М.Ф. Владимирского», Москва

${ }^{10} \mathrm{OOО}$ «БАРСМЕД», Казань

${ }^{11}$ ООО Медицинская многопрофильная клиника «Антуриум», Барнаул

В Национальные клинические рекомендации, действующие в Российской Федерации, определение 10-летнего абсолютного риска остеопорозных переломов FRAX ${ }^{\circledast}$ (http://www.shef.ac.uk/FRAX) включено в качестве дополнительного инструмента для диагностики остеопороза и принятия решения о начале терапии. В основу модели возраст-зависимого порога терапевтического вмешательства, используемого в Российской Федерации, взят абсолютный риск основных остеопорозных переломов (ООП) и не учитывается риск перелома проксимального отдела бедра (ПОБ). Однако, этот порог не всегда удовлетворяет клиницистов, поскольку довольно высок и ограничивает долю пациентов высокого риска, которым показано лечение остеопороза.

В связи с этим имеется потребность в поиске альтернативной модели научно-обоснованного отбора пациентов на лечение остеопороза на основе определения у них высокого риска переломов, что и определило цель настоящего исследования.

Цель исследования. Провести анализ применения для российской популяции возраст-зависимого порога терапевтического вмешательства, основанного на риске переломов ПОБ.

Материалы и методы. Нами проведено многоцентровое одномоментное исследование женщин в постменопаузе, не получавших антиостеопорозной терапии. Материалом для исследования послужили выборки, приближенные к популяционным, предоставленные шестью медицинскими организациями различных регионов Российской Федерации. Для того, чтобы невероятностная выборка была максимально приближена к популяционной, в исследование включались те центры, где есть оборудование DXA денситометрии, и куда пациенты обращаются для диагностики остеопороза без предварительного осмотра специалиста, преимущественно самостоятельно или по направлению врача поликлиники. В исследование были включены женщины в постменопаузе в возрасте 50 лет и старше при наличии результата исследования МПК в шейке бедра (Т-критерий) по результатам денситометрии на DXA аппарате компаний Hologic, GE Lunar или Norland и информации по всем вопросам анкеты FRAX, ответы на которые учитываются при подсчете FRAX. При применении порога рассчитывалась доля женщин, превышавших интервенционный порог, в целом и отдельно по возрастным группам с 5-летним интервалом. Предварительно с использованием калькулятора FRAX ${ }^{\circledR}$ (http://www.shef.ac.uk/FRAX) был рассчитан и построен возраст-зависимый порог вмешательства, основанный на риске переломов ПОБ. Его принцип построения аналогичен таковому для возраст-зависимого порога вмешательства, основанном на риске ООП, используемом в настоящее время в РФ. В основе разработки лежит тот факт, что у любого пациента в возрасте старше 50 лет принято инициировать лечение остеопороза после перенесенного низкоэнергетического перелома. Таким образом, за порог терапевтического вмешательства принимается уровень риска у пациента, перенесшего перелом при отсутствии других факторов риска. Поскольку в каждой возрастной группе риск повторных переломов отличается, кривая графика изменяется с возрастом.

Результаты и обсуждение. В исследование включено 3866 женщин в постменопаузе в возрасте от 50 до 90 лет. При построении порога терапевтического вмешательства на основании риска переломов ПОБ минимальный пороговый риск соответствовал 1,1\% в возрасте 40 лет, увеличивался до 9,1\% к возрасту 84-85 лет и снижался до 7,6\% к возрасту 90 лет. Для определения доли идентифицированных для терапии возраст-зависимый порог терапевтического 
вмешательства, основанный на риске ООП, был дополнен порогом, основанным на риске переломов ПОБ. Лечение должно быть инициировано при превышении порога вмешательства либо по ООП, либо по переломам ПОБ. В данном варианте применения порога терапевтического вмешательства для лечения было идентифицировано 27,4\% российской популяции, при этом в возрастных группах от 50 до 64 лет лечению подлежало около 30\% популяции (от 28,3\% до 32,6\%), тогда как после 65 лет этот показатель снижался и в самых старших возрастных группах составлял 16,7\%. При этом использование порога терапевтического вмешательства, основанного только на риске ООП, позволял идентифицировать для терапии лишь 22,1\% популяции, колебания в возрастных группах составили от 17,2\% до 26,4\%. Максимальная доля идентифицированных для терапии с использованием этого метода наблюдалась в возрастной группе 55-59 лет, в остальных возрастных группах - около 20\%. При анализе числа больных, которых необходимо пролечить для предупреждения одного перелома (ЧБНЛ), использование сочетания возраст-зависимых порогов оказалось достаточно эффективным: идентифицируя 27,4\% популяции, метод позволял выявлять пациентов высокого риска переломов - вероятность переломов у лиц, превысивших порог вмешательства, составила 22,3\%, а ЧБНЛ - 15 . Выводы: Использование возраст-зависимого порога, основанного на риске переломов ПОБ в дополнение к применяемому в настоящее время в РФ порогу терапевтического вмешательства, позволило идентифицировать больше пациентов, подлежащих терапии, однако доля пациентов старших возрастных групп, подлежащих терапии, оставалась достаточно низкой.

КЛЮЧЕВЫЕ СЛОВА: переломы; проксимальный отдел бедренной кости; возраст-зависимый порог терапевтического вмешательства

\section{PROXIMAL FEMUR FRACTURE RISK AS A BASIS FOR THE DEVELOPMENT OF THERAPEUTIC INTERVENTION THRESHOLD BASED ON FRAX MODEL IN THE RUSSIAN POPULATION}

(C) Gladkova E.N. ${ }^{1,2}$, Lesnyak O.M. ${ }^{1,2}$, Ershova O.B. ${ }^{3}$, Skripnikova I.A. ${ }^{4}$, Anoshenkova O.N. ${ }^{5,6}$, Akhverdyan Yu.R. ${ }^{7}$, Belova K.Yu. ${ }^{3}$, Belousova I.B. ${ }^{8}$, Bolshakova E.V. ${ }^{3}$, Dreval A.V. ${ }^{9}$, Zavodovsky B.V. ${ }^{7}$, Ilyin M.V. ${ }^{3}$, Kosmatova O.V. ${ }^{4}$, Kryukova I.V. ${ }^{9}$, Akhatov A.F. ${ }^{10}$, Latfullin A.A. ${ }^{10}$, Leykauskene E.A. ${ }^{11}$, Leonova N.V. ${ }^{11}$, Maksimova Yu.V. ${ }^{5}$, Myagkova M.A. ${ }^{4}$, Novikov V.E. ${ }^{4}$, Nuriev A.R. ${ }^{10}$, Polyakova E.Yu. ${ }^{9}$, Polyakova Yu.V. ${ }^{7}$, Sivordova L.E. ${ }^{7}$, Tavluev V.A. ${ }^{5}$, Shavalieva L.R. ${ }^{10}$

${ }^{1}$ North-Western State Medical University named after I.I. Mechnikov, Saint Petersburg

${ }^{2}$ Clinical Rheumatology Hospital No. 25, Saint Petersburg

${ }^{3}$ Yaroslavl State Medical University, Yaroslavl

${ }^{4}$ National Medical Research Center for Preventive Medicine, Moscow

${ }^{5}$ Maximum Health Medical Center, Tomsk

${ }^{6}$ Siberian State Medical University, Tomsk

${ }^{7}$ Research Institute of Clinical and Experimental Rheumatology named after A.B. Zborovsky, Volgograd

${ }^{8}$ Clinical Hospital No. 101 branch of the North Caucasus Federal Research and Clinical Center, Lermontov

${ }^{9}$ Moscows regional research clinical institute n.a. M.F. Vladimirskiy, Moscow

${ }^{10}$ LLC «BARSMED», Kazan

${ }^{11}$ LLC Medical Multidisciplinary Clinic «Anturium», Barnaul 
ТЯЖЕЛЫЙ ГЛЮКОКОРТИКОИДНЫЙ ОСТЕОПОРОЗ В РОССИЙСКОЙ ФЕДЕРАЦИИ (ИССЛЕДОВАНИЕ ОСТЕО-РФ)

() Е.Н. Гладкова ${ }^{1,2}$, О.М. Лесняк ${ }^{1,2}$, Н.О. Александров ${ }^{3}$, Н.В. Безлюдная ${ }^{4}$, Ж.Е. Белая ${ }^{5}$, Т.А. Гребенникова ${ }^{5}$, А.В. Древаль $^{6}$, О.Б. Ершова7, К.Ю. Белова7, С.О. Мазуренко ${ }^{8}$, И.В. Крюкова ${ }^{6}$, О.В. Добровольская ${ }^{9}$ Д.В. Приймак ${ }^{3}$, Л.Я. Рожинская ${ }^{5}$, Р.Р. Самигуллина' ${ }^{1}$ Н.В. Торопцова ${ }^{9}$

'ФГБОУ ВО «Северо-Западный государственный медицинский университет имени И.И. Мечникова» Минздрава России, Санкт-Петербург

${ }^{2}$ СПб ГБУЗ «Клиническая ревматологическая больница № 25», Санкт-Петербург

${ }^{3} \mathrm{OOO}$ «Лилли Фарма», Москва

${ }^{4}$ ФГБУ «Федеральный центр травматологии, ортопедии и эндопротезирования» Минздрава России, Чебоксары

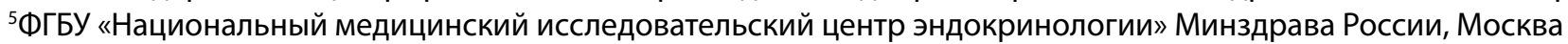

бГБУЗ МО «МОНИКИ им. М.Ф. Владимирского», Москва

7ФГБОУ ВО «Ярославский государственный медицинский университет» Минздрава России, Ярославль

${ }^{8}$ ФГБОУ ВО «Санкт-Петербургский государственный университет», Санкт-Петербург

${ }^{9}$ ФГБНУ «НИИ ревматологии им. В.А. Насоновой», Москва

Глюкокортикоидный остеопороз (ГК ОП) характеризуется быстрой потерей костной массы и увеличением риска переломов уже в ранние сроки после начала терапии глюкокортикоидами (ГК), что обусловливает необходимость тщательного внимания к этой группе пациентов. При этом клинический профиль пациента с тяжелым ГК ОП в России ранее не изучался, что и обусловило актуальность проведенного исследования.

Цель исследования. Оценить клинические характеристики тяжелого глюкокортикоидного остеопороза в специализированных медицинских организациях Российской Федерации.

Материалы и методы. Данное исследование выполнено в рамках многоцентровой программы «Ретроспективное социально-экономическое исследование статуса лечения пациентов с тяжёлым остеопорозом в Российской Федерации» (ОСТЕО-РФ), организованной Российской ассоциацией по остеопорозу и Лигой содействия клиническим исследованиям. В семи крупных российских центрах, специализирующихся на оказании помощи пациентам с остеопорозом, проводился ретроспективный анализ первичной документации пациентов с тяжелым остеопорозом, обратившихся на консультацию в период с 01 января 2014 г. по 31 декабря 2015 г. Пациенты включались в исследование при наличии тяжелого остеопороза при наличии не менее двух описанных в первичной медицинской документации визитов к врачу исследовательского центра и наблюдения в центре не менее 1 года. В анализ включались клинико-демографические данные, результаты исследования МПК при проведении двуэнергетической рентгеновской абсорбциометрии (DXA денситометрии) и данные по перенесенным переломам, в том числе, в процессе наблюдения за пациентом.

Результаты и обсуждение. Демографическая, социальная и клиническая характеристка пациентов

В исследование включено 1000 пациентов: 955 женщин и 45 мужчин в возрасте от 35 до 95 лет, медиана возраста составила 69,0 (62,0-76,0) лет. Сроки наблюдения пациентов в центрах колебались от 12 до 168 мес. с кратностью наблюдения от 2 до 7 визитов. Общая длительность наблюдения пациентов в центрах составила 2864,5 человеко-лет. Всего было зарегистрировано 113 пациентов с ГК ОП. Общая продолжительность наблюдения пациентов с ГК ОП в центрах составила 348,9 человеко-лет.

Нами было проведено сравнение группы пациентов с тяжелым остеопорозом, имеющих в анамнезе указание на прием ГК, и пациентов, никогда не применявших ГК. Пациенты с ГК ОП были на 4 года моложе, чем пациенты, не употребляющие ГК, различий по полу, длительности наблюдения и возрасту менопаузы зарегистрировано не было. На момент установления диагноза более чем две трети пациентов с тяжелым глюкокортикоидным остеопорозом уже были официально признаны инвалидами по заболеванию (58 человек, 66,7\%). Доля лиц с группой инвалидности среди пациентов с ГК ОП в 2 раза превышала аналогичный показатель среди пациентов, не употребляющих ГК. В динамике наблюдалось увеличение этой доли до 78,9\% (р>0,05). Кроме этого, в процессе наблюдения у пациентов с ГК ОП отмечался рост в 2,5 раза доли больных с I группой инвалидности до 8,5\% (6 чел.). Это были пациенты с множественными переломами костей скелета: на одного больного приходилось в среднем 5,0 переломов позвонков и 3,2 невертебральных перелома.

В большинстве случаев (87,6\%) диагноз ГК ОП был установлен после перенесенного низкоэнергетического перелома. Минеральная плотность костной ткани (МПКТ)

Остеопороз по денситометрии с наибольшей частотой определялся в поясничном отделе позвоночника (81,5\%). За период наблюдения доля лиц с низкой МПК хотя бы в одном из отделов скелета снижалась, однако к концу наблюдения она продолжала оставаться высокой, составляя 74,0\%. При проведении анализа частоты ОП, выявленного на основании денситометрии проксимального отдела бедра, установлено, что достоверно чаще низкая МПкТ в бедре (neck, total hip) выявлялась у пациентов с ГК ОП. Так, доля пациентов с ГК ОП, исходно имеющих сниженные показатели 
МПКТ в шейке бедра (neck) составила 61,2\%, тогда как при отсутствии употребления ГК в анамнезе - 39,4\%, для общего показателя по бедру (total hip) - 45,4\% и 24,9\% соответственно. Также было отмечено отсутствие динамики доли пациентов со сниженной МПКТ при ГК ОП в зоне обследования total hip за период наблюдения.

Характеристика переломов

В анализ были включены следующие типы переломов: переломы позвонков, проксимального отдела бедренной кости, дистального отдела предплечья, верхнего конца плечевой кости, дистального отдела голени, ребер. Переломы костей стоп и кистей, костей таза и др. типы переломов, произошедшие у пациентов при низком уровне травмы, были объединены в группу «другие локализации». Наиболее частой локализацией невертебральных переломов у пациентов с ГК ОП был дистальный отдел предплечья. Число новых случаев невертебральных переломов на фоне наблюдения у специалиста по остеопорозу составило 85,9 на 1000 человеко-лет наблюдения, перелома проксимального отдела бедренной кости -14,3 случая на 1000 человеко-лет наблюдения. При этом, аналогичные показатели у пациентов с тяжелым ОП, не принимающих ГК, составили 44,1 и 9,9 соответственно.

На момент начала наблюдения в центре, различий по частоте переломов позвонков у пациентов, принимающих и не принимающих ГК, не отмечалось. Однако пациенты с ГК ОП переносили переломы позвонков в более молодом возрасте $(59,8(51,9-66,9)$ лет и 65, $1(59,1-72,4)$ лет у пациентов, не принимающих ГК, соответственно), p=0,002. В течение наблюдения более высокая частота новых случаев переломов позвонков отмечалась у пациентов с ГК ОП.

В целом новые вертебральные и невертебральные переломы за период наблюдения и лечения развились у 44 пациентов с ГК ОП (38,9\%), в то время как этот же показатель у лиц, не принимавших ГК составил 23,9\%. Следует отметить, что у пациентов с ГК ОП чаще, по сравнению с теми, кто не получал ГК, отмечались множественные переломы тел позвонков (82,5\% и 69,2\% соответственно, $p=0,0013)$.

Выводы. Проведенное исследование показало, что тяжелый глюкокортикоидный остеопороз характеризуется более тяжелыми клиническими проявлениями по сравнению с пациентами, не принимающими глюкокортикоиды. Этот факт диктует необходимость особого внимания к этой группе пациентов, обязательного и более раннего назначения патогенетической терапии ОП, ее длительного применения, подбора лекарственных препаратов, имеющих доказанную эффективность для снижения риска переломов.

КЛЮЧЕВЫЕ СЛОВА: Глюкокортикоидный остеопороз; тяжелый остеопороз; глюкокортикоиды.

\section{SEVERE GLUCOCORTICOID OSTEOPOROSIS IN RUSSIAN FEDERATION (OSTEO-RF STUDY)}

(c) Gladkova E.N. ${ }^{1,2}$, Lesnyak O.M. ${ }^{1,2}$, Alexandrov N.O.3, Bezlyudnaya N. V. 4, Belaya Zh.E.5, Grebennikova T.A. ${ }^{5}$, Dreval A.V. ${ }^{6}$, Ershova O.B. ${ }^{7}$, Belova K.Yu. ${ }^{7}$, Mazurenko S.O. ${ }^{8}$, Kryukova I.V. ${ }^{6}$, Dobrovolskaya O.V. ${ }^{9}$, Priymak D.V. ${ }^{3}$, Rozhinskaya L.Ya. ${ }^{5}$, Samigullina R.R. ${ }^{1}$, Toroptsova N.V. ${ }^{9}$

${ }^{1}$ North-Western State Medical University named after I.I. Mechnikov, Saint Petersburg

${ }^{2}$ Clinical rheumatology hospital No. 25, Saint Petersburg

${ }^{3}$ LLC «Lilly Pharma», Moscow

${ }^{4}$ Federal Center of Traumatology, Orthopedics and Endoprosthetics, Cheboksary

${ }^{5}$ National Medical Research Center of Endocrinology, Moscow

${ }^{6}$ Moscows regional research clinical institute n.a. M.F. Vladimirskiy, Moscow

${ }^{7}$ Yaroslavl State Medical University, Yaroslavl

${ }^{8}$ Saint Petersburg State University, Saint Petersburg

${ }^{9}$ Research Institute of Rheumatology named after V.A. Nasonova, Moscow 
АНЕМИЯ ВСЛЕДСТВИЕ ГИПЕРПАРАТИРЕОИДНОЙ ОСТЕОДИСТРОФИИ: КЛИНИЧЕСКИЙ СЛУЧАЙ

\author{
(с) А.М. Горбачева' , С.С. Шкляев ${ }^{1,2}$, А.К. Еремкина' ${ }^{1}$ Н.Г. Мокрышева'
}

'ФГБУ «НМИЦ эндокринологии» Минздрава России, Москва

ФГБУ «НМИЦ радиологии» Минздрава России, Москва

Цель: Целью представленного клинического случая является демонстрация «неклассического» проявления первичного гиперпаратиреоза (ПГПТ) - микроцитарной гипохромной анемии, развившейся вследствие фиброзно-кистозного остеита.

Материалы и методы: пациентка находилась на стационарном обследовании в ФГБУ «НМИЦ эндокринологии» в октябре 2019 года. Все лабораторные и инструментальные исследования проведены на базе диагностических отделений «НМИЦ эндокринологии».

Результаты: У пациентки 30 лет, перенесшей за полгода до госпитализации переломы обеих бедренных костей, в ходе госпитализации подтвержден ПГПт: на фоне тяжелой гиперкальциемии (альбумин-скорректированный кальций 3,9 ммоль/л) зафиксировано повышение уровня интактного паратиреоидного гормона (иПтГ) до 1423 пг/мл (15-65). Суточная кальциурия составила 7.9 ммоль/сут.

Из осложнений ПГПТ диагностированы двусторонний нефромикролитиаз без нарушения фильтрационной функции почек, снижение минеральной плотности кости (МПК) до уровня тяжелого остеопороза (максимально до -5.2 SD В дистальной трети лучевой кости по Z-критерию). Результаты сцинтиграфии с 99мТс-технетрилом и рентгенографии грудной клетки, грудного и поясничного отделов позвоночника соответствовали картине фиброзно-кистозного остеита. По данным биопсии костной ткани наличие фиброзного остеита подтверждено, на фоне незрелых костных балок и очаговой пролиферации эндоста определялись разрастание фиброретикулярной ткани и очаги некроза.

Лабораторно-инструментальных данных за наличие синдрома множественных эндокринных неоплазий получено не было. По результатам комплексной топической диагностики (УзИ, сцинтиграфия с ОФЭКТ/КТ) выявлено объемное образование правой нижней ОЩЖ размерами до 3,0х1,6х1,3см.

Тяжесть состояния была обусловлена выраженной гиперкальциемией, а также гипохромной микроцитарной (MCV - 75 фл) анемией средней степени тяжести (гемоглобин - 73 г/л), выявленной по результатам общеклинического анализа крови. Имелись абсолютные показания к проведению срочного хирургического лечения ПГПТ, однако первоначально требовалась стабилизация общего состояния пациентки. Учитывая высокий риск гиперкальциемического криза и тяжесть костных нарушений, было принято решение об инъекции деносумаба 60 мг п/к. Параллельно проводилась регидратация, инициирована терапия цинакалцетом с титрацией дозы до 60 мг/сут, с положительной динамикой (снижение уровня альбумин-скорректированного кальция до 2,9 ммоль/л).

Уровни витамина В12, эритропоэтина в сыворотке крови сохранялись в пределах референсных значений, отмечалось снижение уровня железа до 2,5 мкмоль/м при нормальном уровне трансферрина - 2,7 г/л и повышении концентрации ферритина до 198 нг/мл. В рамках госпитализации проводился поиск возможных источников хронической кровопотери. Эзофагогастродуоденоскопия без признаков эрозивно-язвенного поражения. При УзИ органов малого таза выявлены аденомиоз, фолликулярная киста правого яичника. Анализ кала на скрытую кровь отрицательный. Таким образом, классических причин железодефицитной анемии не обнаружено. По результатам УзИ органов брюшной полости картина умеренной спленомегалии (размеры селезенки 11,3×4,5см). Пациентка осмотрена гематологом, состояние расценено как анемия вследствие миелофиброза при фиброзно-кистозном остеите.

С целью коррекции анемического синдрома и максимально быстрой подготовки пациентки к оперативному вмешательству была проведена заместительная терапия двумя трансфузиями изогруппной эритроцитарной взвеси суммарным объемом 636 мл.

После достижения целевого уровня гемоглобина 124 г/л была проведена паратиреоидэктомия. Интраоперационный уровень иПтГ составил 122,8 пг/мл, через сутки после операции - 4,47 пг/мл (15-65), что свидетельствовало о радикальности проведенного вмешательства. При гистологическом анализе верифицирована аденома околощитовидной железы альвеолярно-солидного строения из главных клеток с преобладанием светлых со слабо выраженным полиморфизмом.

Обсуждение: На сегодняшний день в имеющихся клинических рекомендациях по обследованию и ведению пациентов с ПГПТ большое внимание уделяется классическим осложнениям заболевания: поражению почек, костной ткани и ЖКТ. В то же время «неклассические» осложнения ПГПТ, в том числе, анемия зачастую остаются без должного внимания.

Анемия при ПгПт может развиваться в силу нескольких причин. Основной и, вероятно, наиболее частой причиной может быть алиментарный дефицит железа. К хронической кровопотере могут приводить ассоциированные с ПгпТ эрозивно-язвенные поражения ЖКТ, а к нарушению синтеза эритропоэтина - прогрессирующая хроническая болезнь почек вследствие рецидивирующего нефролитиаза. Вероятно, в таком случае речь будет идти о микроцитарной 
и гипохромной анемии. Свою роль может играть и повышение ПТГ, которому ряд авторов приписывает свойства ингибитора эритропоэза, и в таком случае наблюдается преимущественно нормохромный и нормоцитарный вариант анемии.

Отдельным патогенетическим фактором развития анемии при ПГПт могут являться костные нарушения, а именно фиброзно-кистозный остеит. При этом состоянии происходит выраженная перестройка костной ткани (преимущественно литические процессы), крайним проявлением которой являются т.н. «бурые опухоли» - результат разрушения нормальной кости ткани и замещение ее и костного мозга фиброзной тканью. Локализуются такие изменения преимущественно в бедренных и большеберцовых костях, а также костях таза. Описанные склеротические изменения (особенно в костномозговых полостях) могут лежать в основе миелофиброза (в настоящее время хорошо известно, что повышение уровня иПтГ оказывает стимулирующее влияние на пролиферацию костномозговых фибробластов), и, следовательно, быть причиной анемии и иных нарушений кроветворения.

Необходимо отметить, что у данной пациентки наблюдалась гипохромная микроцитарная анемия, в то время как для ПГПТ более характерна нормохромная и нормоцитарная форма. В то же время, на фоне выраженного железодефицита (2,5 мкмоль/л), с учетом исключения основных потенциальных причин анемии - язвенных поражений жКТ, дефицита витамина В12, снижения функции почек и уровня эритропоэтина, алиментарного фактора, значимое снижение уровня гемоглобина у данной пациентки, по всей видимости, было обусловлено тяжелым фиброзно-кистозным остеитом и развившимся миелофиброзом.

Выводы: Тяжесть течения ПГПТ (особенно в случае фиброзно-кистозного остеита) должна настораживать врачей в отношении более активного скрининга анемии. Требуются дальнейшие фундаментальные исследования для определения патогенетических механизмов возникновения анемии при ПГПт.

КЛЮЧЕВЫЕ СЛОВА: Анемия; остеодистрофия; первичный гиперпаратиреоз.

\section{ANEMIA DUE TO HYPERPARATHYROID OSTEODYSTROPHY: A CLINICAL CASE}

(c) Gorbacheva A.M. ${ }^{1}$, Shklyaev S.S. ${ }^{1,2}$, Eremkina A.K. ${ }^{1}$, Mokrysheva N.G. ${ }^{1}$

${ }^{1}$ Endocrinology Research Centre, Moscow

${ }^{2}$ National Medical Research Center of Radiology, Moscow 
ПРИМЕНЕНИЕ ТЕРИПАРАТИДА В КАЧЕСТВЕ ЗАМЕСТИТЕЛЬНОЙ ТЕРАПИИ ПРИ ГИПОПАРАТИРЕОЗЕ

( Г) Гребенникова Т.А., Белая Ж.Е.

ФГБУ «Национальный медицинский исследовательский центр эндокринологии» Минздрава России, Москва

Введение: Гипопаратиреоз характеризуется гипокальциемией, низконормальным уровнем паратиреоидного гормона (ПТГ) и нарушением костного ремоделирования. Как правило, для лечения используются препараты кальция и витамина $\mathrm{D}$, однако, в ряде случаев стандартная терапия не позволяет достичь компенсации состояния либо увеличивает риск развития внекостной кальцификации. Мы приводим описание клинических наблюдений применения рекомбинантного человеческого ПТГ (1-34) (терипаратида) в качестве заместительной терапии гипопаратиреоза различного генеза.

Onисание клинического случая: Пациентка С., впервые обратилась в ФГБУ «НМИЦ эндокринологии» Минздрава России в 68 лет с жалобами на парестезии в области лица, спазмы мышц лица и нижней челюсти, периодическое нарушение глотания, судороги икроножных мышц в ночное время, которые возникли после перенесенной экстрафасциальной тиреоидэктомии и удаления аденомы околощитовидной железы (ОЩЖ). Из анамнеза известно, что в 51 год пациентка перенесла резекцию 2/3 желудка по Бильрот 2 по поводу осложнений язвенной болезни, вследствие чего развился вторичный гиперпаратиреоз на фоне синдрома мальабсорбции и дефицита витамина D, который в дальнейшем привел к образованию аденомы ОЩЖ с формированием третичного гиперпаратиреоза: ПтГ 454 пг/мл (15-65), кальций общий 2,72 ммоль/л (2,2-2,55). На этом фоне у пациентки развился генерализованный остеопороз с низкотравматичными переломами обеих лобковых и седалищных костей, компрессионными переломами тел позвонков Th5-Th9. Денситометрия: L1-L4 -4,2, Total hip -3,4, Radius 1/3 -6 по T-критерию. После хирургического лечения папиллярного рака щитовидной железы и удаления аденомы ОЩЖ у пациентки развился гипопаратиреоз с трудно корригируемой гипокальциемией: ПТГ 22,5 пг/мл (15-65), кальций общий 1,64 ммоль/л (2,2-2,55). В виду отсутствия эффекта от назначения максимально допустимых доз препаратов кальция до 9 г/сут и альфакальцидола 4 мкг/сут была инициирована терапия терипаратидом в дозе 20 мкг 2 раза в день, на фоне которой удалось достичь купирования клинических проявлений гипокальциемии, стабильного повышения уровня кальция общего до нижней границы референсного интервала и уменьшения дозы препаратов кальция (до 3 г/сут) и альфакальцидола (до 2 мкг/сут). Пациентка получает данную терапию более трех лет. На фоне длительной терапии терипаратидом новых переломов не было, отмечается прибавка минеральной плотности костной ткани (MПK): L1-L4 -1,7, Total hip -1,8, Radius 1/3 -2,6 по Т-критерию, нежелательных явлений не выявлено.

Пациент В., 70 лет, обратился с жалобами на судороги в мышцах верхних и нижних конечностях, возникающие до 7 раз в сутки преимущественно в ночное время, а также шум в голове, снижение слуха, трудности при письме и общую слабость. Генерализованные судороги беспокоят пациента с 35 лет, тогда же впервые выявлен низкий уровень кальция в крови. Весь период заболевания пациент получал терапию препаратами кальция в больших дозах (4-7 г/сут), однако клинические признаки гиперкальциемии купировались только после парентерального введения глюконата кальция. Последние 2 года пациент принимал карбонат кальция до 4 г/сут в сочетании с активными метаболитами витамина D до 2 мкг/сут, на фоне чего кальций общий 1,51 ммоль/л (2,15-2,55), кальций ионизированный 0,73 ммоль/л (1,03-1,29), фосфор 1,57 ммоль/л (0,74-1,52), ПтГ 6,5 пг/мл (15-65). При осмотре симптомы Хвостека и Труссо положительные, тест рисования «спирали Архимеда» выявил эссенциальный тремор, при общении с пациентом отмечены мнестические нарушения. Денситометрия: L1-L4 2,2, Neck 1,4, Total hip 2 по T-критерию. Все возможные причины развития гипопаратиреоза были исключены, наследственный генез заболевания в связи с поздней манифестацией также маловероятен, поэтому состояние расценено как идиопатический гипопаратиреоз. В виду длительной декомпенсации заболевания у пациента развилась кальцификация стенок сосудов (в 64 года перенес острый инфаркт миокарда, в дальнейшем проведено стентирование передней нисходящей артерии) и базальных ганглиев головного мозга (синдром Фара подтвержден по результатам КТ, клинически проявлялся эссенциальным тремором и мнестическими нарушениями). Принимая во внимание наличие серьезных осложнений гипопаратиреоза, прием препаратов кальция в больших дозах нежелателен, в связи с чем инициирована терапия терипаратидом в дозе 20 мкг 2 раза в сутки, что позволило снизить суточную дозу препаратов кальция и альфакальцидола с достижением нормокальциемии и нормофосфатемии. Пациентка Н., 33 лет, обратилась с жалобами на периодические судороги в кистях рук, периодические приступы удушья, ухудшение памяти. В 29 лет после потери сознания по результатам МРТ головного мозга диагностирован синдром Фара. При обследовании выявлен гипопаратиреоз: ПТГ 4,9 нг/мл (15-65), кальций общий 1,66 ммоль/л $(2,15-2,55)$, кальций ионизированный 0,83 ммоль/л (1,03-1,29), фосфор 1,74 ммоль/л $(0,74-1,52)$. Денситометрия: L1-L4 0,6, Neck 0,8, Total hip 0,7 по Z-критерию. Наиболее частые причины гипопаратиреоза были исключены. Учитывая наличие у пациентки первичной аменореи (с 16 лет принимает 3ГТ), развитие гипопаратиреоза в молодом возрасте, проводился генетический анализ крови - патологических мутаций не выявлено. Поэтому состояние расценено как аутоиммунный гипопаратиреоз (в связи с первичной дисфункцией нескольких эндокринных желез). На фоне пе- 
рорального и парентерального введения препаратов кальция в сочетании с альфакальцидолом удалось купировать клиническую симптоматику, однако сохранялась субкомпенсация показателей фосфорно-кальциевого обмена: кальций общий 1,72 ммоль/л, фосфор 1,49 ммоль/л (0,74-1,52). После назначения терипаратида в дозе 20 мкг/сут удалось достичь компенсации гипопаратиреоза, полностью отменить альфакальцидол, снизить дозу препаратов кальция до 1 г/сут.

Во всех приведенных клинических наблюдениях пациенты принимали колекальциферол в поддерживающих дозах. Назначение терипаратида для лечения гипопаратиреоза и пролонгация терапии более 24 месяцев проводилась на основании решения Врачебной комиссии, т.к. препарат не зарегистрирован для лечения данного заболевания, а длительность его применения ограничена 24 месяцами согласно инструкции.

Заключение: Первой линией терапии гипопаратиреоза являются препараты кальция и активные метаболиты витамина D, однако наиболее физиологичным способом лечения представляется заместительная терапия препаратом ПТГ. Назначение терипаратида обосновано для компенсации гипокальциемии, когда стандартная терапия остается неэффективной или при развитии значимых осложнений гипопаратиреоза, течение которых может усугубляться при применении высоких доз препаратов кальция.

КЛЮЧЕВЫЕ СЛОВА: Гипопаратиреоз; гипокальциемия; терипаратид.

\section{USE OF TERIPARATIDE AS A REPLACEMENT THERAPY FOR HYPOPARATHYROIDISM}

(c) Grebennikova T.A., Belaya Zh.E.

Endocrinology Research Centre, Moscow 
ПЕРВЫЙ ОПЫТ ПРИМЕНЕНИЯ ИННОВАЦИОННОЙ ТЕХНОЛОГИИ RЕМS В РОССИИ

\author{
(с) А.Л. Григорьева, О.М. Лесняк
}

Клиническая ревматологическая больница №25, Санкт-Петербург

«Золотым стандартом» в диагностике остеопороза является рентгеновская денситометрия позвоночника и проксимальных отделов бедра. Использование в диагностике ультразвуковых методов имеет целый ряд преимуществ (отсутствие лучевой нагрузки, более низкая стоимость большая доступность), но до настоящего времени применение его было ограничено из-за невозможности измерения в «целевых» точках - позвоночнике и бедре. Технология REMS является клинически доступной методикой диагностики остеопороза и оценки риска переломов путем оценки минеральной плотности костной ткани в осевом скелете и проксимальных отделах бедра. Его автоматическая обработка нефильтрованных ультразвуковых сигналов обеспечивает точность измерения, а также позволяет оценить риск переломов. Ранее в многоцентровом исследовании, проведенном в Италии показана хорошая сопоставимость результатов измерения MПК с помощью REMS и DXA.

Цель: целью данной работы было ознакомление с радиочастотной эхографической мультиспектрометрией (REMS), неионизирующей техникой исследования осевого скелета, а также сопоставление результатов измерения минеральной плотности костной ткани полученной при использовании технологии REMS и стандартной рентгеновской денситометрии.

Материалы и методы: на базе отделения лучевой диагностики клинической ревматологической больницы №25 проводилось обследование пациентов, обратившихся на консультацию в центр профилактики остеопороза. Всем пациенткам выполнялось измерение минеральной плотности костной ткани по позвоночнику, шейке бедра и общему показателю бедра с использованием технологии REMS (EchoStudio), а также выполнялась рентгеновская денситометрия на аппарате GE Lunar Prodigy Advance. Также проводился расчет индекса FRAX для оценки риска переломов. В настоящее время обследовано 30 пациенток, средний возраст составил 54 года. Набор пациентов продолжается.

Результаты и обсуждение: В ходе проведенного нами исследования значения минеральной плотности костной ткани измеренные двумя методами не были полностью идентичными. Однако совпадение диагнозов (норма, остеопения или остеопороз) было отмечено в 70\% случаев. В некоторых случаях значения имели выраженные отличия, для объяснения причин таких расхождений необходим дальнейший более детальный анализ. Возможно, различия связаны с тем, что при технологии REMS проводится оценка не только плотности, но и качества костной ткани, в то время как рентгеновский денситометр оценивает только плотность костной ткани. Также радиочастотная мультиспектрометрия позволяет в ходе автоматического анализа исключить из анализа имеющиеся артефакты (остеофиты, кальцификацию связочного аппарата и аорты), в то время как при рентгеновской денситометрии исключить данные артефакты из анализа не представляется возможным.

Выводы: технология REMS является новым методом диагностики и мониторирования пациентов, страдающих остеопорозом. Данный метод измерения минеральной плотности костной ткани является безопасным в связи с отсутствием воздействия ионизирующего изучения. Для оценки сопоставимости результатов измерения с помощью технологии REMS и стандартной рентгеновской денситометрии необходимо продолжение исследования и набор большего количества пациентов. Случаи расхождения установленных диагнозов требуют более детального анализа, результаты которого будут представлены в дальнейшем.

КЛЮЧЕВЫЕ СЛОВА: Технология REMS; риск переломов; остеопороз.

\title{
FIRST EXPERIENCE OF USING REMS INNOVATIVE TECHNOLOGY IN RUSSIA
}

(c) Grigorieva A.L., Lesnyak O.M.

Clinical Rheumatology Hospital No. 25, Saint Petersburg 


\title{
ВЗАИМОСВЯЗЬ САРКОПЕНИИ И МИНЕРАЛЬНОЙ ПЛОТНОСТИ КОСТИ У МУЖЧИН
} С ИШЕМИЧЕСКОЙ БОЛЕЗНЬЮ СЕРДЦА

\author{
( С И.И. Григорьева', Т.А. Раскина', О.С. Малышенко ', Е.В. Усова', К.Е. Кривошапова², В.Л. Масенко²
}

'ФГБОУ ВО «Кемеровский государственный медицинский университет» Минздрава России, Кемерово

ФГБНУ «Научно-исследовательский институт комплексных проблем сердечно-сосудистых заболеваний», Кемерово

Цель. Изучить взаимосвязь показателей мышечной массы, мышечной силы и мышечной функции с минеральной плотностью кости (МПК) у мужчин с ишемической болезнью сердца (ИБС).

Материал и методы. Обследованы 79 мужчин в возрасте старше 50 лет с верифицированной ИБС (средний возраст $63(57 ; 66)$ года).

МПК (г/см²) и Т-критерий (стандартное отклонение) шейки бедренной кости (ШБК) и поясничного отдела позвоночника (L1-L4) оценивали методом двухэнергетической рентгеновской абсорбциометрии (DXA) на костном денситометре «Lunar Prodigy Primo» (США).

Для оценки мышечной массы определяли общую площадь (см²) поясничных мышц аксиального среза на уровне 3-го поясничного позвонка (L3) методом мультиспиральной компьютерной томографии на 64-срезовом компьютерном томографе «Somatom Sensation 64» (Siemens AG Medical Solution, ФРГ). Отношение полученного показателя площади скелетной мускулатуры к квадрату показателя роста пациента определяло «скелетно-мышечный индекс L3» (СМИ). Пороговым значением СМИ считали 52,4 см²/M². Оценку мышечной силы выполняли с помощью механического кистевого динамометра ДК-25. Мышечную функцию исследовали с помощью проб, составляющих батарею коротких тестов физического функционирования (SPPB).

Результаты. Данные, полученные по результатам корреляционного анализа, свидетельствуют о наличии достоверной прямой корреляционной взаимосвязи между МПК и показателями кистевой динамометрии ( $r=0,250 ; p=0,026$ для правой руки и $r=0,247 ; p=0,028$ для левой руки), Т-критерием шейки бедра и показателями кистевой динамометрии $(r=0,245 ; p=0,030$ для правой руки и $r=0,242 ; p=0,032$ для левой руки). Аналогичная связь установлена между МПК тел поясничных позвонков и параметрами динамометрии ( $r=0,237 ; p=0,036$ для правой руки и $r=0,228 ; p=0,043$ для левой руки) и Т-критерием поясничного отдела и параметрами динамометрии ( $r=0,232 ; p=0,039$ для правой руки и $r=0,220$; $\mathrm{p}=0,051$ для левой руки). Не установлено значимой связи между показателями денситометрии и результатом батареи коротких тестов физического функционирования.

Отмечена достоверная прямая связь между общим баллом SPPB и площадью скелетной мускулатуры на уровне L3 $(r=0,249, p=0,026)$, общим баллом SPPB и скелетно-мышечным индексом $(r=0,233, p=0,039)$. Аналогичная связь установлена между результатом теста на подъем со стула и общей площадью скелетной мускулатуры на yровне L3 ( $r=0,262$, $\mathrm{p}=0,019)$ и скелетно-мышечным индексом $(\mathrm{r}=0,220, \mathrm{p}=0,050)$.

Обнаружена достоверная отрицательная связь скорости ходьбы и скелетно-мышечного индекса ( $r=-0,260, p=0,021)$. Взаимосвязи между показателями мышечной массы и силы проследить не удалось.

Заключение. Снижение мышечной силы коррелирует с выраженностью потери костной массы, в то время как снижение мышечной функции коррелирует со снижением мышечной массы. Полученные результаты подтверждают вероятность наличия общих механизмов в развитии саркопении и остеопороза у больных ИБС.

КЛЮЧЕВЫЕ СЛОВА: Саркопения; минеральная плотность кости; ишемическая болезнь сердца.

\section{RELATIONSHIP BETWEEN SARCOPENIA AND BONE MINERAL DENSITY IN MEN WITH CORONARY HEART DISEASE}

(c) Grigorieva I. I. ${ }^{1}$, Raskina T.A. ${ }^{1}$, Malyshenko O.S. ${ }^{1}$, Usova E.V. ${ }^{1}$, Krivoshapova K.E. ${ }^{2}$, Masenko V.L. ${ }^{2}$

${ }^{1}$ Kemerovo State Medical University, Kemerovo

${ }^{2}$ Research Institute for Complex Issues of Cardiovascular Diseases, Kemerovo 
КЛИНИЧЕСКИЙ СЛУЧАЙ. ВТОРИЧНЫЙ ОСТЕОПОРОЗ, АССОЦИИРОВАННЫЙ С ЭНДОГЕННЫМ ГИПЕРКОРТИЦИЗМОМ

(с) О.А. Громова, Н.П. Попова

ООО «ПолиКлиника» (Клиника «Источник»), Челябинск

Вторичный остеопороз встречается всего у 5\% женщин и 20 \% мужчин в общей структуре заболеваемости остеопорозом. Эндокринные нарушения являются одной из самых частых причин развития вторичного остеопороза, однако эндогенный избыток глюкокортикоидов (синдром Кушинга) встречается гораздо реже по сравнению, например, с экзогенным гиперкортицизмом. В связи с этим описанный ниже клинический случай может быть полезен врачам клинической практики.

Пациентка К., 36 лет, обратилась с жалобами на переломы, возникающие без травмы.

Из анамнеза: в 2016 г. во время обычной ходьбы внезапно появились боли в грудной клетке и затрудненное дыхание. В приемном покое проведена рентгенография органов грудной клетки, был диагностирован спонтанный пневмоторакс по причине перелома 7 ребра (травму пациентка отрицает), также выявлены переломы еще 3-х ребер неизвестной давности (костная мозоль). Направлена к ревматологу по месту жительства. В феврале 2017 г. проведена DEXA денситометрии позвоночника, Z-критерий (Total) составил -0,3 CO, был выставлен диагноз: Идиопатический остеопороз. В течение 6 месяцев пациентка принимала таблетированные бисфосфонаты, комбинированные препараты кальция и витамина Д. При повторном проведении DEXА денситометрии позвоночника (август 2017 г.) установлено снижение минеральной плотности костной ткани (МПКТ), Z-критерия (Total) снизился на -2,0 СО. Осмотрена эндокринологом по месту жительства, данные не предоставлены. Самостоятельно обратилась к ревматологу г. Челябинска для уточнения диагноза.

При активном расспросе отмечает увеличение веса на 10 кг за несколько лет, появились изменения во внешности, по поводу чего неоднократно обращалась к врачам различных специальностей. Со слов обследование проведено не было.

Хронические заболевания: артериальная гипертензия (длительность заболевания не уточняет), получает антигипертензивную терапию. Прием глюкокортикостероидов отрицает. Наследственность не отягощена. Меnarche c 12 лет, регулярные безболезненные, по 3 дня через 28 дней. Беременности - 3, роды - 2, выкидыш - 1. Питание регулярное, молочные продукты употребляет ежедневно.

При осмотре: распределение подкожно-жировой клетчатки по верхнему типу (лицо, шея, грудь, живот, окружность талии 95 см), состояние питания повышенное (ИМТ 27 кг/м²), одутловатость и умеренная гиперемия лица (матронизм), выраженная атрофия мышц бедер и голеней. Кожа сухая, мраморная, истончённая, с усиленным сосудистым рисунком. Гиперкератоз ладоней, стоп. Волосы тонкие, диффузная алопеция. Щитовидная железа не увеличена, консистенция мягкая, эластичная, узлы не определяются, при пальпации безболезненная. Сердечно-сосудистая система: пульс 96 в минуту, ритмичный, слабого наполнения, не напряжен, артериальное давление 130/90 мм рт. ст., тоны сердца приглушены, шумы сердца не определяются. Пищеварительная система: язык обложен умеренно налетом серого цвета, влажный, без отпечатков зубов. Живот увеличен за счет подкожно-жировой клетчатки, при поверхностной пальпации мягкий, безболезненный. Мочевыделительная система: диурез достаточный. Никтурия 1 раз за ночь.

Пациентка была направлена к эндокринологу с предварительным диагнозом: Синдром Иценко-Кушинга. Вторичный остеопороз с низкоэнергетическими переломами ребер.

Результаты обследования: анализ слюны на кортизол в 24:00: 18,5 нмоль/л (норма <9,4) - повышение в 2 раза; ночная подавляющая проба с дексаметазоном (1 мг): кортизол в 8:00 - 470 нмоль/л (при норме <50 нмоль/л) - отрицательная; ритм секреции адренокортикотропного гормона (АКТГ): 8:00 АКТГ <5 пг/мл, в 21:00 АКТГ <5пг/мл; большая проба с дексаметазоном (8 мг в 24:00): кортизол в 8:00 - 466 нмоль/л, в 8:00 следующего дня 451 нмоль/л - отрицательная, тиреотропный гормон (ТТГ) 0,492 (мкМЕ/мл), свободный тироксин (Т4 св.) - 16,82 (пмоль/л), паратгормон 4,2 (пг/мл) - норма. Общий и биохимический анализы крови - в пределах нормы. При проведении ультразвукового исследования надпочечников выявлены признаки объёмного образования правого надпочечника (гипоэхогенное образование округлой формы с четкими ровными контурами неоднородной структуры $39 * 35$ мм). Мультиспиральная компьютерная томография подтвердила наличие объёмного образования правого надпочечника (объёмное образование размерами 39*32*37 мм, плотностью + 25 ед Н, с бугристыми контурами, активно накапливающего контраст до +75 ед Н в артериальную фазу, прилежащее к внутренней поверхности печени без признаков инвазии).

Выставлен диагноз. Синдром Иценко-Кушинга, впервые выявленный. Кортикостерома правого надпочечника. Прогрессирующий гиперкортицизм, тяжелое течение. Вторичный остеопороз, тяжёлое течение с низкоэнергетическими переломами рёбер со снижением МПКТ (Z-критерий) в позвоночнике на -2,0 СО. Вторичная артериальная гипертензия 1 степени. Избыточная масса тела.

В ноябре 2017г проведено оперативное лечение - эндоскопическая односторонняя ретроперитониоскопическая адреналэктомия справа. Гистологическое заключение: адренокортикальная аденома правого надпочечника. 
Медикаментозное лечение: преднизолон 5 мг/сут (принимает по ситуации), антигипертензивная терапия, оссеин гидроксиапатитный комплекс, колекальциферол, внутривенно введена золендроновая кислота.

Спустя 9 месяцев после оперативного лечения состояние пациентки значительно улучшилось. Вес снизился на 4 кг, объём талии уменьшился на 3 см. Нормализовалось артериальное давление (100-110 и 80 мм. рт.ст.), антигипертензивная терапия отменена. Матронизма нет («румянец» исчез). Кожа нормального цвета и влажности. Гиперкератоза нет. Волосы, ногти нормальные. Не чаще 1 раза в месяц появляется умеренная слабость, сопровождающаяся снижением АД. Сохраняется атрофия мышц бёдер и голеней. Кортизол суточной мочи 101 нмоль/л (норма).

Через год после введения золендроновой кислоты проведена контрольная DEXA денситометрия, без динамики от предыдущей. Новых переломов за период наблюдения не было.

Обсуждение. Клиническая картина гиперкортицизма достаточно яркая, но в связи с тем, что часть симптомов широко распространены в популяции (ожирение, гипертония, диабет и т.д.), могут возникнуть сложности в своевременной диагностике этого заболевания. Остеопороз при эндогенном гиперкортицизме выявляется у 40-90\% пациентов и имеет свои особенности. Изменения в костеобразовании приводят к возникновению быстро прогрессирующего, тяжелого остеопороза. Степень снижения МПК не соответствует тяжести остеопороза. Даже при наличии низкоэнергетических переломов может не обнаруживаться достоверное снижение минеральной плотности костной ткани. Частыми локализациями переломов при гиперкортицизме являются кости свода черепа, позвоночника, таза, ребер.

Заключение. Таким образом, вторичный остеопороз представляет важную медицинскую проблему. Необходимо помнить о заболеваниях и препаратах, способных приводить к развитию вторичного остеопороза, особенно если на приеме пациент молодого возраста.

КЛЮЧЕВЫЕ СЛОВА: Вторичный остеопороз; эндогенный гиперкортицизм; образование надпочечника.

\section{CLINICAL CASE: SECONDARY OSTEOPOROSIS ASSOCIATED WITH ENDOGENOUS} HYPERCORTISOLISM

(c) Gromova O.A., Popova N.P.

LLC «Polyclinic», Chelyabinsk 
(с) А.К. Грузманов ${ }^{1}$, И.З. Нуруллаев ${ }^{1}$, С.О. Мазуренко ${ }^{1,2}$, Д.М. Крутько ${ }^{1,2}$, О.М. Ильина

'ФГБОУ ВПО «Санкт-Петербургский государственный университет, Санкт-Петербург ${ }^{2}$ СПб ГБУз «Городская больница Святого Великомученика Георгия», Санкт-Петербург

Цель. Острое и хроническое нарушение мозгового кровообращения считаются факторами риска прогрессирования саркопении и остеопороза, приводят к нарушению координации движений пожилых людей, увеличивают риск падений и переломов. В исследовании была поставлена цель оценить состав тела и мышечную силу, а также выявить признаки пресаркопении и саркопении у пожилых пациентов, госпитализированных по причине острого нарушения мозгового кровообращения.

Материалы и методы. В исследуемую группу вошли 60 неврологических пациентов с диагнозами: ишемический инсульт или транзиторная ишемическая атака (15\% всех случаев). Среди них было 35 женщин, 25 мужчин. Средний возраст составил 72,9ะ11,6 лет. Все пациенты были разделены на две группы. Первая состояла из 26 человек, имеющих низкоэнергетические переломы в анамнезе. Вторая включала 34 пациента без патологических переломов в прошлом. Все больные были обследованы с использованием методики биоимпедансометрии. Масса скелетной мускулатуры (МСМ) была рассчитана по следующему уравнению: МСМ (кг) =0,566 х БЖМ (безжировая масса). Индекс массы скелетной мускулатуры (ИМСМ) был подсчитан как МСМ (кг)/ рост (м²). Мышечная сила была измерена с помощью ручного динамометра. Диагностические критерии пресаркопении и саркопении были определены в соответствии с консенсусом европейской рабочей группы по саркопении (EWGSOP 1 и 2).

Результаты и обсуждение. Сниженный показатель мышечной силы (неврологические аспекты были учтены) имели 11 пациентов (42,3 \%) из первой группы и 17 пациентов (50,0 \%) из второй. 4 мужчины из первой группы и 2 мужчин из второй имели ИМСМ ниже порогового значения. Лишь у двоих мужчин из первой группы была диагностирована саркопения согласно критериям European Working Group on Sarcopenia in Older People (EWGSOP). Taкже у двоих мужчин из первой и двоих мужчин из второй была диагностирована пресаркопения согласно критериям EWGSOP. Показатель ИМСМ был ниже диагностического порога лишь у 6 пациентов из 60 (все мужчины). В то же время практически половина пациентов демонстрировала существенное снижение мышечной силы. Это можно рассматривать, как очередное доказательство превалирующей роли мышечной силы над массой скелетной мускулатуры при диагностике саркопении.

Заключение. В нашем исследовании не было обнаружено значительной встречаемости саркопении и пресаркопении у пожилых пациентов с острым или транзиторным нарушением мозгового кровообращения. Не было выявлено статистически значимых различий, как в показателях мышечной массы, так и мышечной силы между двумя группами. Тем не менее, обращает на себя внимание высокая распространенность сниженной мышечной силы. На данный момент именно ее стоит рассматривать как наиболее клинически значимый и менее сложный в оценке критерий саркопении по сравнению с мышечной массой.

КЛЮЧЕВЫЕ СЛОВА: Саркопения; ишемический инсульт; транзиторная ишемическая атака.

\section{PREVALENCE OF SARCOPENIA IN ELDERLY PATIENTS WITH ISCHEMIC STROKE OR TRANSIENT} ISCHEMIC ATTACK

(c) Gruzmanov A.K. ${ }^{1}$, Nurullaev I. Z. ${ }^{1}$, Mazurenko S.O. ${ }^{1,2}$, Krutko D.M. ${ }^{1,2}$, Ilyina O.M. ${ }^{2}$

1Saint Petersburg State University, Saint Petersburg

${ }^{2}$ St. George City Hospital, Saint Petersburg 

ПОКАЗАТЕЛИ У ЖЕНЩИН В ПОСТМЕНОПАУЗЕ

\author{
(с) А.С. Гущин, М.Н. Кирпикова, Н.В. Шмелькова
}

ФГБОУ ВО «Ивановская государственная медицинская академия», Иваново

Лечебно-диагностический центр остеопороза и артроза (ООО «Артрамед»), Иваново

Актуальность: Согласно международным и российским клиническим рекомендациям остеоденситометрия - «золотой» стандарт диагностики остеопороза. Со временем накопились данные о несоответствии между минеральной плотностью костной ткани и случаями переломов. Достаточно часто у женщин с переломом шейки бедра при обследовании определяются показатели минеральной плотности кости, соответствующие остеопении (Т-критерий от -1 до -2,5SD).

Стандартная двухмерная денситометрия позволяет оценить лишь поверхностную плотность кости (г/см²), что ограничивает чувствительность метода и приводит к позднему управлению прогнозом перелома шейки бедра. В результате можно видеть несоответствие клинико-инструментальной картины - наличие переломов при умеренном снижении минеральной плотности кости. В клинической практике от данных денситометрии и определения риска переломов зависит тактика ведения пациента, своевременное назначение патогенетического лечения. Однако важным составляющим прогноза являются особенности микроархитектоники костной ткани: минеральная плотность трабекулярной и кортикальной кости, толщина кортикальной кости.

На европейском конгрессе радиологов (Австрия, 2014 г) впервые была представлена технология 3D-DXA, позволяющая построить трёхмерное изображение бедренной кости на основе двухмерных изображений. В последние годы появилось множество исследований на основе нового метода и их количество возрастает. Изучение показателей 3D-DXA, как более чувствительных, актуально для ранней диагностики высокого риска переломов.

Цель исследования: Изучить особенности микроархитектоники проксимального отдела бедра во взаимосвязи с клинико-инструментальными показателями для определения степени снижения минеральной плотности кости и выявления его прогностической значимости.

Материалы и методы: Исследование проводилось в центре остеопороза на рентгеновском остеоденситометре, оснащенном цифровой 3D-станцией. В исследовании участвовала 71 женщина, из которых сформировали 4 группы: 1) пациенты с нормальными показателями минеральной плотности кости без переломов в анамнезе (n=23); 2) с остеопенией по данным остеоденситометрии без переломов в анамнезе $(\mathrm{n}=21) ; 3)$ пациенты с периферическими переломами и остеопенией в проксимальном отделе бедра $(n=14)$; 4) с центральными переломами в анамнезе $(\mathrm{n}=13)$. В группах анализировались показатели: возраст, индекс массы тела, семейный анамнез переломов, риск 10-летней вероятности основных переломов (FRAX), риск перелома шейки бедра, минеральная плотность кости в поясничном отделе позвоночника и в шейке бедра. Кроме того, на основании 3D-анализа биэнергетической абсорбциометрии рассчитывались общая объемная плотность трабекулярной и кортикальной кости, отдельно анализировались объемная плотность трабекулярной и кортикальной кости в шейке бедра, также производился расчёт толщины кортикальной кости в шейке бедра соответственно по передней, задней, латеральной и медиальной стенкам.

Обработка данных осуществлялась в программе «Statistica 10.0», вычисляли среднее арифметическое, стандартные отклонения, критерий Стьюдента, корреляционный анализ. Различия считали значимыми при р<0,05.

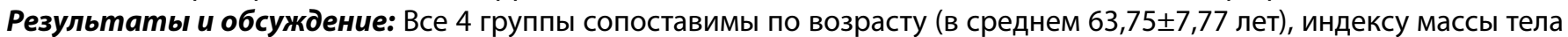

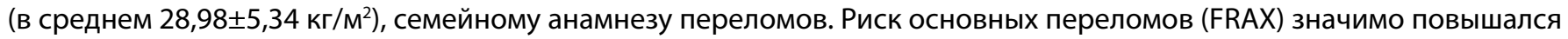

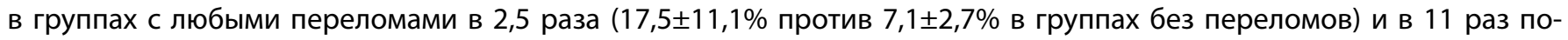

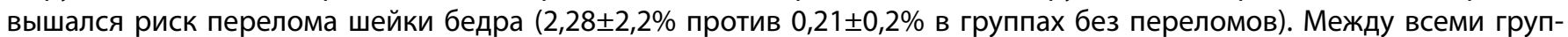
пами по риску основных переломов достоверные отличия были между здоровыми и с остеопенией без переломов

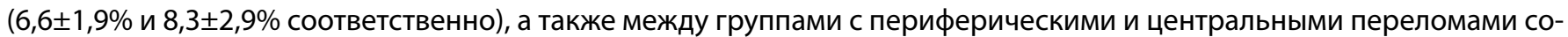

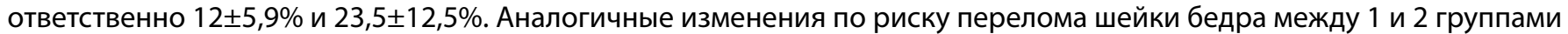

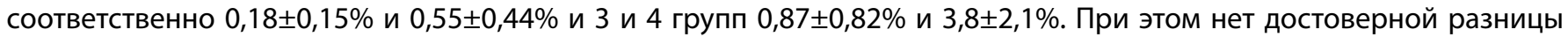
у лиц с остеопенией без переломов и лиц с периферическими переломами в анамнезе.

Анализ минеральной плотности кости в проксимальном отделе бедра показал снижение в группе с остеопенией без переломов в отличие от лиц с нормальной МПК -0,069 г/см² [0,058-0,079] (-6,8\%), группа с периферическими переломами имеет похожие показатели и не отличается от пациентов с остеопенией. Группа с центральными переломами имеет значительное уменьшение плотности -0,266 г/см² [0,252-0,280] (-25,7\%) по сравнению с нормой, а также достоверно отличается от всех других групп. Аналогичные изменения по показателю плотности в шейке бедра: остеопения без переломов -0,115 г/см² [0,108-0,123] $(-12,9 \%)$, группа с периферическими переломами $-0,084$ г/см² [0,075-0,092] (-9\%) от первой группы, сходна с показателем второй группы, пациенты с центральными

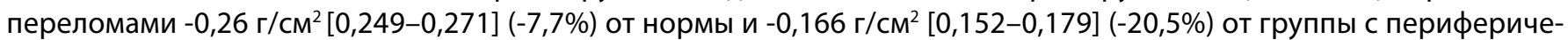
скими переломами. 
В результате анализа данных 3D-DXА удалось установить закономерности изменений в различных участках костной ткани. В группе с остеопенией в отличие от здоровых снижалась объемная плотность трабекулярной кости: общая

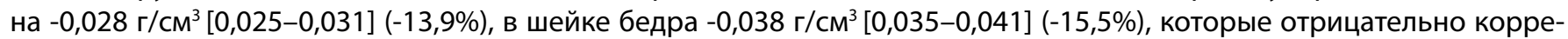
лировали с расчетным риском перелома шейки бедра ( $\mathrm{r}=-0,65 ; \mathrm{p}<0,05)$. Также отмечалось снижение толщины кортикальной кости в шейке бедра: общей $-0,130$ мм $[0,116-0,143](-5,9 \%)$, по стенкам - передней $-0,155$ мм [0,143-0,167] $(-16,2 \%)$, задней $-0,120$ мм [0,110-0,131] (-13\%).

Группа с периферическими переломами значимо отличается от пациентов с остеопенией без переломов по общей объемной плотности кортикальной кости -0,059 г/см³ [0,051-0,068] (-7,9\%). Остальные параметры микроархитектоники аналогичны группе с остеопенией без переломов.

Значимое от всех групп изменение показателей костной ткани наблюдалось в группе наиболее тяжелого остеопороза с центральными переломами: снижались объёмная плотность трабекулярной кости в шейке -0,091 г/см [0,087-0,095] (-37\% от нормы) и общая -0,075 г/см³ [0,071-0,079] (-38,8\% от нормы) и общей плотности кортикальной кости -0,077 г/см³ [0,07-0,084] (-11,2\% от нормы), истончением кортикальной кости в шейке бедра - общей толщины $-0,199$ мм $[0,184-0,213](-14,9 \%)$.

Наибольший интерес представляют результаты групп с остеопенией без переломов и с переломами, у которых МПК не отличалась, однако имеется единственный показатель, различающийся в этих группах, - снижение объемной

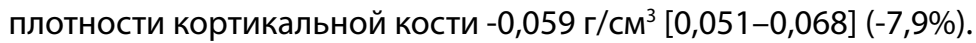

Значительное снижение всех показателей плотности костной ткани сопровождается клинически тяжелым течением остеопороза в виде развития компрессионных переломов позвонков.

Несмотря на зарубежные исследования (ESCEO,2019) показатели 3D-DXA проксимального отдела бедра до сих пор изучались во взаимосвязи с клиническими данными в единичных исследованиях.

Выводы: Снижение минеральной плотности проксимального отдела бедренной кости до остеопении и далее до остеопороза в первую очередь связано со снижением толщины кортикального слоя и снижением объемной плотности трабекулярной кости, обратно взаимосвязанной с риском переломов шейки бедра по FRAX.

Значимым предиктором возникновения периферических переломов у лиц с остеопенией может быть общая объемная плотность кортикальной кости.

КЛЮЧЕВЫЕ СЛОВА: Рентгеновская денситометрия; микроархитектоника костной ткани; остеопороз.

MICROARCHITECTONICS OF BONE TISSUE, CLINICAL AND INSTRUMENTAL CHARACTERISTICS IN POSTMENOPAUSAL WOMEN

(c) Gushchin A.S., Kirpikova M.N., Shmelkova N.V.

Ivanovo State Medical Academy, Russia, Ivanovo

Center for diagnosis and treatment of osteoporosis and arthrosis (LLC «Artramed»), Ivanovo 


\section{() А.С. Гущин ${ }^{1}$, М.Н. Кирпикова ${ }^{1,2}$, И.П. Основина' ${ }^{1}$, М.К. Стаковецкий ${ }^{1,2}$}

ФГБОУ ВО «Ивановская государственная медицинская академия», Иваново

Лечебно-диагностический центр остеопороза и артроза (ООО «Артрамед»), Иваново

Актуальность: Широкая распространенность боли в спине у больных остеопорозом определяет медико-социальную значимость проблемы и требует разработки новых подходов к профилактике и лечению.

Многокомпонентность патогенеза болевого синдрома, наличие острого, хронического и рецидивирующего течения обусловливают необходимость комплексной терапии. При ведении пациентов с болью в спине важно не только купирование боли в максимально ранние сроки, но и профилактика рецидива и хронизации боли путем воздействия на различные механизмы её возникновения. Рекомендуется раннее возвращение к привычному уровню активности при помощи комплекса реабилитационных мероприятий, включающих ЛФК и другие немедикаментозные способы коррекции боли. Наиболее эффективно сочетание различных фармакологических и немедикаментозных методов лечения.

До недавнего времени лазеротерапия глубоко расположенных патологических изменений была невозможна. Традиционные аппараты не могли доставить необходимую дозу энергии к больному участку, не повредив окружающих тканей. HIL-терапия - это самый современный метод лазерного лечения заболеваний опорно-двигательного аппарата с доставкой энергии в глубокие структуры органов и тканей. Уникальность метода основана на действии лазерных импульсов сверхвысокой мощности. Импульсы активно влияют на область патологии, одновременно снимая отек, воспаление и боль. Непосредственно HILT-импульс запатентован и не имеет аналогов. Оборудование разработано в Италии, там же проведены научные исследования, подтверждающие результативность метода, затем метод был запатентован в США и одобрен FDA.

Так как с помощью HIL-терапии одновременно достигаются 3 эффекта: фотомеханический, фотохимический и фототермический - то эта терапия обладает очень высоким противовоспалительным, противоотечным, миорелаксирующим и биостимулирующим воздействием.

Цель работы: Оценить эффективность высокоинтенсивной лазеротерапии (HILT) у больных с постменопаузальным остеопорозом и болью в спине.

Материал и методы: Работа проводилась в Лечебно-диагностическом центре остеопороза и артроза г. Иваново (ООО «АРТРАМЕД») на основании договора с медицинской академией о государственно-частном партнерстве в области научно-исследовательской и учебно-методической работы. В составе центра с 2014 года функционирует первый в центральном федеральном округе (за исключением г.Москва) кабинет HIL-терапии. Группу наблюдения составили 23 пациентки (средний возраст 66,4 12,5 лет) с постменопаузальным остеопорозом, верифицированным методом биэнергетической абсорбциометрии позвоночника и проксимального отдела бедра. Остеопороз сопровождался осложнениями в виде перенесенных ранее периферических переломов и деформациями тел позвонков. Клинические проявления на момент осмотра: боль в нижней части спины, ограничение подвижности пояснично-крестцового отдела позвоночника и мышечно-тонический синдром. Медикаментозная терапия нестероидными противоспалительными препаратами короткими курсами проводилась ранее и была недостаточно эффективна, а на период проведения HIL-терапии HПBП не применялись. При обследовании пояснично-крестцового отдела позвоночника рентгенологически или с помощью МРТ были выявлены деформации тел одного-двух позвонков 1-2 степени тяжести по Genant с отеком, различной степени выраженности дегенеративно-дистрофические изменения в позвоночнике - остеохондроз, осложненный протрузиями дисков, спондилоартроз, сколиоз, кифосколиоз позвоночника. Оценку выраженности боли проводили по шкале ВАШ (визуально-аналоговая шкала) по 10-ти сантиметровой шкале в мм. В среднем всем пациентам было проведено 6 сеансов (от 5 до 7) по стандартному протоколу - аппаратная программа «боль в нижней части спины» с длительностью сеанса в среднем 10-12 мин и достаточно большой мощностью инфракрасного излучения, с периодичностью через один день или ежедневно.

Результаты и обсуждения: Исходно до проведения лазеротерапии выраженность боли в среднем составила 65,4 6,6 мм по ВАШ. После первой процедуры уменьшение болевого синдрома до 30\% отмечали все пациенты, однако продолжительность времени уменьшения или купирования боли была различной - от 3 до 48 часов, в связи с чем потребовались повторные процедуры лазеротерапии. В результате проведенного лечения выраженность боли в спине уменьшилась в среднем до $27 \pm 5,2$ мм по ВАШ (p<0,05), т.е. на $58,7 \%$ от исходного уровня. Следует отметить, что выраженность боли менее 40 мм по ВАШ считается недостоверной и может быть оценена как отсутствие боли.

Выводы: Таким образом, при применении HIL-терапии у больных с осложненным постменопаузальным остеопорозом и болью в спине создаются оптимальные условия для лечения патологии, и сокращается срок лечения. Данный метод немедикаментозной терапии снижает выраженность болевого синдрома на 58,7\% от исходного уровня уже на 3-4 процедуре, то есть эффект сопоставим с современной обезболивающей комплексной медикаментозной терапией. 
HIL-терапия проявляет высокую эффективность при лечении боли в спине, а также отличается удобством и безопасностью: процедура безболезненная и непродолжительная по времени, противопоказания минимальны, в отличие от медикаментозной терапии отсутствуют аллергические реакции, ограничения по возрасту и сопутствующей терапевтической патологии.

КЛЮЧЕВЫЕ СЛОВА: Высокоинтенсивная лазеротерапия; реабилитация; остеопороз.

HIGH-INTENSITY LASER THERAPY (HILT) IN COMPLEX REHABILITATION OF PATIENTS WITH OSTEOPOROSIS

๑ Gushchin A.S. ${ }^{1}$, Kirpikova M.N. ${ }^{1,2}$, Osnovina I.P.', Stakovetsky M.K. ${ }^{1,2}$

Ivanovo State Medical Academy, Russia, Ivanovo

Center for diagnosis and treatment of osteoporosis and arthrosis (LLC «Artramed»), Ivanovo 
'ФГБУ «Институт медико-биологических проблем» РАН, Москва

ФГАОУ ВО «Самарский национальный исследовательский университет имени академика С.П. Королева», Самара ЗФГБОУ ВО Самарский государственный медицинский университет Минздрава России, Самара

Введение. Остеопороз представляет большую опасность не только для пожилых людей, поскольку развитие его может быть обусловлено множеством причин. Так, побочным действием глюкокортикоидов, широко используемых противовоспалительных, иммунодепрессивных, противоаллергических средств, является развитие глюкокортикоидного остеопороза. Также известно снижение минеральной плотности костной ткани у людей, находящихся в условиях невесомости. Множество областей применения стероидных гормонов, развитие дальних космических полетов демонстрируют необходимость разработки мер профилактики остеопоротических изменений. В связи с этим в работе было исследовано влияние минерального костного компонента (МКК) на состояние костной ткани при моделировании глюкокортикоидного остеопороза и условий микрогравитации.

Цель. Изучение структурно-функционального состояния костной ткани при введении минерального костного компонента на фоне стероидиндуцированной костной резорбции и антиортостатического вывешивания.

Материалы и методы. Эксперимент проводили на беспородных лабораторных крысах. Моделирование глюкокортикоидной костной резорбции проводили путем ежедневных внутрибрюшинных инъекций гидрокортизона (ГК). Условия микрогравитации моделировали посредством вывешивания крыс по методу Новикова-Ильина в модификации MoreyHolton. Были созданы группы животных, которым на фоне данных моделей остеорезорбции проводили однократное внутримышечное введение МКК. Определение микротвердости костной ткани проводили по Виккерсу на микротвердомере ПМТ-З. Прямая остеометрия проводилась по оригинальной методике с использованием штангенциркуля, по данным которой были определены два индекса: отношение диаметра диафиза кости к ее массе и индекс Саймона. Рентгенологическое исследование бедренных костей экспериментальных животных было проведено в ветеринарной клинике. Компьютерная томография бедренных костей экспериментальных животных была проведена на рентгеновском цифровом панорамном аппарате с функцией компьютерного томографа. На заключительном этапе проводилось измерение концентрации С-концевых телопептидов, маркера костной резорбции, в сыворотке крови на стрипповом иммуноферментном анализаторе.

Результаты. В ходе работы установлено, что значения поверхностной микротвердости снижаются в группах с моделированием как стероидной резорбции костной ткани, так и условий микрогравитации, а также при совмещении этих двух моделей. Инъекции минерального костного компонента на фоне вызванной резорбции сопровождаются более высокими значениями данного показателя, что свидетельствует о нормализации минерального обмена в костной ткани экспериментальных животных. Остеометрические индексы характеризуют состояние костной ткани по обратной зависимости, и, согласно полученным данным их значения, как правило, возрастают в группах с экзогенной нагрузкой стероидами, вывешиванием и комбинированным воздействием этих факторов. В группах с введением МКК значения индексов оказывались ниже, чем в условиях моделированной остеорезорбции, и в некоторых случаях были близки контрольным. Данные рентгенологического исследования бедренных костей крыс демонстрируют снижение минеральной плотности костной ткани при моделировании глюкокортикоидной остеорезорбции и условий измененной гравитации, а инъекции исследуемого аллогенного биоматериала снижают интенсивность костной резорбции. Проведение компьютерной томографии костной ткани экспериментальных животных продемонстрировало тенденцию снижения значений максимальной плотности кортикального слоя проксимального участка бедренных костей крыс во всех группах с моделированной резорбцией. Инъекции МКК сопровождаются возрастанием значений данного показателя, что говорит об улучшении состояния костной ткани. Анализ кортикального индекса Нордина-Барнетта для бедренных костей крыс, проведенный по данным компьютерной томографии, показал ухудшение состояния костной ткани при инъекциях ГК, Вывешивании крыс и совмещении данных воздействий, что выражалось в снижении значений данного индекса. Введение минерального костного компонента нормализует состояние костной ткани, что сопровождается возрастанием значений кортикального индекса. Увеличение концентрации С-концевыхтелопептидов коллагена I типа в сыворотке крови крыс в группах с моделированием остеорезорбции продемонстрировало ухудшение состояния костной ткани. При инъекциях МКК изменения оказались значительно менее выраженными.

Выводы. Установлено, что внутримышечные инъекции минерального костного компонента на фоне моделирования остеопоротических изменений костной ткани нормализуют её состояние.

КЛЮЧЕВЫЕ СЛОВА: Минеральный костный компонент; остеопороз; глюкокортикоидный остеопороз. 
STRUCTURAL AND FUNCTIONAL STATE OF BONE TISSUE WITH INTRODUCTION OF MINERAL BONE COMPONENT ON THE BACKGROUND OF OSTEOPOROTIC CHANGES MODELING

(c) Daniel M.A. ${ }^{1}$, Romanova D.A. ${ }^{2}$, Pisareva E.V. ${ }^{2}$, Vlasov M.Yu. ${ }^{3}$

${ }^{1}$ Institute of Medical and Biological Problems, Moscow

${ }^{2}$ Samara National Research University named after S.P. Korolev, Samara

${ }^{3}$ Samara State Medical University, Samara 
Цель исследования: оценить состояние минеральной плотности кости (МПК) у пациентов, страдающих ревматоидным артритом (РА) и саркопенией.

Материалы и методы: в исследование включены 79 женщин (медиана возраста 60 [55; 65] лет с достоверным PA, диагностированным в соответствии с критериями ACR/EULAR (2010), 1-2-го функционального класса. Всем пациентам проводились тесты оценки мышечной силы (кистевая динамометрия, тест «Подъем со стула»), двуэнергетическая рентгеновская абсорбциометрия поясничного отдела позвоночника, проксимального отдела бедра и всего тела; определение 10-летней вероятности остеопоротических переломов с использованием алгоритма Fracture Risk Assessment Tool (FRAX ${ }^{\oplus}$ ). Статистический анализ проводился с использованием непараметрических методов. Исследование получило одобрение этического комитета ФГБНУ НИИР им. В.А. Насоновой. Все пациенты подписали информированное согласие на участие.

Результаты: на основании результатов тестов оценки мышечной силы и денситометрии всего тела участники исследования в соответствии с критериями Европейской рабочей группы по изучению саркопении (European Working Group on Sarcopenia in Older people 2, EWGSOP2) были разделены на две группы: 1) с подтвержденной саркопенией $(\mathrm{N}=20$, медиана возраста 59 [53; 64] лет); 2) без саркопении ( $\mathrm{N}=59$, медиана возраста 60 [55; 67] лет). Группы значимо не различались по возрасту, времени наступления менопаузы, длительности постменопаузы, потреблению кальция с продуктами питания, частоте использования и кумулятивной дозе глюкокортикоидов, по величине СОЭ, С-реактивного белка и индекса DAS28. В тоже время у пациентов с саркопенией длительность течения РА была больше, а индекс массы тела меньше, чем у женщин без саркопении ( $p=0,006$ и 0,0001, соответственно). В поясничном отделе позвоночника средние абсолютные значения МПК значимо не различались: 0,892 [0,772; 1,024] г/см² - у пациентов с саркопенией и $0,910[0,785 ; 1,028]$ г/см² - у лиц с нормальной мышечной массой (р>0,05). Средние общий показатель бедра и пока-

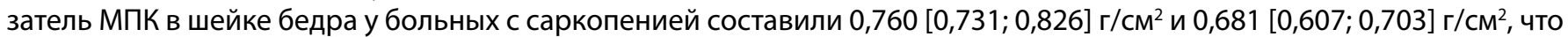

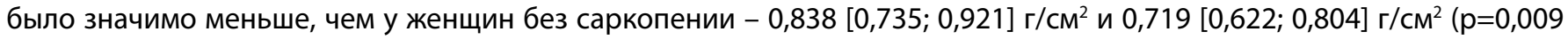
и $\mathrm{p}=0,048$, соответственно).

При расчете 10-летней вероятности остеопоротических переломов оказалось, что риск как переломов всех основных локализаций, так и переломов проксимального отдела бедренной кости был значимо больше у больных РА с саркопенией - 22\% [17,0; 32,0] и 3,1\% [3,0; 7,5] по сравнению с пациентами с нормальной мышечной массой, у которых аналогичные показатели составили $13,0 \%[9,7 ; 18,5]$ и $1,4[0,9 ; 2,78]$, соответственно (p<0,05).

Выводы: женщины с РА и саркопенией характеризовались значимо меньшей МПК в шейке бедренной кости и в проксимальном отделе бедра в целом и имели большую вероятность остеопоротических переломов, рассчитанную по алгоритму FRAX ${ }^{\oplus}$, по сравнению с больными PA с нормальной мышечной силой и массой. Это требует дополнительного внимания врача в отношении тактики назначения противоостеопоротической терапии, с учетом того, что саркопения является самостоятельным фактором риска падений и ухудшает прогноз при переломах.

КЛЮЧЕВЫЕ СЛОВА: Ревматоидный артрит; саркопения; риск переломов.

\section{BONE MINERAL DENSITY AND FRACTURE RISK IN PATIENTS WITH RHEUMATOID ARTHRITIS AND SARCOPENIA}

(c) Demin N.V., Dobrovolskaya O.V., Kolkhidova Z.A., Menshikova A.G., Feklistov A.Yu., Toroptsova N.V.

Ministry of Science and Higher Education, Moscow

Research Institute of Rheumatology named after V.A. Nasonova, Moscow 
РОЛЬ ДЕФИЦИТА ВИТАМИНА D В ПАТОГЕНЕЗЕ АУТОИМУННЫХ ЗАБОЛЕВАНИЙ ЭНДОКРИННОЙ СИСТЕМЫ

( О.С. Деревянко ${ }^{1,2}$, Л.И. Ибрагимова2 , Е.В. Пекарева², М.Р. Рагимов², Т.В. Никонова2 , Л.В. Никанкина²

'ООО «КДФ-Москва», Москва

ФГБУ «Национальный медицинский исследовательский центр эндокринологии» Минздрава России, Москва

Цель. В последние десятилетие появилось большое количество новых данных о роли витамина D не только в регуляции фосфорно-кальциевого обмена, но и его влиянии на развитие и течение аутоиммунных заболеваний. Одной из наиболее частых комбинаций аутоиммунных заболеваний в практике эндокринолога является сахарный диабет 1 типа в сочетании с аутоиммунным тиреоидитом (АИТ).

Целью данного исследовании было оценить уровень 25-гидроксивитамина D (25(OH)D) у пациентов с СД1 без сопутствующей аутоиммунной патологии и пациентов с СД1 в сочетании с АИТ.

Материалы и методы. 72 пациента с СД1 (42 женщины; средний возраст 43,5土12,8 года) находились под наблюдением в НИМЦ Эндокринологии с декабря 2018 года по сентябрь 2019 года. Всем пациентам с СД1 определялись 25(OH)D, паратгормон, кальций, ТTГ, АТ к TПО, АТ к тиреоглобулину. Также исследовались антитела к поджелудочной железе - GAD, тирозинфосфатазе (IA-2), транспортеру цинка (Znt8) - для подтверждения аутоиммунного генеза диабета.

Группу контроля составили 42 здоровых человека без установленных аутоиммунных заболеваний.

Результаты и обсуждение. В группе пациентов с СД1 ( $\mathrm{n}=72)$ значения 25(OH)D были значимо ниже в сравнении с группой контроля - 12,4 [9,1;21,0] против $27,3[22,1 ; 34,7]$ нг/мл, p<0,0001.

30 из 72 пациентов с СД1 имели положительный титр АТ к ТПО и/или ТГ, из них 14 получали лечение тироксином на момент обследования, 7 имели впервые выявленный субклинический гипотиреоз и 16 были носителями антител к ТПО и ТГ с ТТГ в пределах референсных значений.

У пациентов с СД1 с положительным титром АТ к ТПО/ТГ (30 из 72 пациентов) были выявлены более низкие значения 25(OH)D в сравнении с пациентами без антител к щитовидной железе (36 пациентов) - 11,7 [6,8; 22,1] против $20,6[11,1 ; 26,7]$ нг/мл; $p=0,0047$.

Выводы. Данные настоящего исследования показали значительное снижение уровня 25(OH)D у пациентов с CД1, при этом достоверно более низкие значения были у пациентов с СД1 в сочетании с положительным титром АТ к щитовидной железе.

Полученные данные могут свидетельствовать о возможном влиянии дефицита витамина D на развитие неспецифичной аутоиммунной агрессии, направленной против нескольких органов и систем.

Финансирование: Работа выполнена при поддержке гранта № 17-75-30035 Российского научного фонда.

КЛЮЧЕВЫЕ СЛОВА: Дефицит витамина D; аутоиммунный тиреоидит; сахарный диабет 1 типа.

\section{THE ROLE OF VITAMIN D DEFICIENCY IN THE PATHOGENESIS OF AUTOIMMUNE DISEASES OF THE ENDOCRINE SYSTEM}

(c) Derevyanko O.S. ${ }^{1,2}$, Ibragimova L.I. ${ }^{2}$, Pekareva E.V. ${ }^{2}$, Ragimov M.R. ${ }^{2}$, Nikonova T.V. ${ }^{2}$, Nikankina L.V. ${ }^{2}$

'LLC «KDF-Moscow», Moscow

${ }^{2}$ Endocrinology Research Centre, Moscow 
(с) О.С. Деревянко ${ }^{1,2}$, Л.И. Ибрагимова², Е.В. Пекарева², М.Р. Рагимов², Т.В. Никонова², Л.В. Никанкина ${ }^{2}$

${ }^{1}$ ООО «КДФ-Москва», Москва

ФГБУ «Научный медицинский исследовательский центр эндокринологии» Минздрава России, Москва

Цель. Известно, что витамин D участвует в процессах регуляции фосфорно-кальциевого обмена. При этом за последнее десятилетие увеличивается количество данных о роли витамина D в развитии аутоиммунных заболеваний, в частности, сахарного диабета 1 типа (СД1). Известно, что аутоиммунный гастрит встречается у пациентов с СД1 до 10 раз чаще по сравнению с общей популяцией. Ранее сообщалось о роли аутоиммунного гастрита в патогенезе дефицита питательных веществ, в нашем исследовании оценивалась взаимосвязь аутоантител к париетальным клеткам желудка (АТ к ПКЖ), патогномоничных для аутоиммунного гастрита и уровнем витамина D у пациентов с СД1. Целью данного исследования было оценить распространенность дефицита витамина D у пациентов с СД1 и взаимосвязь титра AT к ПКЖ и уровня Витамина D.

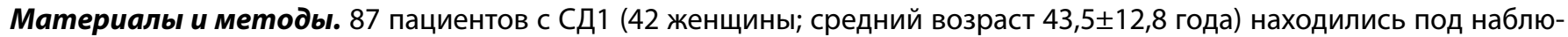
дением в НИМЦ Эндокринологии с декабря 2017 года по ноябрь 2018 года. Всем пациентам с СД1 определялись 25 гидроксивитамин D (25(OH)D), паратгормон, кальций, AT к ПКЖ. Также исследовались антитела к поджелудочной железы - GAD, тирозинфосфатазе IA-2, транспортеру цинка (Znt8) - для подтверждения аутоиммунного генеза диабета. Группу контроля составили 42 здоровых человека без установленных аутоиммунных заболеваний.

Результаты и обсуждение. В группе пациентов с СД1 ( $\mathrm{n}=87)$ значения 25(OH)D были значимо ниже в сравнении с группой контроля - 14,6 [9,1;23,0] против 27,0 [22,1;34,7] нг/мл, p<0,0001.

32 из 87 пациентов с СД1 имели положительный титр АТ к ПКЖ и 55 не имели АТ к ПКЖ. 3начения 25(OH)D в этих группах составляли 9,3 [6,1; 17,0] и 17,4 [9,9-23,6], соответственно. Таким образом, пациенты с СД1 с положительным титром AT к ПКЖ имели достоверно более низкие значения 25(OH)D в сравнении с пациентами с СД1 без АТ к ПКЖ, $\mathrm{p}=0,0011$.

Только 3 из 42 лиц контрольной группы (7\%) имели положительный титр АТ к ПКЖ.

Выводы. Данные настоящего исследования показали значительное снижение уровня 25(OH)D у пациентов с СД1, при этом достоверно более низкие значения были у пациентов с СД1 в сочетании с положительным титром АТ к ПКЖ. Полученные данные свидетельствуют о возможном сочетанном влиянии СД1 и аутоиммунного гастрита на разные звенья патогенеза дефицита Витамина D у данной категории больных.

Финансирование. Работа выполнена при поддержке гранта № 17-75-30035 Российского научного фонда.

КЛЮЧЕВЫЕ СЛОВА: Аутоиммунный гастрит; сахарный диабет 1 типа; дефицит витамина D.

\section{AUTOIMMUNE GASTRITIS - A RISK FACTOR FOR VITAMIN D DEFICIENCY IN PATIENTS WITH TYPE 1 DIABETES MELLITUS?}

(c) Derevyanko O.S. ${ }^{1,2}$, Ibragimova L.I. ${ }^{2}$, Pekareva E.V. ${ }^{2}$, Ragimov M.R. ${ }^{2}$, Nikonova T.V. ${ }^{2}$, Nikankina L.V. ${ }^{2}$

${ }^{1}$ LLC «KDF-Moscow», Moscow

${ }^{2}$ Endocrinology Research Centre, Moscow 
'ФГБОУ ВО «Омский Государственный Медицинский Университет» Минздрава России, Омск

${ }^{2}$ БУЗОО «Клинический Медико-Хирургический Центр», Омск

Остеопороз (ОП) - системное заболевание скелета, при котором снижается прочность кости, что приводит к повышению риска переломов. Остеопороз поражает весь скелет, но, особенно, кости бедра, предплечья, плеча и позвонки. В последние годы выполнен ряд исследований по оценке влияния различных заболеваний на развитие остеопоротических переломов. В литературе обсуждается вопрос о влиянии факторов питания, качества жизни и вредных привычек на метаболизм костной системы.

Цель работы: создание и анализ единой базы данных пациентов с переломами-маркерами остеопороза на дооперационном и послеоперационном этапах.

Задачи: сформировать единый опросник для пациентов, перенесших остепоротический перелом и начавших терапию остеопороза, провести анкетирование этой группы пациентов в ранний (до 1 месяца) и отсроченный (3 и 6 месяцев) постоперационный период, произвести расчеты по выбранным шкалам и опросникам, объединить полученные сведения в единой базе данных, выполнить их статистическую обработку и выявить зависимости. Для оценки качества жизни в работе использовался опросник SF-36, предполагающий оценку уровня физического и психологического компонентов здоровья, оценка уровня питания осуществлялся способом, предлагаемым Европейской Ассоциацией Клинического питания (ESPEN) - «Скрининг нутриционного риска (NRS-2002)» и мини-опросником нутриционного статуса для пожилых людей (MNA), кроме того исследовались показатели бытовой активности, характера сопутствующей патологии, жилищно-бытовых условий, наличия вредных привычек и пр.

Результаты и выводы. Средний возраст опрошенных пациентов составил 76,4 года, преобладали женщины (82,4\%), вредных привычек они не имели. Переломы нижней конечности регистрировались в 62,4\%, верхней - в 37,6\%, большая часть повреждений костей нижней конечности приходилась на чрезвертельные переломы (более $43 \%$ случаев), верхней - на хирургическую шейка плечевой кости (36,4\%). Оперативное лечение было проведено у 81,6\% пациентов, средний предоперационный койко-день составил 4,8. Большинство сопутствующей патологии составили сердечно-сосудистые заболевания (91\%), анемия различной степени наблюдалась у 62\% пациентов, заболевания легких регистрировались у 12,4\%, ЖКТ - у 42,5\% пациентов, сахарный диабет был выявлен у 40\% опрошенных. Среднее количество заболеваний у каждого пациента составило 4,8. Все пациенты (100\% случаев) постоянно принимали медикаменты до травмы и продолжают принимать в посттравматическом периоде в зависимости от сопутствующей патологии, при этом среднее количество препаратов составляет 4,8. Спортивной активностью не занимаются более $90 \%$ опрошенных. Все пациенты живут хотя бы с одним из родственников, при этом 46,3\% нуждаются в дополнительном уходе.

Результаты опросника SF-36, свидетельствовали об улучшении изучаемых показателей после оперативного лечения и начала приема препаратов антирезорбтивной группы. Интегрированный показатель физического здоровья в ранний послеоперационный период снижался на 18,9\%, но полностью восстанавливался уже к 3-м месяцам, а к 6-и месячному сроку даже несколько увеличивался (на 3,8\%). К этому сроку значительно возрастали и остальные исследуемые показателя: общего состояния здоровья (на 16,7\%), ролевого функционирования (на 21,2\%), снижения болевого синдрома (на 38,4\%). Устойчивой потери аппетита, тошноты, рвоты, снижения массы тела пациенты не отмечали, съемные зубные протезы были у 68,2\% опрошенных. Однако скрининг нутриционного риска свидетельствовал о возвращении пациентов к привычному ритму и объему питания - риск недостаточности питания был выявлен у 65,4\% пациентов, результат по шкале NRS-2002 составил менее 3 единиц у всех наблюдаемых пациентов. Таким образом, в результате работы получены новые знания и отмечены некоторые закономерности между статусом питания, качеством жизни и категориями пациентов травматологического профиля. Полученные результаты могут быть использованы в практическом здравоохранении для коррекции режима питания и функциональных нагрузок у пациентов с остеопорозом и переломами как до, так и после выполнения оперативного лечения и на дальнейших этапах реабилитации.

КЛЮЧЕВЫЕ СЛОВА: Остеопороз; переломы; качество жизни.

\section{ASSESSMENT OF THE QUALITY OF LIFE IN PATIENTS WITH FRACTURES - MARKER OF OSTEOPOROSIS (OBSERVATIONAL STUDY)}

(c) Dzyuba G.G. ${ }^{1}$, Stasenko I.N. ${ }^{1}$, Kendys T.N. ${ }^{2}$, Ibragimova N.A. ${ }^{2}$

'Omsk State Medical University, Omsk

${ }^{2}$ Clinical Medical and Surgical Center, Omsk 


\section{(с) Е.В. Добровольская ${ }^{1}$, Д.В. Турчанинов², Е.А. Вильмс², Е.А. Быкова}

'БУЗ Омской области «Клинический диагностический центр», Омск

ФГБОУ ВО Омский Государственный Медицинский Университет Минздрава России, Омск

Остеопороз и связанные с ним переломы во всем мире представляют собой серьезную проблему здравоохранения с удручающими последствиями, приводящими к повышенному уровню смертности и инвалидизации.

Результаты исследований, проведенных в различных регионах РФ, продемонстрировали, что низкий уровень витамина D наблюдается у лиц различного возраста независимо от региона проживания.

Применение кальция и витамина D является основой как профилактики, так и фармакотерапии остеопороза. Следует подчеркнуть, что, помимо прямого влияния на метаболизм костей, витамин D оказывает сильное благоприятное влияние на мышечную силу и функцию и, следовательно, снижает риск падений.

Цель исследования: сравнительная оценка обеспеченности витамином D пациентов с различными проявлениями остеопороза и здоровых лиц.

Материалы и методы: Обследованы 4304 пациента, обратившихся в лечебные учреждения г. Омска за период январь - декабрь 2017 года. Среди них пациенты с диагнозом остеопороз (M80. M81) - (n=1084), с диагнозом остеопения (M.85.8) ( $\mathrm{n}=423)$ и лица без подозрения на эти заболевания $(\mathrm{n}=2392)$.

Предметом исследования являлось содержание метаболита 25(OH)D в сыворотке крови вышеперечисленных категорий пациентов.

Дизайн исследования: поперечное (одномоментное) эпидемиологическое исследование. Период проведения исследования: с января по декабрь 2017 года.

Обеспеченность витамином D определяли по уровню содержания метаболита витамина D кальцидиола в сыворотке крови [25(OH)D], взятой натощак из локтевой вены. Определение проводилось методом иммунохемилюминесцентного анализа на анализаторе Architect i2000 или электрохемилюминесцентного анализа на анализаторе Cobas е601 в аккредитованной лаборатории Бюджетного учреждения здравоохранения Омской области «Клинический диагностический центр».

Оценку D-витаминного статуса проводили на основании следующих критериев: нормальным считали содержание 25(ОН)D в пределах 30,01-80 нг/мл, 20,01-30 нг/мл соответствовали недостаточности, 10,01-20 нг/мл - дефициту, $<10$ гг/мл тяжелому дефициту, >80 нг/мл - избытку.

Поскольку возраст является одним из факторов, определяющих как экзогенное поступление, так и эндогенный синтез витамина, была сформирована группа сравнения из здоровых лиц со средним возрастом, соответствующим диагно-

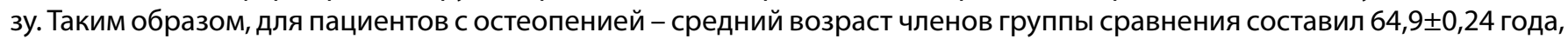

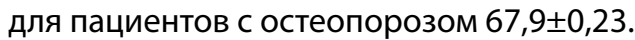

При анализе группы пациентов с остеопорозом и остеопенией в зависимости от факта приема препаратов витамина D для лечения (критерии, длительность?) были разделены на соответствующие подгруппы.

Результаты: Социально-демографическая характеристика: большинство исследуемых составили лица женско-

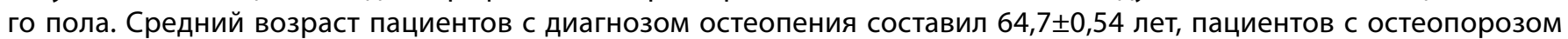
$67,4 \pm 0,3$ лет.

В группе пациентов с диагнозом остеопения у половины обследованных выявлен дефицит витамина D различной глубины, 38,37\% имели уровень, соответствующий недостаточности, и только 11,63\% показали оптимальный уровень 25(OH)D в сыворотке крови. Медиана уровня 25(OH)D занимала пограничное положение с дефицитом и составила $19,9(14,7 ; 25,4)$ нг/мл.

Как уровень обеспеченности, так и структура нарушений D-витаминного статуса пациентов этой группы имели отличия от показателей здоровых лиц. Для группы условно здоровых лиц (группа сравнения для пациентов с остеопенией) характерно более высокое медианное значение $25(\mathrm{OH}) \mathrm{D} 21,6(15,1 ; 28,9)$ и меньшая распространенность таких состояний как дефицит и недостаточность: 46,5\%, и 34,19\% соответственно.

В группе исследуемых с остеопорозом дефицитное состояние сопровождало 62,5\% пациентов, причем явление глубокого дефицита в этой группе встречалось в два раза чаще. Значения 25(OH)D в сыворотке соответствующие недостаточности имели $26,43 \%$, доля лиц с нормальной обеспеченностью не отличалась от группы пациентов с явлениями остеопении и составила $11,1 \%$.

Структура нарушений D-витаминного статуса пациентов с остеопорозом, сопровождающимся переломами отличалась еще большей распространенностью дефицитных состояний - 64,3\%, в то время как недостаточность сопровождала 25,1\% исследуемых, и 10,6\% имели значения в диапазоне нормальных. 
Отличия больных различными формами остеопороза от представителей контрольной группы из здоровых лиц проявлялись как более низком медианном значении метаболита 25(OH)D в сыворотке крови, так и большей распространенности дефицитных состояний среди обследуемых с различными вариантами остеопороза.

Пациенты с остеопенией, получающий колекальциферол, демонстрировали лучший уровень обеспеченности витамином D. Пациенты с оптимальным уровнем обеспеченности составили 42,3\%, тем не менее $32 \%$ имели недостаток, а 25,2\% - дефицитные состояния. Медианное значение уровня 25(OH)D у пациентов, принимающих препараты витамина D находилось в диапазоне субоптимальных значений и составляло $26,73(19,9 ; 34,5)$.

Сывороточные концентрации 25(OH)D в группах пациентов, получающих препараты витамина D с различными проявлениями остеопороза, явлениями остеопении находились на одном уровне, между собой не различались. Медианные концентрации исследуемого метаболита в сыворотке крови пациентов, получающих терапию, были выше, чем у здоровых людей, более чем на 5 нг/мл.

\section{Выводы:}

1. Пациенты с разными стадиями остеопоротического процесса демонстрировали разный уровень обеспеченности витамином D. Отмечалось уменьшение концентрации 25(OH)D сыворотке по мере прогрессирования этого состояния. Таким образом, медиана содержания кальцидиола в сыворотке крови имела наиболее низкое значение при остеопорозе, сопровождающимся переломами $17,4(13,4 ; 22,9)$.

2. Имели место отличия уровней 25(OH)D в сыворотке крови пациентов с остеопенией, остеопорозом без переломов и остеопорозом с переломами и здоровых людей без симптомов остеопороза соответствующей возрастной группы. 3.Пациенты с остеопенией и остеопорозом, получающие препараты витамина $\mathrm{D}$, имели гораздо лучшую обеспеченность, чем больные без лечения и здоровые пациенты, без жалоб и клинических признаков остеопороза соответствующей возрастной группы.

4. На фоне лечения препаратами витамина D уровень $25(\mathrm{OH}) \mathrm{D}$ в сыворотке крови значимо увеличивался, однако не достигал даже нижней границы нормальной обеспеченности (30 нг/мл). На фоне приема препарата отклонение от нормальных значений 25(OH)D выявлено у 61,62\% обследованных, причем 25,97\% из них имели дефицит, а 2,74\% глубокий дефицит.

5. Несмотря на то, что уровень 25(OH)D, характерный для остеопении и для остеопороза (с переломами и без) различается, на приеме витамина D достигаются при всех заболеваниях примерно одинаковые уровни 25-26 нг/мл.

КЛЮЧЕВЫЕ СЛОВА: Остеопения; остеопороз; витамин D.

\section{CHARACTERISTICS OF THE VITAMIN D STATUS OF PATIENTS WITH OSTEOPENIA AND OSTEOPOROSIS IN THE POPULATION OF THE OMSK REGION, THE POTENTIAL FOR CORRECTION: WHAT WE CAN AND CANNOT DOTODAY}

(c) Dobrovolskaya E.V. ${ }^{1}$, Turchaninov D.V. ${ }^{2}$, Wilms E.A. ${ }^{2}$, Bykova E.A. ${ }^{1}$

${ }^{1}$ Clinical and Diagnostic Center, Omsk

${ }^{2}$ Omsk State Medical University, Omsk 


\section{( О.В. Добровольская, П.С. Коваленко, Н.В. Демин, Н.В. Торопцова, И.С. Дыдыкина, О.А. Никитинская, Е.Л. Насонов}

Министерство науки и высшего образования РФ, Москва

ФГБНУ «Научно-исследовательский институт ревматологии имени В.А. Насоновой», Москва

Цель исследования: сравнить эффект двухлетнего лечения деносумабом (ДСБ) на минеральную плотность кости (МПК) у больных ревматоидным артритом (РА) с остеопорозом (ОП) и у женщин с постменопаузальным ОП.

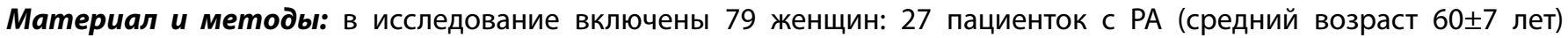
и 52 женщины с постменопаузальным ОП (средний возраст 62 11 лет). Группы не различались по величине индекса массы тела и длительности постменопаузы. Все пациентки получали лечение ДСБ 60 мг подкожно 1 раз в 6 месяцев, а также препаратами кальция (500-1000 мг) и витамина D (800-1000 ME) ежедневно. МПК измерялась с использованием двуэнергетической рентгеновской абсорбциометрии (DXA - Dual-Energy X-ray Absorptiometry, Hologic Discovery A) в поясничном отделе позвоночника (L1-L4), проксимальном отделе бедра в целом (ПОБ) и дистальной трети предплечья. МПК определялась в начале исследования, через 1 и 2 года терапии ДСБ. На каждом визите участникам исследования проводился биохимический анализ крови и опрос для сбора информации о нежелательных явлениях на фоне терапии ДСБ и произошедших новых низкоэнергетических переломах. Исследование одобрено этическим комитетом ФГБНУ НИИР им. В.А. Насоновой. Все женщины подписали информированное согласие на участие в исследовании.

Результаты: на фоне лечения ДСБ произошло значимое увеличение МПК во всех областях измерения как у женщин без ревматических заболеваний (РЗ), так и у пациенток с РА. Прирост МПК у женщин с РА и ОП за два года составил B L1-L4 6,0\%, в ПОБ - 2,8\% и в дистальной трети предплечья - 2,2\%; у лиц без воспалительных P3 за это же время МПК увеличилась на 7,6\%, 3,6\% и 1,6\%, соответственно. У пациентов с РА эффект ДСБ не зависел от исходного уровня иммунологических маркеров воспаления и использования глюкокортикоидов. Длительная терапия ДСБ не оказала положительного эффекта на активность РА. При оценке влияния ДСБ на деструкцию костной ткани мелких суставов кистей и стоп было выявлено, что у 78\% пациентов отсутствовали изменения в счете эрозий и общем счете по Sharp-van der Heijde, а у 22\% отмечалась отрицательная динамика этих показателей. Прогрессирование сужения суставной щели отмечено лишь у $15 \%$ женщин с РА, а у $85 \%$ - отрицательной динамики за два года не отмечено. Средняя концентрация кальция в сыворотке крови на фоне терапии ДСБ значимо не изменялась в обеих группах, в том числе не отмечено случаев гипокальциемии. Также за весь период наблюдения не было значимых колебаний уровня сывороточного креатинина. Частота нежелательных явлений составила 3,8\% в группе больных РА, необходимости отмены ДСБ при этом не было. За время наблюдения не произошло новых низкоэнергетических переломов и случаев инфекционных осложнений в обеих группах. Двухлетняя приверженность лечению ДСБ составила $85 \%$.

Заключение: эффективность лечения ДСБ у пациенток с ОП на фоне РА в течение 2х лет, оцененная по динамике МПК B L1-L4, ПОБ и дистальной трети предплечья, была сопоставима с результатами лечения женщин спостменопаузальным ОП. ДСБ эффективен и безопасен для терапии ОП у больных РА на фоне лечения глюкокортикоидами. Приверженность терапии ДСБ высокая, она составила 85\% к концу второго года наблюдения.

КЛЮЧЕВЫЕ СЛОВА: Ревматоидный артрит; остеопороз; деносумаб.

\section{DENOSUMAB IN THE TREATMENT OF OSTEOPOROSIS IN PATIENTS WITH RHEUMATOID ARTHRITIS (RESULTS OF 2-YEAR FOLLOW-UP)}

(c) Dobrovolskaya O.V., Kovalenko P.S., Demin N.V., Toroptsova N.V., Dydykina I.S., Nikitinskaya O.A., Nasonov E.L.

Ministry of Science and Higher Education, Moscow

Research Institute of Rheumatology named after V.A. Nasonova, Moscow 
ВИТАМИН D И ДРУГИЕ ЛАБОРАТОРНЫЕ ПОКАЗАТЕЛИ У ПОЖИЛЫХ В ЗИМНЕЕ ВРЕМЯ ГОДА

\author{
(с) В.В. Дорофейков ${ }^{1}$, Н.Н. Петрова², И.В. Кайстря ${ }^{3}$
}

${ }^{1}$ НГУ физической культуры, спорта и здоровья им. П.Ф. Лесгафта, Санкт-Петербург

${ }^{2}$ Санкт-Петербургский государственный университет, Санкт-Петербург

${ }^{3}$ Клиника «Современные медицинские технологии», Санкт-Петербург

В последние годы появились многочисленные данные о важной роли витамина D в области охраны здоровья населения, в том числе пожилых. О возможной протективной роли витамина D при сердечно-сосудистых заболеваниях свидетельствуют данные об обратной корреляции между его уровнем и кальцификацией коронарных сосудов. Дефицит витамина D индуцирует гипертрофию миокарда и повышает продукцию внутриклеточного матрикса в его ткани, способствует атерогенным изменениям липидного профиля. Россия в силу своего географического положения находится в зоне низкой инсоляции, поэтому все ее жители входят в группу риска дефицита витамина D.

Целью настоящей работы было изучение статуса витамина D в популяции свободно живущих пожилых жителей Санкт-Петербурга и его связи с другими лабораторными показателями состояния здоровья.

Материалы и методы. В зимний период (февраль-март) были обследованы 209 добровольцев, не принимавших препараты витамина D в течение предыдущих 6 месяцев. 72,7\% выборки составляли женщины, 27,3\% - мужчины. При включении в исследование возраст пациентов варьировал от 71 до 91 года. Забор крови при визите для определения сывороточных уровней липидного спектра, биохимических, гормональных показателей, концентрации 25(ОН)D, плазменного уровня мозгового натрийуретического пептида (МНП) проводили натощак. Все показатели исследовали на биохимическом и иммуноферментном автоанализаторах ведущих производителей (США). Изучение статистических закономерностей проводили параметрическими и непараметрическими критериями. Различия во всех случаях оценивали как статистически значимыми при $\mathrm{p}<0,05$.

Результаты. Уровень 25(OH)D у пациентов в нашем исследовании варьировал от 5,0 до 28,0 нг/мл. Рассчитанный нами непараметрический медианный доверительный интервал, рекомендуемый для практического использования, позволяет утверждать, что медиана витамина D популяционной совокупности пожилых жителей Санкт-Петербурга с доверительной вероятностью 0,95 будет находиться в пределах от 14,9 до 16,8 нг/мл. Различий в обеспеченности витамином D по полу не выявлено. Концентрацию 25(OH)D ниже 10 мг/мл мы расценивали как авитаминоз, диапазон от 10 до 20 мг/мл включительно, рассматривали как дефицит, от 21 до 30 мг/мл как пониженный уровень витамина D в организме. В соответствии с этой классификацией пациенты нашей выборки были разделены на 3 группы: группа авитаминоза - 9,6\% всех образцов; группа дефицита - 66,0\%; группа пониженного содержания витамина - 24,4\%. Полученные группы были протестированы с помощью рангового анализа вариаций по Краскелу-Уоллису с медианным тестом на предмет различий в них уровней мозгового натрийуретического пептида (МНП). Средний уровень МНП последовательно понижается от группы пациентов с авитаминозом к категории пониженного уровня 25(OH)D. Приведение показателей МнП к дихотомическому виду с точкой деления более 100 пг/мл (граница нормы) и последующий расчёт относительного риска между группами показал, что у пациентов с авитаминозом риск повышенного уровня МНП в 1,9 раза вероятней, чем в группе дефицита и в 2,6 раза выше, чем в группе с пониженным уровнем витамина $D(O H)$. Mы не обнаружили с помощью рангового коэффициента корреляции Спирмана значимых взаимных влияний между уровнем 25(OH)D и показателями липидного спектра, атерогенного индекса плазмы, гликированного гемоглобина НbА ${ }_{1 c^{\prime}}$ эстрадиола, тестостерона, ультрачувствительного С-реактивного белка, которые без сомнения связаны с развитием атеросклероза. Теснота связи концентрации витамина $\mathrm{D}(\mathrm{OH})$ с уровнем мозгового натрийуретического пептида характеризовалась $r_{s}=0,187(p=0,007)$.

Обсуждение результатов. В исследованиях последних лет показана важная прогностическая роль мозгового натрийуретического пептида в развитии неблагоприятных сердечно-сосудистых событий. В нашем исследовании уровень МНП значимо различался в группах дефицита витамина D, причем его увеличение последовательно наблюдалось при переходе от категории пониженного содержания к группе гиповитаминоза и далее к авитаминозу. Вероятно, выраженный дефицит витамина D может нарушать минеральный состав и приводить к ослаблению сердечной мышцы, что проявляется повышением уровня МНП и, следовательно, увеличением риска развития и прогрессирования сердечной недостаточности. Полученные данные свидетельствуют о том, что потенциальный эффект от профилактических мер, направленных на коррекцию дефицита витамина D, может быть значительным.

КЛЮЧЕВЫЕ СЛОВА: Витамин D; мозговой натрийуретический пептид; сердечная недостаточность. 
VITAMIN D AND OTHER LABORATORY INDICATORS IN THE ELDERLY PATIENTS IN WINTER

(c) Dorofeykov V.V. ${ }^{1}$, Petrova N.N. ${ }^{2}$, Kaistrya I.V. ${ }^{3}$

' Lesgaft National State University of Physical Education, Sport and Health, Saint Petersburg

${ }^{2}$ Saint Petersburg State University, Saint Petersburg

${ }^{3}$ Clinic «Modern Medical Technologies», Saint Petersburg 
ФГБУ «Национальный медицинский исследовательский центр реабилитации и курортологии» Минздрава России, Москва

Целью исследования было изучение влияния приема комплексной биологически активной добавки к пище с кальцием и витаминами $\mathrm{D}_{3}$ и $\mathrm{B}_{6}$, В том числе в сочетании с антирезорбтивной терапией, на эффективность и длительность эффекта медицинской реабилитации у пациентов с остеопорозом и высоким риском остеопорозных переломов.

Материал и методы. В проспективное контролируемое исследование включили 119 мужчин и женщин с остеопорозом и(или) высоким риском переломов по модели FRAX, в возрасте от 50 до 80 лет, поступающих на стационарное лечение по профилю «медицинская реабилитация». В 1-ю исследуемую группу (ИГ1) вошел 41 пациент (возраст $67,4 \pm 8,6$ лет), уже получавший антирезорбтивную терапию. В ИГ2 и ИГЗ методом рандомизации включили по 39 па-

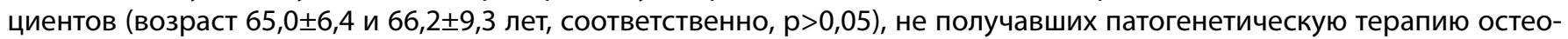
пороза. Пациентам ИГ1 и ИГ2 была назначена к применению в течение 12 мес комплексная биологически активная добавка к пище Остеомед форте (ОФ), содержащая в суточной дозировке кальция цитрат 1000 мг (210 мг Са²+), витамин D3 600 ME, пиридоксина гидрохлорид 2 мг в составе HDBA-органик-комплекса с витамином B 6 . Пациенты ИГЗ составили группу контроля.

Пациенты всех групп прошли обследование, которое включало тензодинамометрию с оценкой силы мышц сгибателей спины (СС), разгибателей спины (РС), левых и правых боковых сгибателей (ЛБС и ПБС) исходно, через 20 сут после завершения курса реабилитации, затем через 6 и 12 мес после начала исследования; исследование координационной функции методом стабилометрии на аппарате Стабилан 1.0 - платформе, регистрирующей основные характеристики управления позой пациентов на основе измерения координат центра давления (ЦД) в плоскости опоры; функциональные тесты на оценку кондиционных и координационных двигательных способностей: тест «встань и иди», тест 10-метровой ходьбы, тесты на выносливость мышц спины и живота к статической и динамической нагрузке, тест для оценки статического равновесия «стойка на одной ноге» с открытыми и закрытыми глазами, тест ходьбы на месте (тест Фукуды).

Результаты. Через 20 сут после завершения комплексного курса медицинской реабилитации отмечалось повышение силы исследуемых групп мышц у пациентов всех трех групп $(p<0,05)$. Проспективное динамическое наблюдение показало, что достигнутые в процессе 20-дневных тренировок более высокие по сравнению с исходным уровнем показатели мышечной силы сохранялись до 12 мес в РС и СС у пациентов ИГ1 и ИГ2, принимавших ОФ, и до 6 мес в ЛБС и ПБС у пациентов ИГ1 ( $<<0,05$ в сравнении со значениями через 20 сут) . У пациентов в группе контроля достигнутый эффект медицинской реабилитации полностью регрессировал уже через 6 мес, а уровень силы ЛБС и ПБС через 12 мес был даже ниже, чем до начала лечения ( $<<0,05)$. Более того, у пациентов ИГЗ результаты тензодинамометрии, достигнутые на фоне реабилитации и зарегистрированные в процессе дальнейшего наблюдения, были ниже, чем в ИГ1 и ИГ2 (p<0,05).

Исследование стабилометрических показателей продемонстрировало, что у всех пациентов после курса реабилитации наблюдалось увеличение коэффициента равновесия (КР) стоя как с закрытыми, так и с открытыми глазами, уменьшение скорости смещения ЦД, а также площади статокинезиограммы у пациентов ИГ1 и ИГ2, получавших ОФ $(p<0,05)$. Улучшение значений параметров стабилометрии по сравнению с исходным уровнем сохранялось только у пациентов, принимавших 12 мес ОФ (скорость смещения ЦД в ИГ2 - до 12 мес, площадь статокинезиограммы в ИГ1 и ИГ2 - до 6 мес). У пациентов группы контроля ИГЗ, не получавших ОФ, в отличие от лечившихся пациентов, отмечалось ухудшение значений КР с закрытыми и открытыми глазами и площади статокинезиограммы в отдаленные сроки после завершения реабилитации (через 6 и 12 мес) по сравнению с исходным уровнем $(p<0,05)$.

Сразу после курса медицинской реабилитации, значимая положительная динамика результатов функциональных тестов была зарегистрирована только в тесте «стойка на одной ноге» с открытыми глазами: на левой — во всех группах, на правой - в ИГ1 ( $<<0,05)$. Достигнутый эффект в течение 12 мес наблюдения сохранялся только по показателям первого теста в ИГ1. Было отмечено также ухудшение значения среднего показателя теста «стойка на правой ноге» в группе контроля через 12 мес по сравнению с исходными значениями ( $<<0,05)$.

\section{Выводы:}

1. Комплексная медицинская реабилитация у пациентов с остеопорозом и высоким риском переломов способствует повышению мышечной силы и улучшению функции равновесия.

2. Прием комплексной добавки к пище, содержащей цитрат кальция, витамин $\mathrm{D}_{3}$ и HDBA-органик-комплекс с витамином $\mathrm{B}_{6}(\mathrm{OФ)}$, способствует сохранению достигнутых во время реабилитации значений показателей мышечной силы в РС и СС в течение 12 мес и в ЛБС и ПБС в течение 6 мес. 
3. Прием комплексной добавки к пище ОФ предотвращает ухудшение баланса и устойчивости у пациентов с остеопорозом и высоким риском переломов в отдаленные сроки после завершения курса реабилитации.

4. Эффект приема ОФ в сочетании с антирезорбтивными препаратами выше, чем в виде монотерапии.

5. Длительный прием добавок к пище, содержащих соли кальция и витамин $\mathrm{D}_{3}$ в том числе с дополнительными биологическими агентами, может быть рекомендован для поддержания эффекта реабилитационных мероприятий у пациентов с остеопорозом и высоким риском переломов, в том числе в комбинации с антирезорбтивной терапией.

КЛЮЧЕВЫЕ СЛОВА: Остеопороз; кальций; витамин D.

THE ROLE OF LONG-TERM INTAKE OF CALCIUM SUPPLEMENTS, VITAMINS D3 AND B6 IN MAINTAINING THE EFFECT OF MEDICAL REHABILITATION IN PATIENTS WITH OSTEOPOROSIS AND HIGH RISK OF FRACTURES

๑ Marchenkova L.A., Makarova E.V., Vasilyeva V.A., Eremushkin M.A.

National Medical Research Center of Rehabilitation and Balneology, Moscow, Russia 
